\title{
EFECTO DE EXTRACTOS ACUOSOS RADICALES Y FOLIARES DE ECOTIPOS DE TRIGO (TRITICUM AESTIVUM L.) SOBRE EL CRECIMIENTO MICELIAL IN VITRO DE GAEUMANNOMYCES GRAMINIS VAR. TRITICI
}

\author{
EFFECT OF AQUEOUS EXTRACTS OF ROOT AND LEAF \\ OF WILD TYPE WHEAT (TRITICUM AESTIVUM L.) OVER \\ THE MYCELIAL GROWTH OF G. GRAMINIS IN VITRO
}

\author{
Carla Enríquez T. ${ }^{1}$; Emma Bensch T. ${ }^{1}$; Jaime Guerrero C. ${ }^{1}$; Aliro Contreras $N .{ }^{1}$
}

\begin{abstract}
RESUMEN
Esta investigación se realizó con el propósito de evaluar el efecto de extractos acuosos de ecotipos de trigo (Triticum aestivum L.) sobre el crecimiento micelial in vitro de Gaeumannomyces graminis var. tritici. Se utilizaron 17 extractos obtenidos de raíces y hojas de los ecotipos de trigo Castaño, Cebada, Diente de perro, G8, Grano de oro, Caín, Linaza I, Linaza II, NN1, NN17, NN24, NN31, NN35, Pulil, R3, Rachel y Varón, y cultivares comerciales de avena cv. Urano, trigo cv. Kumpa y Otto a las concentraciones 1 y $5 \%$ p/v. Se evaluó el radio promedio del crecimiento micelial ( $\mathrm{mm}$ ) desde el centro de la placa petri contenida con APD y el extracto respectivo, siempre en el mismo sentido y lugar, a partir de las 24 horas postsiembra y cada 24 horas hasta completar la placa control. Se utilizó un diseño experimental completamente al azar. Los datos fueron analizados mediante ANDEVA y comparación de medias por las pruebas LSD y Tukey $(\mathrm{p}<0,05)$. Todos los extractos acuosos de ecotipos de trigo ejercieron efecto inhibitorio del crecimiento micelial de G. graminis var. tritici. Este efecto fue superior al de cultivares comerciales de avena cv. Urano y trigo cvs. Kumpa y Otto. La secuencia de mayor a menor efecto inhibitorio del crecimiento micelial fue la siguiente: extracto radical al 1\% (ecotipos Varón, NN1 y Pulil); al 5\% (ecotipos Linaza I, Caín, Varón, Grano de oro y NN1). Extracto foliar al 1\% (ecotipos Castaño y Grano de oro); al 5\% (ecotipos NN17, NN24, NN31, Caín y Varón).
\end{abstract}

Palabras clave: Ecotipo, extractos acuosos, Triticum aestivum, Gaeumannomyces graminis, alelopatía.

\begin{abstract}
This research was made with the purpose of evaluating the effect of aqueous extracts of wild type wheat (Triticum aestivum $L$.) over the mycelial growth in vitro of Gaeumannomyces graminis var. tritici. There were used 17 extracts obtained of root and leaf of wild type wheat: Castaño, Cebada, Diente de perro, G8, Grano de oro, Caín, Linaza I, Linaza II, NN1, NN17, NN24, NN31, NN35, Pulil, R3, Rachel and Varón, also varieties of Kumpa and Otto wheat and (Urano) oats, to concentrations 1 y $5 \%$ w/v. There was an evaluation of the radio average of the mycelial growth $(\mathrm{mm})$ from the center of the plate contained with PDA and their respective extract, always in the same sense and place, as of the 24 hours after inoculation and every 24 hours till the plate control was completed. A full-random design was used. The data were analyzed by ANOVA and the average was compared by test of LSD and Tukey $(P \leq 0,05)$.

All the aqueous extracts of roots and leaves of wild type of wheat had an inhibiting effect over the micelial growth of $\mathrm{G}$. graminis var. tritici. The allelopathyc effect over this fungus was superior to the Kumpa and Otto wheat (Urano) oats and (nn) barley. The sequence from greater to smaller inhibiting effect of the micelial growth was the following one; radical extract to 1\% wild type of wheat (Varón, NN 1 and Pulil); to 5\% (Linaza I, grano de oro, Varón, and NN 1). Extract to leaf to 1\% (Grano de oro and castaño); to 5\% (NN 17, NN 24, NN 31, Caín and Varón).
\end{abstract}

Key words: Wild type, aqueous extracts, Triticum aestivum, Gaeumannomyces graminis, allelopathic.

1 Universidad de La Frontera, Facultad de Ciencias Agropecuarias y Forestales.

E-mail: carlaenriquez.agro@gmail.com; eabensch@ufro.cl; jguerrero@ufro.cl, aliroc@ufro.cl

Fecha de Recepción: 18 Octubre 2007

Fecha de Aceptación: 20 Diciembre 2007 
MENDES, L.C.; VARGAS, M.A.T.; HUNGRIA, M. 1998. Adubação nitrogenada e inoculação do feijoeiro em solo dos cerrados. In: Reunião Brasileira de Fertilizade do solo e Nutrição de Plantas, 23; Reunião Brasileira sobre Micorrizas, 7; Simpósio Brasileiro de Microbiologia do solo, 5; Reunião Brasileira de Biologia do solo, 2, Caxambu, 1998. Resumos. Caxambu: Universidade Federal de Lavras, p. 202.

PEREIRA, P.A.A.; ARAÚJO, R.S.; ROCHA, R.E.M.; STEINMETZ, S. 1984. Capacidade dos genótipos de feijoeiro de fixar $\mathrm{N}_{2}$ atmosférico. Pesquisa Agropecuária Brasileira, v. 19, p. 811-815.

PERES, J.R.R.; VIDOR, C. 1980. Seleção de estirpes de Rhizobium japonicum e competitividade por sítios de infecção nodular em estirpes de soja. Agronomia Sulriograndense, Santa Maria, v. 16, p. 205-219.

PESSOA, A.C.S.; LUCHESE, E.B.; CAVALLET, L.E.; GRIS, E.P. 1999. Produtividade de soja em resposta à adubação foliar, tratamento de sementes com molibdênio e inoculação com Bradirhizobium japonicum. Maringá - PR Acta Scientiarum, 21:531-535.

ROSOLEM, C.A. 1987. Nutrição e adubação do feijoeiro. Piracicaba: Potafós, 93 p. (Boletim Técnico, 8).

RUSCHEL, A.P. 1982. Field evaluation of N2- fixation and $\mathrm{N}$ - utilization by Phaseolus vulgaris beans varieties determined by N15isotope dilution. Plant and Soil, The Hague, v. 65 , p. $397-407$.
SÁ, N.M.H. 1993. Selection and characterization of Rhizobium spp. Strains stable and capable in fixing nitrogenin bean. Microbiology, Madson, v. 24, p. 38-48.

SANTILLANA, N.; FREIRE, J.R.J.; SÁ, E.L.S.; SATO, M. 1998. Avaliação de estirpes de rizóbios para a produção de inoculantes para trevo vermelho. Revista Brasileira de Ciência do Solo, Campinas, v. 22, p. 231-237.

SILVA, D.M.; COSTA,A.N.; LIMA, P.F.; ANDRADE, M.C.F.E. 1999. O sistema simbiótico Phaseolus vulgaris-Rhizobium leguminosarum em ambiente com disponibilidades distintas de fósforo. In: Reunião Nacional de Pesquisa do feijão, 4. , 1999. Anais... EMBRAPA/EBDA, v. 1, p. 98-99.

TAYLOR, R.W.; WILLIANS, M.L.; SISTANI, K.R. 1991. $\mathrm{N}_{2}$ fixation by soybean-bradyrhizobium combinationsunder acidity, low $\mathrm{P}$ and right $\mathrm{Al}$ stresses. Plant and Soil, The Hague, v. 131, p. 293-300.

THIES, J.E.; SINGLETON, P.W.; BOHLOOL, B.B. 1991 Influence of the size of indigenous rhizobial populations on establishment and symbiotic performance of introduced rhizobia on field-grown legumes. Applied and Environmental Microbiology, Washington, v. 57, p. 19-28.

TSAI, S.M. 1993. Minimizing the effect of mineral nitrogenon biological nitrogen fixation in common bean byincreasing nutrient levels. Plant and Soil, The Hague, v. 152, p. 131-38.

VINCENT, J.M. 1970. A manual for the practical study of the root-nodule bacteria. IPB HANDBOOK ${ }^{\circ} 15$, London: Blackwell Scientific Publ., 164 p. 
sucesso da inoculação, assim estirpes nativas geneticamente estáveis, adaptadas as condições do solo e a genótipos de feijoeiro, demonstram diferenças em promover benefícios na simbiose de diferentes cultivares (Peres \& Vidor,1980; Santillana et al., 1998; Carvalho \& Stamford,1999; Fernandes \& Fernandes, 2000).

\section{CONCLUSÕES}

Esses dados evidenciam que a fixação biológica de $\mathrm{N}_{2}$ utilizando a inoculação de estirpes eficientes

\section{LITERATURA CITADA}

AMARGER, D.S.; HAMAKAWA, P.J. 1997. Estimativa do número de células viáveis de rizóbio no solo e em inoculantes por infecção em plantas. In: HUNGRIA, M., ARAÚJO, R. S. (Eds.). Manual de métodos empregados em estudos de microbiologia agrícola. EMBRAPA-SPI, Brasília, Brasil, pp. 63-94

ARAUJO, R.S. FIXAÇÃO BIOLÓGICA DO NITROGÊNIO EM FEIJÃO. 1994. In: ARAÚJO, R.S.; HUNGRIA, M. (Ed.) Microorganismos de importância agrícola. Brasília: Embrapa-SP, $236 \mathrm{p}$.

BARBOSA FILHO, M.P.; FAGERIA, N.K.; SILVA, O.F.DA. FONTES. 2005. doses e parcelamento da adubaçao nitrogenada em cobertura para feijoeiro comun irrigado. Ciênc. agrotec., Larvas, v. 29, n. 1, fev.

BUTTERY, E.S.P.; PARK, S.J.; FINDLAY, W.J. 1987. Growth and yield of white bean (Phaseolus vulgaris L.) in response to nitrogen, phosphorus and potassium fertilizer and to inoculation with Rhizobium. Canadian Journal of Plant Sciences, v. 67, p. 425-432.

CARVALHO, F.G.; STAMFORD, N.P. 1999. Fixação do $\mathrm{N}_{2} \mathrm{em}$ leucena (Leucaena leucocephala) em solo da região semiárida brasileira submetido à salinização. Revista Brasileira de Ciência do Solo, Viçosa, MG, v. 23, p. 237-243.

COLETTA FILHO, H.D. 1993. Avaliação da fixação biológica do $\mathrm{N}_{2}$ em genótipos de feijoeiro. Piracicaba, ESALQ/USP, 72 p. Dissertação de Mestrado.

EMPRESA BRASILEIRA DE PESQUISA AGROPECUÁRIA - EMBRAPA. 1999a. Centro Nacional de Pesquisa de Soja. Recomendações técnicas para a cultura da soja no Paraná 1999/2000. Londrina, 236 p.

FERNANDES, M.F.; FERNANDES, R.P.M. 2000. Seleção inicial e caracterização parcial de rizóbios de tabuleiros costeiros quando associados ao guandu. Revista Brasileira de Ciência do Solo, Viçosa, MG, v. 24, p. 321-327.

FERREIRA, A.N.; ARF, O.; CARVALHO, M.A.C. de $e t$ al. Rhizobium tropici strains for inoculation of the common bean. Sci. agric., July/Sept. 2000, vol. 57, n 3, p. 507-512.

FREIRE, J.R.J. 1992. Fixação do nitrogênio pela simbiose Rhizobium/Leguminosas. In: CARDOSO, E.J.B.N; TSAI,S.M.; NEVES, M.C.P. (Cords.). Microbiologia do solo. Campinas: Sociedade Brasileira de Ciência do Solo, p. 121-140. de Rhizobium em cultivar nodulante de feijoeiro ou seu cultivo em solos com população nativa eficiente, pode possibilitar a suplementação ou até mesmo a não utilização de nitrogênio em cobertura na cultura do feijoeiro, sem perdas no rendimento da produtividade.

\section{AGRADECIMENTOS}

Ao Banco do Nordeste pela colaboração financeira e ao CNPq pelas bolsas de Iniciação Científica e de Pós-doutorado.

GLIESSMAN, S.R. 2001. Agroecologia: processos ecológicos em agricultura sustentável. 2. ed. Porto Alegre: UFRGS, $653 \mathrm{p}$.

GRAHAM, P.H. 1981. Some problems of nodulation and symbiotic nitrogen fixation in Phaseolus vulgaris L.: a riview. Field Crops Research, v. 4, p. 93-112.

HARDARSON, G. 1993. Methods for enhancing symbiotic nitrogen fixation. Plant Soil, v. 152, p. 1-17.

HOAGLAND, D.R.; ARNON, D.I. 1950. The water culture methodfor growing plants without soils. Berkeley: California Agricultural Experimental Station, 347 p.

HUNGRIA, M.; ARAÚJO, R.S. 1994. Manual de métodos empregados em estudos de microbiologia agrícola. Brasília: EMBRAPA.

HUNGRIA, M.; ANDRADE, D.S.; CHUEIRE, L.A.O.; PROBANZA, A.; GUTTIERREZ-MANERO, F.J.; MEGIAS, M. 2000. Isolation and characterization of new efficient competitive bean (Phaseolus vulgaris L.) rhizobia from Brazil. Soil Biology \& Biochesmistry, v. 32, p. $1515-1528$.

HUNGRIA, M.; ANDRADE, D.S.; COLOZZI-FILHO, A.; BALOTA, E.L. 1997. Interação entre microrganismos do solo, feijoeiro e milho em monocultura e consorcio. Pesquisa Agropecuária Brasileira, v. 32, p. 807-818.

HUNGRIA, M.; FRANCO, A.A. 1993. Effects of right temperature on nodulation and nitrogen fixation byPhaseolus vulgaris L. Plant and Soil, The Hague,v. 149, p. 95-102.

HUNGRIA, M.; NEVES, M.C.P. 1987. Cultivar and Rhizobium strain effects on nitrogen fixation and transport in Phaseolus vulgaris L. Plant and Soil, v. 103, p. 111-121.

HUNGRIA, M.; NISHI, C.Y.M.; COHN, J.; STACEY, G. 1996. Comparison between parental and variant soybean Bradyrhizobium strains with regard to the production of lipo-chitin nodulation signals, early stages of root infection, nodule occupancy, and $\mathrm{N}_{2}$ fixation. Plant and Soil, v. 186, p. 331-341.

HUNGRIA, M.; VARGAS, M.A.T. 2000. Environmental factors affecting $\mathrm{N}_{2}$ fixation in grain legumes in the tropics, with an emphasis on Brazil. Field Crops Research, 151-164.

MELO, I.S.; AZEVEDO, J.L. 1998. Ecologia microbiana. Brasília: EMBRAPA/CNPMA, 488 p. 
Tabela 3

Número médio de sementes por vagem de plantas de diferentes genótipos de feijoeiro, sem e com inoculação de estirpes nativas de Rhizobium sp., isoladas de solos de sete municípios do estado do Espírito Santo. Alegre, 2006

\begin{tabular}{|l|c|c|c|c|c|c|c|c|c|c|c|c|c|c|}
\hline \multirow{2}{*}{ Genótipos } & \multicolumn{2}{|c|}{ Pinheiros } & \multicolumn{2}{c|}{ Vila Pavão } & \multicolumn{2}{c|}{ Colatina } & \multicolumn{2}{c|}{ Nova Venécia } & \multicolumn{2}{c|}{ Sooretama } & \multicolumn{2}{c|}{ Alegre } & \multicolumn{2}{c|}{ Linhares } \\
\cline { 2 - 15 } & C/IN & S/IN & C/IN & S/IN & C/IN & S/IN & C/IN & S/IN & C/IN & S/IN & C/IN & S/IN & C/IN & S/IN \\
\hline BATT-477 & - & $4,0 \mathrm{a}$ & $5,1 \mathrm{aA}$ & $4,5 \mathrm{aA}$ & - & $3,9 \mathrm{a}$ & $6,0 \mathrm{aA}$ & $3,0 \mathrm{aA}$ & $3,0 \mathrm{aA}$ & $4,3 \mathrm{aA}$ & $5,5 \mathrm{aA}$ & $4,0 \mathrm{aA}$ & $4,2 \mathrm{aA}$ & $4,6 \mathrm{aA}$ \\
\hline Amarelinho & $3,8 \mathrm{aA}$ & $4,9 \mathrm{aA}$ & $4,7 \mathrm{aA}$ & $4,4 \mathrm{aA}$ & $2,9 \mathrm{aA}$ & $4,0 \mathrm{aA}$ & $3,3 \mathrm{aA}$ & $4,3 \mathrm{aA}$ & $5,5 \mathrm{aA}$ & $3,7 \mathrm{aA}$ & $3,7 \mathrm{aA}$ & $4,1 \mathrm{aA}$ & $4,5 \mathrm{aA}$ & $4,3 \mathrm{aA}$ \\
\hline Macuquinho & $2,8 \mathrm{aA}$ & $4,1 \mathrm{aA}$ & $4,8 \mathrm{aA}$ & $4,3 \mathrm{aA}$ & $4,3 \mathrm{aA}$ & $3,6 \mathrm{aA}$ & $4,0 \mathrm{aA}$ & $3,0 \mathrm{aA}$ & $5,0 \mathrm{aA}$ & $5,7 \mathrm{aA}$ & $5,0 \mathrm{aA}$ & $4,5 \mathrm{aA}$ & $3,7 \mathrm{aA}$ & $4,2 \mathrm{aA}$ \\
\hline Imperial & - & $4,1 \mathrm{a}$ & $4,1 \mathrm{aA}$ & $4,0 \mathrm{aA}$ & $5,0 \mathrm{aA}$ & $4,0 \mathrm{aA}$ & $4,5 \mathrm{aA}$ & $2,5 \mathrm{aA}$ & $3,1 \mathrm{aA}$ & $3,5 \mathrm{aA}$ & $5,4 \mathrm{aA}$ & $4,9 \mathrm{aA}$ & $4,7 \mathrm{aA}$ & $2,0 \mathrm{aA}$ \\
\hline Uirapuru & $5,0 \mathrm{aA}$ & $3,0 \mathrm{aA}$ & $4,0 \mathrm{aA}$ & $5,0 \mathrm{aA}$ & $5,3 \mathrm{aA}$ & $4,2 \mathrm{aA}$ & $3,3 \mathrm{aA}$ & $4,0 \mathrm{aA}$ & - & $4,5 \mathrm{a}$ & $3,5 \mathrm{aA}$ & $4,8 \mathrm{aA}$ & $4,2 \mathrm{aA}$ & $3,8 \mathrm{aA}$ \\
\hline Serrano & $5,2 \mathrm{aA}$ & $3,5 \mathrm{aA}$ & $4,1 \mathrm{aA}$ & $3,7 \mathrm{aA}$ & $4,4 \mathrm{aA}$ & $4,0 \mathrm{aA}$ & $5,1 \mathrm{aA}$ & $4,2 \mathrm{aA}$ & $4,7 \mathrm{aA}$ & $4,7 \mathrm{aA}$ & $3,5 \mathrm{aA}$ & $2,5 \mathrm{aA}$ & $3,6 \mathrm{aA}$ & $3,4 \mathrm{aA}$ \\
\hline IAPAR81 & $3,0 \mathrm{aA}$ & $4,1 \mathrm{aA}$ & $3,1 \mathrm{aA}$ & $2,5 \mathrm{aA}$ & $2,0 \mathrm{aA}$ & $3,9 \mathrm{aA}$ & $4,1 \mathrm{aA}$ & $3,5 \mathrm{aA}$ & $3,1 \mathrm{aA}$ & $4,7 \mathrm{aA}$ & $3,2 \mathrm{aA}$ & $2,4 \mathrm{aA}$ & $3,1 \mathrm{aA}$ & $3,0 \mathrm{aA}$ \\
\hline Bate Estrada & $4,3 \mathrm{aA}$ & $3,6 \mathrm{aA}$ & $2,6 \mathrm{aA}$ & $3,5 \mathrm{aA}$ & $2,5 \mathrm{aA}$ & $3,0 \mathrm{aA}$ & $2,0 \mathrm{aA}$ & $5,3 \mathrm{aA}$ & $2,8 \mathrm{aA}$ & $3,6 \mathrm{aA}$ & $3,9 \mathrm{aA}$ & $2,4 \mathrm{aA}$ & $3,2 \mathrm{aA}$ & $3,5 \mathrm{aA}$ \\
\hline EL-22 & $4,1 \mathrm{aA}$ & $4,6 \mathrm{aA}$ & $4,8 \mathrm{aA}$ & $5,0 \mathrm{aA}$ & $3,6 \mathrm{aA}$ & $2,7 \mathrm{aA}$ & $2,9 \mathrm{aA}$ & $4,1 \mathrm{aA}$ & $6,3 \mathrm{aA}$ & $4,3 \mathrm{aA}$ & - & $3,1 \mathrm{a}$ & $4,6 \mathrm{aA}$ & $4,5 \mathrm{aA}$ \\
\hline Preto Meia Lua & $2,9 \mathrm{aA}$ & $1,8 \mathrm{aA}$ & $2,3 \mathrm{aA}$ & $3,1 \mathrm{aA}$ & $3,6 \mathrm{aA}$ & $3,3 \mathrm{aA}$ & $2,4 \mathrm{a}$ & - & $3,6 \mathrm{aA}$ & $3,6 \mathrm{aA}$ & $3,4 \mathrm{aA}$ & $2,3 \mathrm{aA}$ & $1,4 \mathrm{aA}$ & $3,8 \mathrm{aA}$ \\
\hline
\end{tabular}

1 Médias seguidas pela mesma letra minúscula na coluna e mesma letra maiúscula na linha pertencem ao mesmo agrupamento, ao nível de 5\% de significância, pelo teste de Scott-Knott.

Tabela 4

Produção média (kg/ha) de diferentes genótipos de feijoeiro, sem e com inoculação de estirpes nativas de Rhizobium sp., isoladas de solos de sete municípios do estado do Espírito Santo. Alegre, 2006

\begin{tabular}{|c|c|c|c|c|c|c|c|c|c|c|c|c|c|c|}
\hline \multirow{2}{*}{ Genótipos } & \multicolumn{2}{|c|}{ Pinheiros } & \multicolumn{2}{|c|}{ Vila Pavão } & \multicolumn{2}{|c|}{ Colatina } & \multicolumn{2}{|c|}{ Nova Venécia } & \multicolumn{2}{|c|}{ Sooretama } & \multicolumn{2}{|c|}{ Alegre } & \multicolumn{2}{|c|}{ Linhares } \\
\hline & C/IN & S/IN & C/IN & S/IN & C/IN & S/IN & C/IN & S/IN & C/IN & S/IN & C/IN & S/IN & C/IN & $\mathrm{S} / \mathrm{IN}$ \\
\hline BATT-477 & - & $210 \mathrm{~b}^{1 /}$ & $240 \mathrm{bA}$ & $390 \mathrm{cA}$ & - & $360 \mathrm{~b}$ & $120 \mathrm{aA}$ & $30 \mathrm{aA}$ & $60 \mathrm{aA}$ & $360 \mathrm{aA}$ & $330 \mathrm{cA}$ & $600 \mathrm{aA}$ & $510 \mathrm{bA}$ & $930 \mathrm{aA}$ \\
\hline Amarelinho & $180 \mathrm{~dB}$ & $1650 \mathrm{aA}$ & $330 \mathrm{bA}$ & $450 \mathrm{cA}$ & $210 \mathrm{aA}$ & $300 \mathrm{bA}$ & $120 \mathrm{aA}$ & $150 \mathrm{aA}$ & $390 \mathrm{aA}$ & $360 \mathrm{aA}$ & $690 \mathrm{bA}$ & $360 \mathrm{aA}$ & $1080 \mathrm{aA}$ & $1290 \mathrm{aA}$ \\
\hline Macuquinho & $240 \mathrm{dA}$ & $270 \mathrm{bA}$ & $210 \mathrm{bA}$ & $330 \mathrm{cA}$ & $390 \mathrm{aA}$ & $420 \mathrm{bA}$ & $210 \mathrm{aA}$ & $180 \mathrm{aA}$ & $570 \mathrm{aA}$ & $720 \mathrm{aA}$ & $330 \mathrm{cA}$ & $300 \mathrm{aA}$ & $630 \mathrm{bA}$ & $600 \mathrm{bA}$ \\
\hline Imperial & - & $180 \mathrm{~b}$ & $720 \mathrm{aA}$ & $150 \mathrm{cB}$ & $510 \mathrm{aA}$ & $90 \mathrm{bA}$ & $270 \mathrm{aA}$ & $60 \mathrm{aA}$ & $630 \mathrm{aA}$ & $390 \mathrm{aA}$ & $840 \mathrm{bA}$ & $360 \mathrm{aB}$ & $840 \mathrm{bA}$ & $270 \mathrm{bB}$ \\
\hline Uirapuru & $570 \mathrm{cA}$ & $570 \mathrm{bA}$ & $840 \mathrm{aA}$ & $480 \mathrm{cA}$ & $210 \mathrm{aA}$ & $900 \mathrm{aA}$ & $570 \mathrm{aA}$ & $90 \mathrm{aB}$ & - & $360 a$ & $420 \mathrm{cA}$ & $510 \mathrm{aA}$ & $630 \mathrm{bA}$ & $270 \mathrm{bA}$ \\
\hline Serrano & $1260 \mathrm{aA}$ & $480 \mathrm{~dB}$ & $570 \mathrm{bA}$ & $420 \mathrm{cA}$ & $600 \mathrm{aA}$ & $300 \mathrm{bA}$ & $360 \mathrm{aA}$ & $240 \mathrm{aA}$ & $360 \mathrm{aA}$ & $570 \mathrm{aA}$ & $660 \mathrm{bA}$ & $270 \mathrm{aB}$ & $570 \mathrm{bA}$ & $450 \mathrm{bA}$ \\
\hline IAPAR81 & $180 \mathrm{~dB}$ & $1110 \mathrm{aA}$ & $510 \mathrm{bA}$ & $90 \mathrm{cB}$ & $330 \mathrm{aA}$ & $570 \mathrm{aA}$ & $660 \mathrm{aA}$ & $420 \mathrm{aA}$ & $750 \mathrm{aA}$ & $600 \mathrm{aA}$ & $660 \mathrm{bA}$ & $330 \mathrm{aA}$ & $1500 \mathrm{aA}$ & $960 \mathrm{aB}$ \\
\hline Bate Estrada & $810 \mathrm{bA}$ & $390 \mathrm{bA}$ & $900 \mathrm{aA}$ & $780 \mathrm{bA}$ & $330 \mathrm{aA}$ & $300 \mathrm{bA}$ & $270 \mathrm{aB}$ & $960 \mathrm{aA}$ & $180 \mathrm{aA}$ & $540 \mathrm{aA}$ & $2250 \mathrm{aA}$ & $330 \mathrm{aB}$ & $450 \mathrm{bA}$ & $630 \mathrm{bA}$ \\
\hline EL-22 & $510 \mathrm{cA}$ & $690 \mathrm{bA}$ & $1080 \mathrm{aA}$ & $1290 \mathrm{aA}$ & $360 \mathrm{aA}$ & $150 \mathrm{bA}$ & $150 \mathrm{aA}$ & $540 \mathrm{aA}$ & $540 \mathrm{aA}$ & $930 \mathrm{aA}$ & - & $510 a$ & $1440 \mathrm{aA}$ & $750 \mathrm{bB}$ \\
\hline Preto Meia Lua & $510 \mathrm{cA}$ & $600 \mathrm{bA}$ & $630 \mathrm{bB}$ & $1110 \mathrm{aA}$ & $330 \mathrm{aA}$ & $510 \mathrm{aA}$ & $240 \mathrm{a}$ & - & $240 \mathrm{aA}$ & $330 \mathrm{aA}$ & $690 \mathrm{bA}$ & $630 \mathrm{aA}$ & $90 \mathrm{bB}$ & $690 \mathrm{bA}$ \\
\hline
\end{tabular}

1 Médias seguidas pela mesma letra minúscula na coluna e mesma letra maiúscula na linha pertencem ao mesmo agrupamento, ao nível de 5\% de significância, pelo teste de Scott-Knott. 
Tabela 2

Número médio de vagens por planta de diferentes genótipos de feijoeiro, sem e com inoculação de estirpes nativas de Rhizobium sp., isoladas de solos de sete municípios do estado do Espírito Santo. Alegre, 2006

\begin{tabular}{|c|c|c|c|c|c|c|c|c|c|c|c|c|c|c|}
\hline \multirow{2}{*}{ Genótipos } & \multicolumn{2}{|c|}{ Pinheiros } & \multicolumn{2}{|c|}{ Vila Pavão } & \multicolumn{2}{|c|}{ Colatina } & \multicolumn{2}{|c|}{ Nova Venécia } & \multicolumn{2}{|c|}{ Sooretama } & \multicolumn{2}{|c|}{ Alegre } & \multicolumn{2}{|c|}{ Linhares } \\
\hline & C/IN & S/IN & C/IN & S/IN & C/IN & S/IN & C/IN & S/IN & C/IN & S/IN & $\mathrm{C} / \mathrm{IN}$ & S/IN & C/IN & S/IN \\
\hline BATT-477 & - & $1,0 \mathrm{~b}^{1}$ & $1,3 \mathrm{cA}$ & $2,3 \mathrm{bA}$ & - & $1,8 \mathrm{a}$ & $1,0 \mathrm{aA}$ & $1,0 \mathrm{aA}$ & $1,0 \mathrm{bA}$ & $1,5 \mathrm{aA}$ & $1,5 \mathrm{cA}$ & $2,8 \mathrm{aA}$ & $2,7 \mathrm{bA}$ & $3,3 \mathrm{bA}$ \\
\hline Amarelinho & $1,5 \mathrm{bB}$ & $6,7 \mathrm{aA}$ & $2,0 \mathrm{cA}$ & $2,5 \mathrm{bA}$ & $2,3 \mathrm{aA}$ & $2,3 \mathrm{aA}$ & $1,0 \mathrm{aA}$ & $1,3 \mathrm{aA}$ & $2,0 \mathrm{bA}$ & $2,3 \mathrm{aA}$ & $4,0 \mathrm{bA}$ & $2,3 \mathrm{aA}$ & $4,5 \mathrm{bA}$ & $6,0 \mathrm{aA}$ \\
\hline Macuquinho & $2,0 \mathrm{bA}$ & $2,0 \mathrm{bA}$ & $1,5 \mathrm{cA}$ & $2,0 \mathrm{bA}$ & $3,0 \mathrm{aA}$ & $3,0 \mathrm{aA}$ & $2,0 \mathrm{aA}$ & $2,5 \mathrm{aA}$ & $3,0 \mathrm{bA}$ & $3,0 \mathrm{aA}$ & $1,5 \mathrm{cA}$ & $2,0 \mathrm{aA}$ & $3,5 \mathrm{bA}$ & $4,0 \mathrm{bA}$ \\
\hline Imperial & - & $1,5 \mathrm{~b}$ & $4,0 \mathrm{bA}$ & $1,3 \mathrm{bB}$ & $3,5 \mathrm{aA}$ & $1,0 \mathrm{aA}$ & $2,0 \mathrm{aA}$ & $1,0 \mathrm{aA}$ & $8,0 \mathrm{aA}$ & $3,0 \mathrm{aB}$ & $3,8 \mathrm{bA}$ & $2,3 \mathrm{aA}$ & $4,3 \mathrm{bA}$ & $3,0 \mathrm{bA}$ \\
\hline Uirapuru & $2,3 \mathrm{bA}$ & $2,8 \mathrm{bA}$ & $4,0 \mathrm{bA}$ & $2,3 \mathrm{bA}$ & $1,0 \mathrm{aB}$ & $3,5 \mathrm{aA}$ & $3,3 \mathrm{aA}$ & $1,0 \mathrm{aB}$ & - & $2,0 \mathrm{aA}$ & $2,5 \mathrm{cA}$ & $1,8 \mathrm{aA}$ & $3,5 \mathrm{bA}$ & $2,5 \mathrm{bA}$ \\
\hline Serrano & $4,8 \mathrm{aA}$ & $3,0 \mathrm{bA}$ & $2,8 \mathrm{cA}$ & $2,8 \mathrm{bA}$ & $2,8 \mathrm{aA}$ & $1,5 \mathrm{aA}$ & $1,8 \mathrm{aA}$ & $1,3 \mathrm{aA}$ & $2,0 \mathrm{bA}$ & $3,3 \mathrm{aA}$ & $3,5 \mathrm{bA}$ & $2,0 \mathrm{aA}$ & $3,5 \mathrm{bA}$ & $3,3 \mathrm{bA}$ \\
\hline IAPAR81 & $1,0 \mathrm{bB}$ & $4,3 \mathrm{bA}$ & $3,3 \mathrm{bA}$ & $1,3 \mathrm{bA}$ & $2,0 \mathrm{aA}$ & $2,5 \mathrm{aA}$ & $2,5 \mathrm{aA}$ & $1,8 \mathrm{aA}$ & $3,5 \mathrm{bA}$ & $2,7 \mathrm{aA}$ & $3,3 \mathrm{bA}$ & $2,8 \mathrm{aA}$ & $7,8 \mathrm{aA}$ & $5,3 \mathrm{aB}$ \\
\hline Bate Estrada & $2,7 \mathrm{bA}$ & $2,3 \mathrm{bA}$ & $6,5 \mathrm{aA}$ & $3,8 \mathrm{aB}$ & $2,0 \mathrm{aA}$ & $3,0 \mathrm{aA}$ & $1,5 \mathrm{aA}$ & $3,3 \mathrm{aA}$ & $1,7 \mathrm{bA}$ & $2,8 \mathrm{aA}$ & $7,5 \mathrm{aA}$ & $2,8 \mathrm{aB}$ & $2,7 \mathrm{bA}$ & $3,0 \mathrm{bA}$ \\
\hline EL-22 & $2,8 \mathrm{bA}$ & $3,8 \mathrm{bA}$ & $4,3 \mathrm{bA}$ & $5,0 \mathrm{aA}$ & $2,5 \mathrm{aA}$ & $1,7 \mathrm{aA}$ & $2,0 \mathrm{aA}$ & $2,8 \mathrm{aA}$ & $2,3 \mathrm{bB}$ & $4,3 \mathrm{aA}$ & - & $3,3 \mathrm{a}$ & $6,8 \mathrm{aA}$ & $4,0 \mathrm{bB}$ \\
\hline Preto Meia Lua & $2,8 \mathrm{bA}$ & $3,3 \mathrm{bA}$ & $3,3 \mathrm{bA}$ & $4,5 \mathrm{aA}$ & $1,5 \mathrm{aA}$ & $2,3 \mathrm{aA}$ & $1,3 \mathrm{a}$ & - & $2,7 \mathrm{bA}$ & $2,8 \mathrm{aA}$ & $4,3 \mathrm{bA}$ & $3,3 \mathrm{aA}$ & $2,5 \mathrm{bA}$ & $2,8 \mathrm{bA}$ \\
\hline
\end{tabular}

1 Médias seguidas pela mesma letra minúscula na coluna e mesma letra maiúscula na linha pertencem ao mesmo agrupamento, ao nível de 5\% de significância, pelo teste de Scott-Knott.

de diferentes genótipos de feijoeiro, sem e com inoculação de estirpes nativas de Rhizobium sp., isoladas de solos de sete municípios do estado do Espírito Santo. Pode ser observado, para todos os isolados, que não houve diferença significativa comparando os plantios com e sem inoculação. Quando se compara o comportamento do mesmo genótipo com inoculação, nos diferentes solos, pode ser verificado, também, que não houve nenhuma diferença significativa. Esses resultados discordam dos da EMBRAPA (1999), porém estão de acordo com os de PESSOA et al. (1999).

\section{PRODUTIVIDADE TOTAL}

Na Tabela 4 esta apresentado o estudo da produção média de diferentes genótipos de feijoeiro, sem e com inoculação de estirpes nativas de Rhizobium sp., isoladas de solos de sete municípios do estado do Espírito Santo. Pode ser observado, de forma geral, que houve pouca diferença significativa comparando os plantios com e sem inoculação. Pode ser destaca- do, no entanto, os isolados de Vila Pavão, Alegre e Linhares quando inoculados no genótipo Imperial; isolado de Nova Venécia inoculado no "Uirapuru"; isolados de Pinheiros e Alegre no "Serrano"; isolados de Vila Pavão e Linhares no "IAPAR 81; isolado de Alegre no" Bate Estrada" e isolado de Linhares no EL 22. Quando se compara o comportamento do mesmo genótipo com inoculação, nos diferentes solos, podem ser destacados os genótipos: BATT 477 com os isolados de Vila Pavão, Nova Venécia, Alegre e Linhares; Amarelinho com os isolados de Alegre e Linhares; Imperial com os isolados de Vila Pavão, Sooretama, Alegre e Linhares; Uirapuru com os isolados de Pinheiros, Vila Pavão, Nova Venécia e Linhares; Serrano com o isolado de Pinheiros; IAPAR 81 com o isolado de Linhares; Bate Estrada com o isolado de Alegre; EL 22 com os isolados de Vila Pavão e Linhares e Preto Meia Lua com os isolados de Pinheiros, Vila Pavão e Alegre.

Os resultados obtidos confirmam que a característica intrínseca da planta hospedeira (o feijoeiro) e da bactéria fixadora de nitrogênio (Rhizobium), são de suma importância para o 
Tabela 1

Médias da altura de planta (ALT), número de nós (NOS), peso da matéria fresca da parte aérea (PMF), peso matéria seca da parte aérea (PMS) e número de nódulos de plantas de feijoeiro. Alegre, 2007

\begin{tabular}{|c|c|c|c|c|c|}
\hline Origem do Inóculo & ALT & NOS & PMF & PMS & NOD \\
\hline $\mathrm{T} 1$ & $49,13^{1}$ & 10,00 & 24,11 & 3,98 & $325,75 \mathrm{ab}^{2}$ \\
\hline $\mathrm{T} 2$ & 52,81 & 10,88 & 30,40 & 4,87 & $374,13 \mathrm{ab}$ \\
\hline $\mathrm{T} 3$ & 66,75 & 10,63 & 26,43 & 4,05 & $239,75 b$ \\
\hline $\mathrm{T} 4$ & 43,25 & 10,25 & 25,34 & 4,02 & $381,00 \mathrm{ab}$ \\
\hline T5 & 71,00 & 10,50 & 31,61 & 4,78 & $285,75 b$ \\
\hline $\mathrm{T} 6$ & 34,88 & 10,25 & 24,59 & 3,77 & $326,75 \mathrm{ab}$ \\
\hline $\mathrm{T} 7$ & 55,75 & 10,13 & 27,62 & 4,77 & $358,00 \mathrm{ab}$ \\
\hline $\mathrm{T} 8$ & 61,63 & 10,63 & 30,05 & 4,85 & $296,25 \mathrm{ab}$ \\
\hline T9 & 47,63 & 11,75 & 33,79 & 4,88 & $477,25 a$ \\
\hline T10 & 41,63 & 9,75 & 19,05 & 3,27 & $56,13 \mathrm{c}$ \\
\hline
\end{tabular}

Não significativo a $5 \%$ de probabilidade pelo teste F;

Médias seguidas pela mesma letra na coluna, não diferem estatisticamente ao nível de 5\% de probabilidade, pelo teste de Tukey.

uniformidade deste elemento no tratamento dois, pode ter influenciado decisivamente no maior desenvolvimento deste tratamento superando todos os demais, porém a fixação de nitrogênio pelas bactérias do gênero Rhizobium sp. em simbiose com o feijoeiro é uma relação que deve ser estudada com mais detalhes; pois mesmo a adubação nitrogenada apresentando-se a priori mais eficiente, os efeitos ambientais da fixação biológica são incontestáveis, e a longo prazo, a produtividade tende a aumentar a medida que se vai elevando a população nativa e o nível de matéria orgânica no solo.

\section{AVALIAÇÃO DO EFEITO DA INOCULAÇÃO SOBRE A PRODUTIVIDADE}

\section{Número de Vagens por Planta}

Na Tabela 2 esta apresentado o estudo do número médio de vagens por planta de diferentes genótipos de feijoeiro, sem e com inoculação de estirpes nativas de Rhizobium sp., isoladas de solos de sete municípios do estado do Espírito Santo. Pode ser observado, de forma geral, que não houve diferença significativa comparando os plantios com e sem inoculação. Algumas exceções podem ser destacadas para os genótipos: Imperial com o isolado de Vila Pavão e Sooretama; Uirapuru com o isolado de Nova Venécia; IAPAR 81 com o isolado de Linhares; Bate Estrada com os isolados de Vila Pavão e Alegre e EL 22 com o isolado de Linhares. Quando se compara o comportamento do mesmo genótipo com inoculação, nos diferentes solos, pode se destacar o comportamento dos genótipos: Amarelinho inoculado com os isolado de Alegre e Linhares; Imperial inoculado com o isolado de Sooretama; Serrano inoculado com os isolado de Pinheiros, Alegre e Linhares; IAPAR 81 inoculado com o isolado de Linhares; Bate Estrada inoculado com os isolado de Vila Pavão e Alegre; EL 22 inoculado com os isolado de Vila Pavão e Linhares e Preto Meia Lua inoculado com os isolado de Pinheiros, Vila Pavão, Sooretama, Alegre e Linhares, sendo que essa diferença entre as estirpes nativas de Rhizobium em relação cada cultivar também foi observada por THIES et al. (1991).

\section{NÚMERO DE SEMENTES POR VAGEM}

Na Tabela 3 esta apresentado o estudo do número médio de sementes por vagem de plantas 
com as bactérias isoladas e com a estirpe conhecida, e transplantadas para recipientes contendo areia esterilizada em autoclave. O preparo do inoculante (109 células $\mathrm{mL}^{-1}$ ), a inoculação das sementes e as condições de crescimento foram realizados segundo Hungria et al.(1996).

O experimento foi montado no delineamento inteiramente casualizado com quatro repetições e 10 tratamentos, tendo: T1 = Inóculo de Pinheiros, T2 = Inóculo de Vila Pavão, T3 = Inóculo de Colatina, T4 = Inóculo de Nova Venécia, T5 = Inóculo de Sooretama, T6 = Inóculo de Alegre, T7 = Inóculo de Linhares, T8 = Inóculo Padrão CIAT 899, T9 = Sem inóculo com adição de nitrogênio T10 = Sem inóculo e sem adição de nitrogênio Ás plantas foram cultivadas em areia esterilizada mantidas em casa de vegetação, irrigadas de modo a manter sempre úmida a areia, sem que houvesse lixiviação de água e nutrientes, foi utilizado a solução nutritiva conforme descrito por Hoagland \& Arnon (1950).

Após 30 dias de plantio foram avaliadas as seguintes características: altura de planta, número de nódulos, matérias fresca e seca da parte aérea. A matéria seca foi determinada colocando a matéria fresca em estufa de circulação forçada, à temperatura de $80^{\circ} \mathrm{C}$, durante um período de 72 horas.

\section{AVALIAÇÃO DO EFEITO DA INOCULAÇÃO SOBRE A PRODUTIVIDADE}

Para estudar o efeito da inoculação de populações nativas de Rhizobium sp. sobre a produtividade das linhagens de feijoeiro tolerantes a seca foram avaliados os genótipos tolerantes ao déficit hídrico: Amarelinho, Macuquinho, Imperial, EL 22, BATT 477, Uirapuru, IAPAR-81, Bate Estrada, Serrano e Preto Meia Lua. Estes genótipos foram inoculados com as estirpes isoladas e cultivados no respectivo solo do qual o inoculante foi isolado.

$\mathrm{O}$ experimento foi conduzido no delineamento inteiramente casualizado, utilizando o esquema fatorial $10 \times 7$ (10 genótipos e 7 inoculantes) com quatro repetições, tendo como unidade experimental um vaso com duas plantas, sendo realizado adubação nitrogenada no tratamento não inoculado.

No estádio de maturação fisiológica (R9) foram avaliadas as seguintes características: altura de plantas, número de vagens por planta, número de sementes por vagem e produtividade total. Os dados foram analisados estatisticamente, utilizando o software SAEG (Sistema de Análise Estatística e Genética).

\section{RESULTADOS E DISCUSSÃO}

\section{COLETA DE AMOSTRAS DE SOLOS E ISOLA- MENTO DAS ESTIRPES DE RHIZOBIUM SP.}

O isolamento das bactérias fixadoras de nitrogênio foi realizado com sucesso, seguindo os critérios descritos conforme Vincent (1970); Hungria \& Araújo, 1994; Melo \& Azevedo, 1998, mostrando um bom crescimento de todas as estirpes, sendo estas de fácil reprodução em meio de cultura com extrato de levedura-manitol-agar em pH 6,8 (Hungria \& Araújo, 1994).

\section{AVALIAÇÃO DA FIXAÇÃO BIOLÓGICA DO NITROGÊNIO}

$\mathrm{Na}$ Tabela 1 foram avaliados dados referentes às características: altura de planta (ALT), número de nós da planta (NOS), peso da matéria fresca (PMF) e seca da parte aérea (PMS) e número de nódulos (NOD). Sendo que para as quatro primeiras características não houve diferença significativa entre os tratamentos, ao nível de 5\% de probabilidade, mostrando que a simbiose feijoeiro-rizóbio foi capaz de fixar $\mathrm{N}_{2}$ e suprir as necessidades das plantas, proporcionando desenvolvimento semelhante àquelas que receberam adubação nitrogenada em cobertura, estes dados também foram observados por Ferreira et al. (2000) e Mendes et al. (1998).

Para a característica número de nódulos (NOD) de plantas de feijoeiro do cultivar Carioca houve diferença significativa ao nível de $5 \%$ de probabilidade pelo teste de Tukey. Sendo o tratamento com maior número de nódulos o sem inóculo com $\mathrm{N} 2$, os intermediários foram os inóculos isolados dos solos de Pinheiros, Vila Pavão, Nova Venécia, Alegre, inóculo Padrão - CIAT 899, Linhares e os que apresentaram os resultados inferiores foram os inóculos isolados dos solos de Colatina, Sooretama e o sem inóculo e sem N2. O números de nódulos nos tratamentos não inoculados também foram observados por Ferreira et al. (2000).

Concordando com Barbosa et al. (2005) a matéria seca da parte aérea foi maior no tratamento que recebeu a solução nutritiva com nitrogênio (T9), provavelmente pela maior uniformidade e quantidade de nitrogênio fornecido à planta. Isto também pode explicar o melhor desenvolvimento para a altura de planta, matéria fresca da parte aérea.

Sendo o nitrogênio um componente essencial para a molécula de clorofila, a maior quantidade e 
fixar o nitrogênio atmosférico e fornecê-lo à cultura, é mecanismo biológico capaz de substituir, pelo menos parcialmente, a adubação nitrogenada resultando numa diminuição dos custos com adubação nitrogenada, aumento da produtividade, além de evitar a lixiviação de nitrato, para águas subterrâneas (Hungria et al., 1997).

Vários fatores interferem na eficiência simbiótica das estirpes de Rhizobium em condições de campo, tais como temperatura (Hungria \& Franco, 1993; Sá, 1993), acidez do solo (Taylor et al., 1991; Coletta Filho, 1993), concentração de nutrientes (Tsai, 1993) e o cultivar de feijoeiro (Ruschel, 1982).

Esses fatores em conjunto promovem pequenas nodulações e, consequentemente, perda da resposta à inoculação, diminuindo a eficiência do feijoeiro em estabelecer uma relação simbiótica com bactérias (Graham, 1981; Pereira et al., 1984; Buttery et al., 1987; Hardarson, 1993). A nodulação mesmo não sendo eficiente para suprir toda a exigência de nitrogênio requerida pela planta promove certa redução na utilização da adubação nitrogenada, representando uma economia considerável (Araújo, 1994). Assim a característica intrínseca do feijoeiro e da bactéria fixadora de nitrogênio (Rhizobium) é de grande importância para o sucesso da inoculação.

Dessa forma estirpes nativas geneticamente estáveis, adaptadas as condições do solo e a genótipos de feijoeiro, fazem com que ocorra um maior sucesso na relação simbiótica. Diante do exposto, o objetivo deste trabalho foi selecionar linhagens promissoras de feijoeiro tolerantes a seca (Phaseolus vulgaris L.) com capacidade de fixação biológica do nitrogênio, utilizando populações nativas de bactérias do gênero Rhizobium.

\section{MATERIAIS E MÉTODOS}

O experimento foi conduzido em casa de vegetação do Centro de Ciências Agrárias da Universidade Federal do Espírito Santo (CCAUFES), localizada no município de Alegre - ES, com as coordenadas geográficas de $20^{\circ} 45^{\prime}$ de latitude $\mathrm{Sul}, 41^{\circ} 28^{\prime}$ de longitude Oeste e altitude de $150 \mathrm{~m}$. O clima da região, de acordo com a classificação de Köppen é do tipo "Aw", tropical, com médias de temperatura mínima e máxima anual, no local dos estudos, de $18^{\circ} \mathrm{C}$ e $31^{\circ} \mathrm{C}$, respectivamente.

\section{COLETA DE AMOSTRAS DE SOLOS E ISOLA- MENTO DAS ESTIRPES DE RHIZOBIUM SP.}

Foram coletadas amostras de solo dos municípios de Pinheiros, Vila Pavão, Colatina, Nova Venécia, Sooretama, Linhares e Alegre, localizados no Estado do Espírito Santo, onde houve cultivo de feijoeiro por vários anos. O isolamento das bactérias foi realizado conforme descrito por Amarger \& Hamakawa (1997), com o intuito de isolar populações nativas de bactérias do gênero Rhizobium.

Sementes do cultivar Capixaba Precoce, considerada boa planta hospedeira fixadora de $\mathrm{N}_{2}$ (Hungria \& Neves, 1987; Silva et al., 1999), foram previamente desinfetadas por imersão em etanol 70\% e em hipoclorito de sódio 4\%, seguindo-se de cinco lavagens em água destilada estéril (Vincent, 1970; Hungria \& Araújo, 1994), e colocadas para germinar em papel tipo germitest. Três dias após a emergência da radícula, as plântulas foram inoculadas com uma solução de solo, preparada com 1,0 g de solo de cada local coletado, diluído em $10 \mathrm{~mL}$ de água destilada, sendo imediatamente transferidas para vasos de Leonard modificados e mantidos em casa de vegetação, conforme descrito por Amarger \& Hamakawa (1997).

Após 40 dias inoculação os nódulos foram coletados, desinfetados, macerados e semeados em placas de Petri contendo meio de cultura com extrato de levedura-manitol-ágar em pH 6,8 (Hungria \& Araújo, 1994), seguido de novos plaqueamentos, utilizando-se a técnica de esgotamento de alça, a fim de se obter colônias puras de crescimento homogêneo e livre de contaminantes (Vincent, 1970; Hungria \& Araújo, 1994; Melo \& Azevedo, 1998).

\section{AVALIAÇÃO DA FIXAÇÃO BIOLÓGICA DO NITROGÊNIO}

Esta etapa foi realizada em casa de vegetação utilizando recipientes plásticos de $2 \mathrm{~L}$ para plantio e avaliação das taxas de fixação de $\mathrm{N}_{2}$ das estirpes isoladas das diferentes amostras do solo da região Norte do Estado do Espírito Santo. O comportamento destas estirpes foi comparado com uma estirpe considerada como boa nodulante (tipo padrão EMBRAPA Agromicrobiologia, CIAT 899).

Para avaliar a eficiência de fixação biológica de nitrogênio pelas estirpes nativas isoladas foi utilizado o cultivar carioca, onde suas sementes foram colocadas em germinador com temperatura de $30 \pm 1{ }^{\circ} \mathrm{C}$ e após a emissão da radícula, as plântulas foram inoculadas 


\title{
AVALIAÇÃO DA FIXAÇÃO BIOLÓGICA DO NITROGÊNIO EM GENÓTIPOS DE FEIJOEIROS TOLERANTES A SECA ${ }^{1}$
}

\author{
EVALUATION OF BIOLOGICAL FIXATION OF NITROGEN \\ IN RHIZOBIUM UNDER WATER DEFICIT
}

\author{
Willian Bucker Moraes ${ }^{2}$; Sebastião Martins Filho ${ }^{3}$; Giovanni de Oliveira Garcia ${ }^{4}$; Simone de Paiva \\ Caetano $^{5}$; Wanderson Bucker Moraes ${ }^{5}$; Fernando Carrara Cosmi $^{2}$
}

\section{RESUMO}

Vários fatores como a temperatura, acidez do solo, teor de nutrientes e cultivar, interferem na eficiência simbiótica das estirpes de Rhizobium em condições de campo. Com objetivo de avaliar a capacidade de fixação biológica de nitrogênio de estirpes nativas de Rhizobium sp. foi realizado um experimento em vasos montado no delineamento inteiramente casualizado no esquema fatorial 10x7 (10 linhagens de feijoeiro consideradas tolerantes ao déficit hídrico, sendo estas: Amarelinho, Macuquinho, Imperial, EL 22, BATT 477, Uirapuru, IAPAR-81, Bate Estrada, Serrano e Preto Meia Lua e 7 inoculantes isolados dos solos dos municípios de Colatina, Vila Pavão, Nova Venécia, Pinheiros, Sooretama, Linhares e Alegre, no estado do Espírito Santo, com quatro repetições. Os dados demonstraram que a fixação biológica de $\mathrm{N}_{2}$ utilizando a inoculação de estirpes eficientes de Rhizobium em cultivar nodulante de feijoeiro ou seu cultivo em solos com população nativa eficiente, pode possibilitar a suplementação ou até mesmo à não utilização de nitrogênio em cobertura na cultura do feijoeiro, sem perdas no rendimento da produtividade.

Palavras chave: Rhizobium, Phaseolus Vulgaris L., adubação nitrogenada.

\begin{abstract}
Several factors as the temperature, soil acidity, content of nutrients and cultivate interfere in the symbiotic efficiency of the ancestries of Rhizobium in field conditions. With the objective of evaluating the capacity of biological fixation of nitrogen of native ancestries of Rhizobium sp. an experiment was accomplished in vases set up in the delineate entirely casualty in the factorial outline 10x7 (10 bean plant lineages considered tolerant to the water deficit, being these: Amarelinho, Macuquinho, Imperial, EL 22, BATT 477, Uirapuru, IAPAR-81, Bate Estrada, Serrano and Preto Meia Lua and 7 isolated inoculate of the soils of the municipal districts of Colatina, Vila Pavão, Nova Venécia, Pinheiros, Sooretama, Linhares and Alegre in Espírito Saint state, with four repetitions. The data demonstrated that the biological fixation of $N 2$ using the inoculation of efficient ancestries of Rhizobium in cultivating bean plant nodule cultivation in soils with efficient native population, it can make possible the supplement or even to the not use of nitrogen in covering in the culture bean plant, without losses in the income of the productivity.
\end{abstract} Key words: Rhizobium, Phaseolus Vulgaris L., nitrogen manuring.

\section{INTRODUÇÃO}

O Feijoeiro (Phaseolus vulgaris L.) é cultivado em boa parte do planeta. No Brasil, uma área de aproximadamente 5,5 milhões de ha é ocupada para seu plantio, contribuindo com aproximadamente $28 \%$ do consumo de proteínas da população (Hungria et al., 2000).

A expressão do potencial de produção da cultura do feijoeiro depende, dentre outros fatores, de um adequado fornecimento de nutrientes, sendo muito exigente em termos nutricionais, principalmente com relação ao nitrogênio e potássio (Rosolem, 1987).

O nitrogênio quando não disponível geralmente limita a produção das culturas. Desta forma à fixação biológica do nitrogênio é uma alternativa para um manejo sustentável dos solos (Hungria \& Vargas, 2000; Gliessman, 2001). A associação do feijoeiro com bactérias do gênero Rhizobium, capazes de

\footnotetext{
Trabalho financiado pelo Banco do Nordeste.

Mestrando em Produção Vegetal, Depto de Produção Vegetal, CCAUFES, Alegre - ES. E-mail: moraeswb@hotmail.com

Engo Agrônomo, Prof. Adjunto Dr., DPI/UFV, Viçosa - MG.

Engo Agrônomo Prof. Dr., Depto de Engenharia Rural, CCAUFES, Alegre - ES.

5 Acadêmico do curso de agronomia, Depto de Produção Vegetal, CCAUFES, Alegre - ES.
} 



\section{LITERATURA CITADA}

A.C.C. 2002. Centro Provincial de Meteorología Las Tunas. Informe del comportamiento de las variables del clima en la provincia Las Tunas, Folleto impresión ligera.

ACOSTA, F.; LUIS, A. 1986. Estudio de la evapotranspiración en caña de azúcar. INACA, Riego y Drenaje: 2(2): 22-61.

ALLEN R.; PEREIRA, L.; RAES, D.; SMITH, M. 1998. Crop evapotranspiration: guidelines for computing crop water requirements. Rome: FAO, Irrigation Drainage Pág. 56.

JENSEN, M.; BURMAN, R.;ALLEN, R. 1990. Evapotranspiration and Irrigation Water Requirements. ASCE Manuals and Reports on Engineering Practice $N^{\circ} 70.332 \mathrm{pp}$

LOGGIA, F.; PENSINI, M.; SARDO, V. 2005. HargreavesSamani method and evaporation pan in the estimation of reference evapotranspiration. ISHS Acta Horticulturae 449: II international symposium on irrigation of horticultural crops, 2002. Disponible en http://www.actahort.org/. Consulta mayo.
MARTELO, MARÍA. 1989. Selección de la fórmula de evapotranspiración mejor adaptada al área de Guanare-Masparro. Rev. Fac. Agron. (Maracay), 15: 185-206.

PENMAN, H.L. 1948. Natural evaporation from open water, bare soil and grass. Proc. R. Soc. London, Ser. A. 193: 120-145.

REY, R.; DE LA HOZ, L.; STINCER, J. 1978. Cálculo de la evapotranspiración de los cultivos agrícolas. Método del Evaporímetro Clase A. Ciencia y Técnica en la Agricultura, Riego y Drenaje. Vol I, No 1 . Enero.

SMITH M.; ALLEN, R.; MONTEITH, J.L.; PERRIER, A.; SANTOS PEREIRA, L. 1990. Report on the expert consultation on procedures for revision of FAO guidelines for prediction of crop water requirements. Reunión FAO, Roma. 28-31 mayo.

VÁZQUEZ, R. 2003. Desarrollo sostenible. Ojeada agrometeorológica en el contexto de la sostenibilidad agrícola. Congreso Internacional de Meteorología, La Habana (Formato electrónico). 
De esta forma se lograron ocho ecuaciones con posibilidades de ser utilizadas, las que se relacionan a continuación (Cuadro 3), así como su coeficiente de determinación. Como se aprecia los coeficientes de determinación fueron altos en todos los casos, oscilando entre 0,85 y 0,98 , lo que refleja un buen ajuste entre las variables.

Donde Ev y T son la evaporación mensual $(\mathrm{mm})$ y la temperatura promedio mensual para una localidad.

\section{Cuadro 2}

Relación entre las variables climáticas y los valores de ETo calculados por las fórmulas de mejor adaptación a la zona norte de Las Tunas

\begin{tabular}{|l|c|c|c|c|c|}
\hline \multirow{2}{*}{\multicolumn{1}{|c|}{ Fórmula }} & \multicolumn{5}{|c|}{ Coeficiente de correlación } \\
\cline { 2 - 6 } & Temperatura & Humedad Relativa & Velocidad del viento & Insolación & Evaporación \\
\hline Turc & 0,83 & $-0,04$ & 0,66 & 0,96 & 0,93 \\
\hline Hargreaves-Samani & 0,80 & $-0,09$ & 0,65 & 0,94 & 0,77 \\
\hline Penman-Monteith & 0,73 & $-0,14$ & $-0,05$ & 0,75 & 0,97 \\
\hline Blanney Morin & 0,67 & 0,02 & 0,48 & 0,95 & 0,98 \\
\hline
\end{tabular}

Cuadro 3

Ecuaciones de regresión obtenidas

\begin{tabular}{|l|l|c|c|}
\hline \multicolumn{1}{|c|}{ Fórmula base } & \multicolumn{1}{c|}{ Ecuación } & No. Ecuación & R $^{\mathbf{2}}$ \\
\hline Penman Monteith & $\mathrm{ETo}=11,9+0,613 * \mathrm{Ev}$ & 1 & 0,95 \\
\hline Penman Monteith & $\mathrm{ETo}=-51,9+0,538^{*} \mathrm{Ev}+3,08 * \mathrm{~T}$ & 2 & 0,90 \\
\hline Turc & $\mathrm{ETo}=33,2+0,517 * \mathrm{Ev}$ & 3 & 0,87 \\
\hline Turc & $\mathrm{ETo}=-83,2+5,61 * \mathrm{~T}+0,38 * \mathrm{Ev}$ & 4 & 0,98 \\
\hline Hargreaves Samani & $\mathrm{ETo}=-177+10,1 * \mathrm{~T}+0,286 * \mathrm{Ev}$ & 5 & 0,88 \\
\hline Hargreaves Samani & $\mathrm{ETo}=-241+14,7 * \mathrm{~T}$ & 6 & 0,97 \\
\hline Blaney Morin & $\mathrm{ETo}=-10,4+1,27 * \mathrm{~T}+0,537 * \mathrm{Ev}$ & 7 & 0,97 \\
\hline Blaney Morin & $\mathrm{ETo}=16,1+0,568 * \mathrm{Ev}$ & 8 & 0,85 \\
\hline
\end{tabular}

\section{CONCLUSIONES}

Las fórmulas que mejor reflejaron el comportamiento real de la evapotranspiración de referencia en el norte de Las Tunas fueron la de Hargreaves Samani, Penman Monteith, Turc y Blaney Morin.

Se obtuvo una alta correlación directa entre la evapotranspiración de referencia calculada y las variables del clima temperatura media, insolación y evaporación.

Se obtuvieron ocho ecuaciones de regresión para el cálculo de la evapotranspiración de referencia, factibles de poder utilizarse en el cálculo de las necesidades hídricas de los cultivos en las condiciones del norte de Las Tunas. 
La fórmula de Penman Monteith se derivó de la de Penman de 1948, y tanto ésta como la de Turc, han sido mencionadas por Rey et al. (1978) con posibilidades de ser aplicadas para el cálculo de la evapotranspiración de referencia, porque ambas se adaptan bien a climas húmedos como el de Cuba, pero tienen el inconveniente práctico de que necesitan una gran cantidad de datos, por lo que se ven limitadas para ser aplicadas a nivel local, desde el punto de vista de la poca disponibilidad de éstos.

De acuerdo al criterio de los mismos autores, las fórmulas que en este estudio arrojaron valores inadecuados para ser seleccionadas (Blaney Criddle y Thorntwaite) tienen el inconveniente de que se basan en la temperatura, y esta variable por sí sola no es buena indicadora del poder evaporante de la atmósfera.

Criterios más actuales sostenidos por Jensen (1990) señalan las fórmulas de Penman Monteith y Hargreaves Samani con buenas posibilidades para ser empleadas en el cálculo de la evapotranspiración de referencia en el trópico, con desviaciones que oscilaron entre $\pm 1 \%$ y $\pm 4 \%$ respecto a la evapotranspiración obtenida en lisímetros instalados en esas condiciones, mientras Loggia et al. (2002) señalaron a Hargreaves Samani con buenas posibilidades de aplicación, pues los inconvenientes que presenta el que utilice la temperatura como indicador de la evapotranspiración se corrigen con la introducción del término $\mathrm{Ra}$ (radiación equivalente en $\mathrm{mm} /$ día), el que depende de la latitud del lugar y refleja mejor las condiciones locales.

En el Cuadro 2 se observa la alta correlación directa existente entre los valores calculados por las cuatro mejores fórmulas con la temperatura, la insolación y la evaporación. Las fórmulas de $\mathrm{T}$ y HS, mientras BM y PM se correlacionaron mejor con la evaporación. Todas mostraron una muy débil relación inversa con la humedad relativa y se diferenciaron respecto a su relación con la velocidad del viento, pues en el caso de PM se observa una muy débil correlación inversa con esta variable, mientras las restantes presentaron correlaciones directas significativas.

Los valores del coeficiente de correlación para la temperatura, aunque son menores que los alcanzados con la variable Insolación y Evaporación, también son altos, por lo que se puede afirmar que las tres variables de conjunto influyen directamente sobre la magnitud del poder evaporante que se alcance en una localidad. Estos resultados coinciden con lo planteado en la literatura al respecto, pues en estudios reportados por Acosta y Luis (1986); Jensen, et al. (1990); Smith, et al. (1990) y Allen, et al. (1998) se destaca la gran influencia que provocan estas tres variables, siendo las causantes principales de los volúmenes de agua que entran a la atmósfera desde el suelo, ya sea por la vía de la evaporación o de la transpiración.

A partir de los resultados analizados se procedió a buscar las ecuaciones de regresión mediante las cuales fuera posible obtener, para cada una de las cuatro seleccionadas, una fórmula local que relacionara las tasas de ETo calculadas con las variables del clima y poder utilizarse en el futuro con fines de predicción de las necesidades hídricas de los cultivos en el ambiente subhúmedo seco del norte de Las Tunas.

\section{Cuadro 1}

Comparación e índices utilizados para determinar la fórmula de ETo mejor adaptada al norte de Las Tunas

\begin{tabular}{|l|c|c|c|c|c|c|c|}
\hline \multicolumn{1}{|c|}{ Fórmula } & IE & Poscón & R & Poscón & RP & Poscón & Puntuación general \\
\hline García López & 11,7 & 3 & 0,85 & 2 & 77,3 & 4 & 9 \\
\hline Thornthwaite & 16,4 & 1 & 0,78 & 1 & 68,0 & 1 & 3 \\
\hline Turc & 9,9 & 4 & 0,89 & 4 & 78,8 & 3 & 11 \\
\hline Hargreaves-Samani & 8,7 & 6 & 0,904 & 6 & 76,7 & 5 & 17 \\
\hline Penman-Monteith & 8,3 & 7 & 0,92 & 7 & 76,2 & 6 & 20 \\
\hline Blanney Morin & 9,1 & 5 & 0,901 & 5 & 73,6 & 7 & 17 \\
\hline Blanney Criddle & 12,6 & 2 & 0,85 & 3 & 97,9 & 2 & 7 \\
\hline
\end{tabular}


éstas y planificar estrategias agrícolas que ayuden a evitar equívocos y obtener resultados sostenibles (Vázquez, 2003).

El cálculo de la evapotranspiración es el primer paso para establecer las necesidades de riego de los cultivos, y en él se unen dos procesos energéticos, evaporación y transpiración, mediante los cuales se produce transferencia de vapor a la atmósfera (Penman, 1948).

En condiciones tropicales el cálculo del balance hídrico hecho a partir de fórmulas de evapotranspiración presenta diferencias apreciables con él obtenido a partir de mediciones de humedad en el suelo. Entre otras cosas, estas diferencias se deben a que tales métodos no son representativos para aquellas condiciones, al haberse desarrollado en latitudes templadas. Por este motivo se considera conveniente disponer de una ecuación más adaptable al trópico.

El presente trabajo se efectuó con el objetivo de estudiar la dinámica de la evapotranspiración de referencia (ETo) que refleje el comportamiento real del proceso en las condiciones del norte de Las Tunas que puedan ser utilizadas con fines de planificación y explotación del riego.

\section{MATERIALES Y MÉTODOS}

Se realizó un estudio de la dinámica de la evapotranspiración de referencia en la región norte de la provincia Las Tunas, obteniéndose mediante regresión ecuaciones regionales para el cálculo de la misma en las condiciones de la zona.

Se trabajó con siete fórmulas de cálculo de la evapotranspiración de referencia (ETo) corrientemente empleadas en el país y a su vez de las más citadas por la literatura: Penman Monteith, Hargreaves Samani, Turc, García-López, Thornthwaite, Blaney Criddle y Blaney Morin.

Los datos climatológicos utilizados fueron los promedios mensuales del período 1975-2002 (28 años), provenientes de la Estación Meteorológica de Puerto Padre.

Se aplicó la metodología de Martelo (1989) para comparar las tasas de evapotranspiración de referencia calculadas por las fórmulas anteriores con la obtenida por métodos aerodinámicos y lisimétricos (ETp) referida por ACC (2002).

La comparación se realizó por medio de tres índices:
1. Índice Estacional (IE)

2. Relación Porcentual(RP)

3. Coeficiente de Correlación (r)

Una vez calculada la ETp mediante las siete fórmulas y habiéndose estimado los tres índices para cada una de ellas, se procedió a su jerarquización mediante un sencillo sistema de pesos asignados de manera arbitraria. A la que mejor ajuste tenía en cada índice se le asignaron 7 puntos y así en orden decreciente hasta la de menor ajuste. Luego se sumó la puntuación obtenida en cada índice y se consideraron importantes sólo aquellas fórmulas que aparecieron ubicadas en los primeros cuatro lugares. De esta manera pudo elegirse con mayor objetividad la fórmula mejor adaptada.

Después de elegir la mejor fórmula para cada estación se procedió a correlacionar la ETp así calculada con las variables del clima a fin de comprobar cuál o cuáles eran las que mayor influencia tenían sobre el poder evaporante de la atmósfera, resultando la evaporación y la temperatura las que mayor correlación mostraron con la ETo, procediéndose entonces a calcular ecuaciones de regresión entre cada fórmula original y las mencionadas variables, obteniéndose así 8 ecuaciones de regresión con un buen ajuste (dos por cada fórmula original).

\section{RESULTADOS Y DISCUSIÓN}

Según se observa en el Cuadro 1, los índices estacionales oscilaron entre 8,3 y 16,4. Las fórmulas Penman Monteith (PM) y Hargreaves Samani (HS) alcanzaron los mejores valores, seguidas de Blaney Morin (BM) y Turc (T). En cuanto al coeficiente de correlación, éste osciló entre 0,78 y 0,92 y los resultados no difirieron mucho respecto al aspecto anterior, siendo de nuevo las cuatro fórmulas mencionadas las que también ocuparon los primeros lugares, repitiéndose el mismo orden. Al analizar la relación porcentual, ésta varió entre 68 y 97,9 y se observaron algunas diferencias en comparación con los dos índices analizados, aunque tres (BM, PM y HS) de las cuatro fórmulas señaladas estuvieron en los primeros lugares, siendo García López (GL) la cuarta de mejor posición en este caso.

De las siete fórmulas probadas, cuatro se seleccionaron como mejor adaptadas de acuerdo a la puntuación final creciente que logró cada una. Éstas fueron por orden jerárquico: PM, HS, BM y T. 


\title{
OBTENCIÓN DE MODELOS PARA LA DETERMINACIÓN DE LA EVAPOTRANSPIRACIÓN DE REFERENCIA EN CONDICIONES DE CLIMA SUBHÚMEDO SECO EN LAS TUNAS, CUBA
}

\author{
GETTING MODELS TO DETERMINE THE REFERENCE \\ EVAPORATION-PERSPIRATION UNDER SUBHUMID-DRY \\ WEATHER CONDITIONS IN LAS TUNAS, CUBA
}

MsC. Leyder Santana Peña ; DrC. Esteban Peña Peña ${ }^{2}$

\begin{abstract}
RESUMEN
Para estimar la evapotranspiración de referencia (ETo) en la zona norte de Las Tunas en Cuba, se realizó un estudio en el que se comparó su dinámica en la zona y se comparó con la evapotranspiración potencial (ETp) medida en lisímetro. Se emplearon los métodos de Penman-Monteith (PM), Turc (T), Hargreaves Samani (HS), Thorntwaite (Th), Blaney Criddle (BC) y Blaney Morin (BM). Las fórmulas que mejor reflejaron el comportamiento real de la evapotranspiración de referencia en el norte de Las Tunas fueron la de Hargreaves Samani, Penman Monteith, Turc y Blaney Morin. Se obtuvo una alta correlación directa entre la evapotranspiración de referencia calculada y las variables del clima: temperatura media, insolación y evaporación. Se obtuvieron ocho ecuaciones de regresión para el cálculo de la evapotranspiración de referencia, factibles de poder utilizarse en el cálculo de las necesidades hídricas de los cultivos en las condiciones del norte de Las Tunas.

Palabras clave: Evapotranspiración; evapotranspitación de referencia.
\end{abstract}

\begin{abstract}
To estimate the reference evaporation-perspiration (ETo) in the north area of Las Tunas in Cuba, it was carried out a study about its dynamics and was compared with the potential evaporation-perspiration (ETP) measure in lysimeter. There were used the methods of Penman-Monteith (PM), Turc (T), Hargreaves Samani (HS), Thorntwaite (Th), Blaney Criddle (BC) and Blaney Morin (BM). The equations that better reflected the real behavior of the reference evaporation-perspiration in the north of The Tunas were those of Hargreaves Samani, Penman Monteith, Turc and Blaney Morin. A high direct correlation was obtained among the evaporation-perspiration of calculated reference and the variables of the climate: half temperature, heatstroke and evaporation. Eight regression equations were obtained for the calculation of the reference evaporation-perspiration, feasible of being able to be used in the calculation of the hydrics necessities of the crops under the conditions of the north of Las Tunas.

key words: Evaporation-perspiration, Referente Evaporation-perspiration.
\end{abstract}

\section{INTRODUCCIÓN}

Cuba está trabajando en la formación de una conciencia de la naturaleza en la población y ha desarrollado planes de producción de alimentos utilizando diferentes alternativas que por un lado satisfagan las necesidades de la población y por otro que constituyan verdaderos sistemas sostenibles. No tener un conocimiento sobre las condiciones hídricas de una región ha causado en muchos lugares del mundo grandes desastres agrícolas. Con técnicas nada complejas es posible hacer estudios de

1 Profesor Auxiliar, Facultad de Agronomía, Centro de Estudios de Desarrollo Agrario en Las Tunas. Centro Universitario de Las Tunas.Cuba. leyder@ult.edu.cu

2 Profesor Titular, Centro de Estudios de Desarrollo Agrario en Las Tunas. Facultad de Agronomía. Centro Universitario de Las Tunas. Cuba. Dirección postal Avenida Carlos J. Finlay s/n Reparto Buenavista, Las Tunas. Cuba. Código 75200. esteban@ ult.edu.cu 



\section{LITERATURA CITADA}

CAPINERA, J.L.; SCHERER, C.W.; SIMKINS, J.B. 1997. Habitat associations of grasshoppers at the McArtur Agroecology Research Center, Lake Placid, Florida. Florida Entomologist, 80 (2): 253-61.

CIGLIANO, M.M.; DE WYSIECKI, M.L.; LANGE, C.E. 2000. Grasshopper species diversity in the Pampas, Argentina. Journal Diversity and Distributions 6: 81-93.

DE WYSIECKI, M.L.; SÁNCHEZ, N.E.; RICCI, S.E. 2000. Grassland ans shrubland grasshopper community composition in northerns La Pampa province, Argentina. J. Orthoptera Res. 9: 211-221.

DI RIENZO, J.A.; GUZMÁN, A.W.; CASANOVES, F. 2002 A multiple Comparison Method based on the distribution of the Root Node Distance of a binary tree Obtained by Average Linkage of the Matriz of Euclidean Distances Between Treatment Means. JABES 7(2) 1-14.

GUIDO, A.S.; CARBONELL, J. 1965. Investigaciones sobre un factor (F) en la estimación de las poblaciones de tucuras. Rev. Soc. Entomológica Argentina 26 (1-4): 93-9.

INFOSTAT. 2004. Manual del Usuario. Grupo InfoStat, FCA, Univ. Nac. Córdoba. $1^{\text {ra }}$ Ed. Editorial Brujas Argentina.

INTA. 1970. Haga su propio sistema de alarma. Serie Agricultura - Sanidad Vegetal. Publ. divulgación. 8 pp.

INTA. 1972. Así vive la voraz tucura. Serie Agricultura-Sanidad Vegetal. Publ. divulgación. 8 pp.

LIEBERMAN, J. 1963. Nueva contribución al conocimiento de las tucuras. INTA. Serie de informes de tecnicos. $\mathrm{N}^{\mathrm{o}} 56$. $45 \mathrm{pp}$.

LIEBERMAN, J. 1972. The current state of the locust and grasshopper problem in Argentina. In: Proc. Ins. Study conf. Current and Future problems of Acridiology. London, 1970, pp. 191-7.

LIEBERMAN, J.; SCHIUMA, R. 1946. Las tucuras más perjudiciales de nuestra agricultura y ganadería. Min. Agr. Instituto de Sanidad Vegetal. Serie B. 2 (7): 62 pp.

MONTGOMERY, D.C. 1991. Diseño y análisis de experimentos. Ed. Iberoamérica. México. 589 pp.

RONDEROS, R.A. 1996. Stability and diversity of grasshopper species due to spatial heterogeneity. Proceedings $4^{\text {th }}$ Trienal Meeting Pan American Acridology Society 1985, USA, pp. 121-124.

SALTO, C.; BELTRAME, R. 1999a. Especies y distribución de tucuras en pasturas de la región centro oeste de Santa Fe y centro este de Córdoba. Pp. 196-199. Publ. Miscelánea no 89. EEA INTA Rafaela, Sta. Fe.

SALTO, C.; BELTRAME, B.R. 1999. Manejo y reconocimiento de tucuras. Centro oeste de Santa Fe y centro este de Córdoba. Pp. 196-199. Publ. Miscelánea nº 99. EEA INTA Rafaela Sta. Fe. 23 pp.

SÁNCHEZ, N.E.; DE WYSIECKI, M.L. 1990. Quantitative evaluation of feeding activity of the grashopper Dichroplus pratensis (Orthoptera: Acrididae) in a natural grassland of La Pampa, Argentina. Environ. Entomol. 19 (5): 1392-5.

VES LOSADA, J.C.; BAUDINO, E.M. 1998. Influencia de sistemas de labranza sobre la población de tucuras (Orthoptera: Acrididae). Bol. Divulgación Téc. № 59. EEA Anguil. 6 pp.

ZEQUIN, L.; BELTRAME, R.; LUISELLI, S.; SALTO, C.; STRASSER., R. 1999. Abundancia y diversidad de tucuras (Orthoptera: Acridoidea) en el centro oeste de santa fe y centro este de cordoba. Anuario INTA Rafaela. Sta. Fe. 120 pp. 
mejor momento para el relevamiento de la primera generación, ya que detecta los juveniles de las especies de ciclo temprano, intermedio y tardío (INTA 1972). Sin embargo, aquí fue detectada tardíamente (densidad en descenso).

Los estudios de referencia (Lieberman 1963) provienen de desoves y fechas de emergencia en Guaminí, Tornquist y Coronel Suárez, al S.O. de Buenos Aires, cerca del límite con La Pampa, mientras que el partido de Arrecifes se encuentra en el N.O. de la provincia. La emergencia fue más temprana por la temperatura local relativamente más elevada y la falla en la detección de la primera generación se debió al inicio tardío de los relevamientos para la zona.

En la segunda generación, el pico final de abundancia correspondió a los adultos de otoño, que son aquellos que producen los desoves invernantes $\mathrm{y}$, por lo tanto, son los padres de la primera generación de primavera (INTA 1970 y 1972). La soja -ya en etapa reproductiva-, con la mayor abundancia relativa para ésta época, pareció actuar como su reservorio de otoño.

Sobre las variables de monitoreo consideradas aquí (posición en el lote y operador), Salto y Beltrame (1999a) en alfalfa, achicoria y campo natural, obtuvieron en la mitad de las parcelas mayor abundancia en los bordes, en una tercera parte igual abundancia $y$, en el resto, menor abundancia en los bordes. Por lo tanto, si bien hubo una diferenciación entre estos estratos, no siempre fue a favor del borde.

La tendencia en los datos muestra que en aquellas fechas y variables para las cuales se obtuvieron diferencias significativas, visualmente no se aprecian diferencias entre los bordes. Lo opuesto sucede donde las apreciables diferencias visuales entre los bordes según el vecino, que no se reflejaron en las pruebas estadísticas. Debe remarcarse sin embargo que la abundancia fue relativamente baja, para todas las fechas y recursos.

La mayor abundancia hallada ocasionalmente en los bordes podría deberse no a una distribución consistentemente estratificada dentro de la parcela, sino como resultado de un vecino particular para el borde en cuestión. En el presente trabajo, los vecinos variaron para cada borde, pudiendo tratarse de soja, caminos, pastura, pastizal o canal de arroyo. A partir de la tendencia mencionada, una fuente de infestación de riesgo -en aquellos con alta abundancia- fue un recurso similar al relevado, ya que ello determina una oferta continua, que la presencia del alambrado no interrumpe. Otro vecino riesgoso fue un área inculta, o estable y sin remoción -camino, canal de arroyo- que sustenta poblaciones permanentes de tucuras.

La recomendación corriente de tomar dos estratos: 'bordes' y 'centro' de la parcela, no sería suficiente. La diferencia en la densidad de estos estratos, consecuencia de un vecino riesgoso como fuente de infestación, es determinada sólo por algunos de estos vecinos. Esta diferencia no se verifica para cualquier situación y no siempre es detectada al considerar solamente los bordes respecto del centro. En ausencia de vecinos riesgosos como fuente de inóculo, o si se hallaran sólo en algunos de los bordes, la estratificación como método corriente para todos ellos implicaría un incremento innecesario en el costo del monitoreo.

Las diferencias entre operadores en el muestreo con red se relacionarían con su contextura física, que influye en la fuerza y el recorrido del golpe de la red. Ambos operadores eran muy similares físicamente, por lo cual las diferencias obtenidas es más probable que sean producto del azar, dada su baja ocurrencia. Los autores discrepan en la consideración de los operadores: Guido y Carbonell (1965) aconsejan calcular un 'factor' específico de conversión para cada operador, pero Cigliano et al. (2000) emplearon siempre los mismos dos operadores para asegurar la estabilidad en la colecta con red.

En los hechos, el resultado es la adopción de la red de arrastre, de mayor rapidez en la obtención de resultados, facilidad de uso y bajo requerimiento de entrenamiento específico, lo que implica un alto retorno con bajo costo, que aún provee una imagen satisfactoria del sistema biológico. La red genera una medida indirecta de la abundancia, pero refleja ajustadamente sus variaciones espacio-temporales y por lo tanto resulta un sistema adecuado para el objetivo del monitoreo: contar con una herramienta de diagnóstico para las decisiones de intervención.

Dada la amplia dispersión de las tucuras en el territorio y la creciente importancia de los cultivos bajo siembra directa, emerge la necesidad de implementar estudios locales sobre diversos aspectos, como las fechas críticas para la emergencia en primavera, o sobre su importancia en tales áreas. 
debido al cultivo (5 de 11 fechas). Hubo un efecto de interacción entre el cultivo y la posición en la parcela ( 2 fechas). Por lo tanto, no se observó una respuesta diferente, debida al operador o la posición dentro de la parcela.

\section{DISCUSIÓN}

Los valores de la Figura 3 corresponden a 400 golpes de red / parcela. El máximo en el pastizal fue de 0,355 indiv. / golpe de red; 0,1475 en la pastura sin pastoreo; 0,074 en soja y casi 0,034 indiv. / golpe en la pastura con pastoreo. Estos valores fueron inferiores a todas las referencias locales, que se hallaron entre 0,7 y 9 indiv. / golpe de red (Cigliano et al., 2000; de Wysiecki et al., 2000; ves Losada y Baudino, 1998; Salto y Beltrame, 1999.a.; Zequin et al., 1999).

Si bien durante el invierno previo se buscaron desoves para cotejar la fecha de emergencia de la primera generación, no fue posible hallar ninguno. Ello coincidió entonces con la baja abundancia registrada con la red, la cual sin embargo detectó sus variaciones en la segunda generación, de inferior abundancia para casi todas las fechas y recursos. Al respecto, ya que en cada parcela se realizó un total de 400 golpes de red, el tamaño de la muestra utlizada aquí fue igual o superior a aquélla en todas las referencias consultadas.

Para casi todos los recursos, la alta densidad de mediados de noviembre -debidas mayormente a las juveniles- no fue superada en las fechas posteriores. La excepción fue el cultivo de soja, donde el máximo se produjo en el mes de febrero y fue debido a los adultos, no por los juveniles. A fin de la temporada, en todos los recursos, la densidad de adultos superó a la correspondiente a las juveniles. Para mediados de febrero la soja, en la cual se presentó la mayor abundancia relativa, actuaría como su reservorio de otoño.

Los adultos son quienes presentan el mayor consumo de biomasa, mayor aún en la etapa prerreproductiva (Sánchez \& de Wysiecki, 1990). Por otra parte, los adultos de otoño son quienes producen los desoves invernantes y, por lo tanto, son los padres de la generación de primavera. Considerando que su etapa reproductiva no daría comienzo sino hasta fines de marzo o principios de abril (INTA 1970 y 1972), esto se traduce un mes de consumo como adultos prerreproductivos. La alta densidad de adultos prerreproductivos y reproductivos involucra un alto riesgo, dado su alto consumo y movilidad, especialmente si se ubican en la soja en su etapa de floración en adelante, en un período crítico para el daño por defoliación.

En la proporción de especies capturadas en uno y otro estado, los resultados del cultivo de soja fueron diferentes a los del pastizal y pasturas. Las especies capturadas como dominantes en forma adulta, en general no lo fueron como juveniles; la soja no sería un recurso adecuado para el desarrollo de sus poblaciones. Por otra parte, los resultados aquí presentados mostrarían que el saltamontes del pastizal, con una abundancia muy alta, no migraría hacia la soja, presentando riesgo de invasión sólo hacia las pasturas. Sin embargo, su alta abundancia en las pasturas podría forzar a los Acrídidos que predominan en pasturas y soja, a migrar a su vez hacia esta última, justamente cuando el cultivo se halla en etapa reproductiva y las tucuras en su período de mayor consumo.

La mayor abundancia relativa del mes de noviembre para la pastura y el pastizal correspondieron tanto a $D$. punctulatus - una especie temprana (INTA 1972)- como al Tettigonüdae. Este último, dada su dominancia en el pastizal e importancia alta en la pastura, define la curva de la primera generación. El segundo máximo de abundancia correspondería con la emergencia de la segunda generación (INTA 1972), donde habrían prevalecido los dos Gomphocerinae. En la soja se registró un pico en enero en los juveniles, pero el máximo correspondió a febrero y para los adultos, donde dominó R. (Dichroplus) bergi, uno de los Gomphocerinae y D. punctulatus.

Sobre el Tetrigidae (tucura pigmea), Lieberman y Schiuma (1946) los definen como higrófilos y no tendrían ninguna relevancia para los cultivos. Para el Tettigonüdae que dominó en pastizal y tuvo alguna importancia en la pastura, la soja no fue un recurso favorable. Estos Ensifera o saltamontes verdaderos se relacionan con canales de irrigación y otros ambientes umbríos (Capinera et al., 1997) y no suelen tomarse en cuenta en los relevamientos, dirigidos principalmente a Celífera. Dichroplus, Ronderosia y demás Acrídidos que dominaron en la soja, se habrían desplazado sólo desde o hacia la pastura.

La respuesta obtenida en las variaciones de abundancia resultó del predominio de especies de emergencia temprana. Fines de noviembre sería el 
Tabla 3

Resultados del ANVA y prueba DGC (alfa $=0,05)$ para el total de tucuras por cultivo, posición y operador (variables de monitoreo)

\begin{tabular}{|c|c|c|c|c|c|c|}
\hline Fecha & Cultivos & F. de Var. & $\mathbf{p}$ & Cultivo & Pos. & DGC \\
\hline \multirow[t]{4}{*}{$9 / 1$} & Ptzl. & Cultivo & $<0,0001$ & Past. $S / p$ & $\mathrm{C}$ & $\mathrm{a}$ \\
\hline & Past. S/p & Cult.* Pos. & 0,0082 & Past. S/p & B & $\mathrm{a}$ \\
\hline & & & & Ptzl. & B & $\mathrm{a}$ \\
\hline & & & & Ptzl. & $\mathrm{C}$ & b \\
\hline
\end{tabular}

\begin{tabular}{|c|c|c|c|c|c|c|c|c|c|}
\hline Fecha & Cultivos & F. de Var. & $\mathbf{p}$ & Cultivo & DGC & Oper. & Pos. & Media & DGC \\
\hline \multirow[t]{4}{*}{$4 / 2$} & Past. S/p & Cultivo & $<0,0001$ & Past. C/p & a & B & $\mathrm{C}$ & 3,17 & a \\
\hline & Past. C/p & Oper.* Pos. & 0,0225 & Past. S/p & b & A & B & 3,42 & $\mathrm{a}$ \\
\hline & Soja & & & Soja & c & A & $\mathrm{C}$ & 4,33 & $\mathrm{a}$ \\
\hline & & & & & & B & B & 6,00 & $\mathrm{~b}$ \\
\hline
\end{tabular}

\begin{tabular}{|c|c|c|c|c|c|c|}
\hline Fecha & Cultivos & F. de Var. & $\mathbf{p}$ & & Cultivo & DGC \\
\hline $23 / 2$ & Ptzl. & Cultivo & 0,0004 & & Past. S/p & $\mathrm{a}$ \\
\hline & Past. S/p & & & & Soja & $\mathrm{a}$ \\
\hline & Soja & & & & Ptzl. & b \\
\hline
\end{tabular}

\begin{tabular}{|c|c|c|c|c|c|c|}
\hline Fecha & Cultivos & F. de Var. & $\mathbf{p}$ & Cultivo & Pos. & DGC \\
\hline \multirow[t]{6}{*}{$1 / 3$} & Past. C/p & Cultivo & 0,0005 & Past. S/p & $\mathrm{C}$ & $\mathrm{a}$ \\
\hline & Past. S/p & Cult.* Pos. & 0,0001 & Past. C/p & $\mathrm{C}$ & $\mathrm{a}$ \\
\hline & Ptzl. & & & Past. C/p & B & $\mathrm{a}$ \\
\hline & & & & Ptzl. & B & $\mathrm{a}$ \\
\hline & & & & Ptzl. & $\mathrm{C}$ & $\mathrm{b}$ \\
\hline & & & & Past. S/p & B & $\mathrm{b}$ \\
\hline
\end{tabular}

\begin{tabular}{|c|l|c|c|c|c|c|}
\hline Fecha & Cultivos & F. de Var. & $\mathbf{p}$ & & Cultivo & DGC \\
\hline $9 / 4$ & Ptzl. & Cultivo & 0,009 & & Past. C/p & a \\
\hline & Past. S/p & & & & Past. S/p & b \\
\hline & Past. C/p & & & & Ptzl. & b \\
\hline
\end{tabular}

Referencias: El valor de $p<0,05$ implica que la prueba (ANVA) es significativa. Para la prueba DGC, letras diferentes en la última columna significa que las medias, ordenadas de menor a mayor, fueron significativamente diferentes $($ alfa $=0,05)$. 


$$
\begin{aligned}
& \text { PASTURAS } \\
& \text { \% JUVENILES } \\
& 327 \text { ejemplares }
\end{aligned}
$$

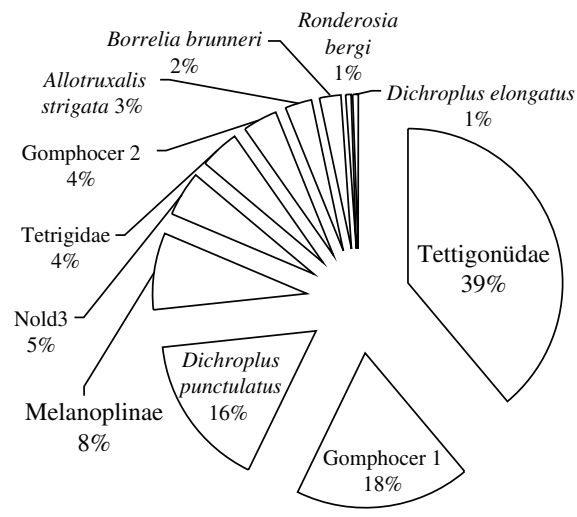

SOJA

$\%$ JUVENILES

149 ejemplares

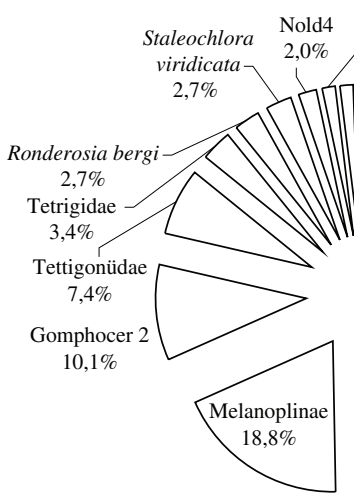

PASTIZALES

$\%$ JUVENILES

737 ejemplares

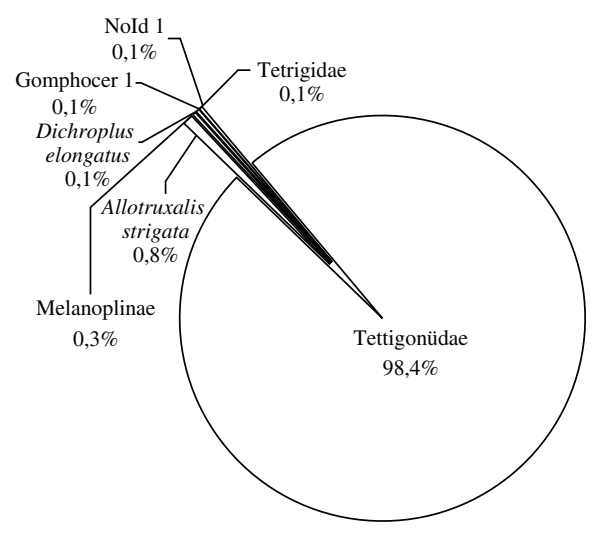

PASTURAS

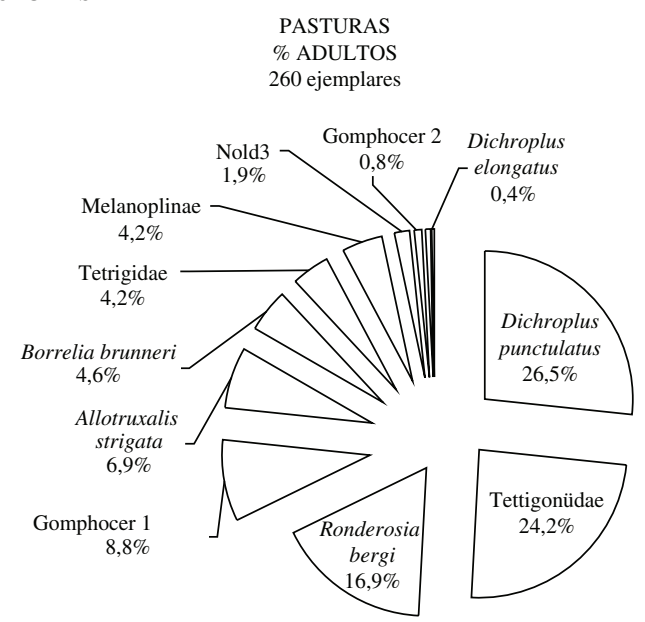

SOJA

\% ADULTOS

288 ejemplares

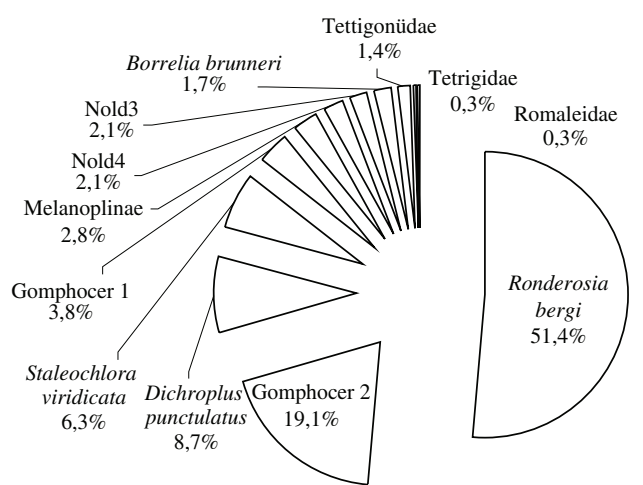

PASTIZALES

PASTIZALES

$\%$ ADULTOS

222 ejemplares

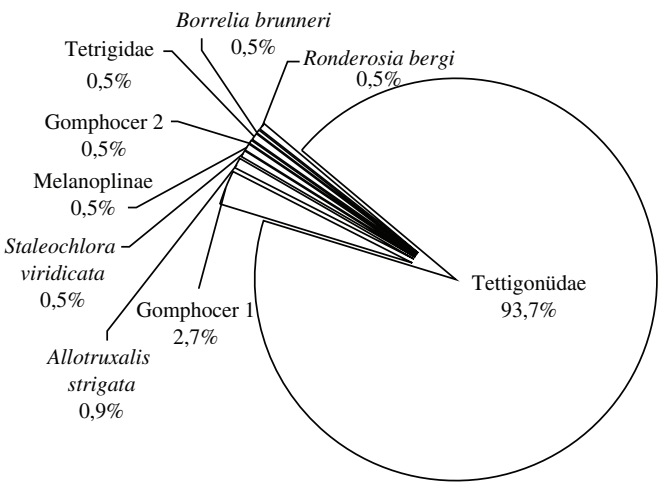

Porcentaje relativo de especies de Orthoptera

Figura 4. Presencia relativa de especies de tucuras y número de ejemplares colectados por recurso. 
Tabla 2

Ejemplares de tucuras obtenidas en los relevamientos

\begin{tabular}{|c|c|}
\hline \multicolumn{2}{|c|}{ ORDEN ORTHOPTERA } \\
\hline \multicolumn{2}{|l|}{ Suborden ENSIFERA } \\
\hline \multirow{2}{*}{$\begin{array}{l}\text { SUPERFAMILIAS } \\
\text { Tettigoniidae } \\
\text { FAMILIA } \\
\text { Tettigoniidae }\end{array}$} & (*) 1 especie \\
\hline & 1 no identificada (saltamontes o grillo verde) \\
\hline \multicolumn{2}{|c|}{ Suborden CAELIFERA } \\
\hline \multirow{2}{*}{$\begin{array}{l}\text { SUPERFAMILIAS } \\
\text { Acridoidea Burmeister } 1839 \\
\text { FAMILIA } \\
\text { Tetrigidae Uvarov } 1940 \text { (=Acrydiidae Werner 1936) }\end{array}$} & (*) 1 especie \\
\hline & 1 no identificada (acridio pigmeo) \\
\hline \multirow{4}{*}{$\begin{array}{l}\text { FAMILIA } \\
\text { Romaleidae Roberts } 1941 \text { (2) }\end{array}$} & (*) 3 especies \\
\hline & Chromacris sp. (tucura de las quintas) \\
\hline & Staleochlora (Elaechlora) viridicata (tucura verde) \\
\hline & 1 no identificada \\
\hline \multicolumn{2}{|l|}{$\begin{array}{l}\text { FAMILIA } \\
\text { Acrididae MacLeay } 1821 \text { (30 subf.) endémica S\&C Am. }\end{array}$} \\
\hline $\begin{array}{l}\text { Subfamilias } \\
\text { Acridinae }\end{array}$ & $\begin{array}{l}\text { (*) } 1 \text { especie } \\
\text { Allotruxalis strigata }\end{array}$ \\
\hline \multirow{3}{*}{ Gomphocerinae J \& B } & (*) 3 especies \\
\hline & Borrellia brunneri (tucura de Bruner) \\
\hline & 2 no identificadas \\
\hline \multirow{5}{*}{ Melanoplinae Scud 1897} & (*) 4 especies \\
\hline & Dichroplus elongatus (tucura alargada de alfalfares) \\
\hline & Ronderosia (Dichroplus) bergi (tucura de Berg) \\
\hline & Beaecris (Dichroplus) punctulatus (tucura punteada) \\
\hline & 1 no identificada \\
\hline
\end{tabular}

Las 5 especies más importantes fueron: la misma Tettigonüdae dominante en los pastizales, junto a Dichroplus punctulatus, Ronderosia (Dichroplus) bergi y otros 2 Acrididae de las Subfamilias Gomphocerinae y Melanoplinae (la misma a la que corresponde el género Dichroplus).

Dado que los potreros denominados aquí con o sin pastoreo modificaban tal situación a través de las fechas de muestreo, la diferencia en su abundancia relativa se relaciona con la migración local-dentro del recurso- en función de la disponibilidad de forraje entre lotes.
En la soja, la situación se invirtió para las capturas por estado y también para las especies. La menor proporción correspondió a los juveniles $(34,1 \%)$ y la mayor a los adultos $(65,90 \%)$. En cuanto a las especies presentes, alrededor del $85 \%$ en ambos estados correspondieron a 6 de ellas: Ronderosia (Dichroplus) bergi, Dichroplus punctulatus, el mismo Tettigonüdae y 3 Acrididae, 2 de la Subfamilia Gomphocerinae y 1 Melanoplinae. El restante $15 \%$ se repartió entre 8 diferentes especies.

Respecto del análisis sobre las variables de monitoreo (Tabla 3), el efecto más importante fue 
Tabla 1

Resultados del ANVA y prueba de Tukey $($ alfa $=\mathbf{0 , 0 5}$ ) para abundancia por recurso

\begin{tabular}{|c|c|c|c|c|c|}
\hline Fecha & Variable & Recursos & $\mathbf{F}$ & $\mathbf{p}$ & Tukey \\
\hline \multirow{6}{*}{ 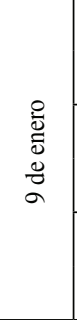 } & \multirow{2}{*}{ Adultos } & Pastizal & 25,0 & 0,0377 & $\mathrm{a}$ \\
\hline & & Pastura s/pastoreo & & & $\mathrm{b}$ \\
\hline & \multirow{2}{*}{ Juveniles } & Pastizal & 4,55 & 0,1667 & - \\
\hline & & Pastura s/pastoreo & & & - \\
\hline & \multirow{2}{*}{ Total } & Pastizal & 5,01 & 0,1546 & - \\
\hline & & Pastura s/pastoreo & & & - \\
\hline \multirow{6}{*}{$\begin{array}{l}0 \\
\stackrel{0}{0} \\
\tilde{0} \\
0 \\
0 \\
0\end{array}$} & \multirow{2}{*}{ Adultos } & Pastizal & 18,38 & 0,050 & - \\
\hline & & Soja & & & - \\
\hline & \multirow{2}{*}{ Juveniles } & Pastizal & 456,03 & 0,0022 & $\mathrm{a}$ \\
\hline & & Soja & & & $\mathrm{b}$ \\
\hline & \multirow{2}{*}{ Total } & Pastizal & 15,94 & 0,0574 & - \\
\hline & & Soja & & & - \\
\hline \multirow{9}{*}{$\begin{array}{l}\stackrel{0}{0} \\
\stackrel{0}{0} \\
\stackrel{0}{0} \\
8 \\
+ \\
+\end{array}$} & \multirow{3}{*}{ Adultos } & Soja & 35,69 & 0,0081 & $\mathrm{a}$ \\
\hline & & Pastura s/pastoreo & & & $\mathrm{b}$ \\
\hline & & Pastura c/pastoreo & & & $\mathrm{b}$ \\
\hline & \multirow{3}{*}{ Juveniles } & Pastura s/pastoreo & 11,80 & 0,0379 & $\mathrm{a}$ \\
\hline & & Soja & & & $a b$ \\
\hline & & Pastura c/pastoreo & & & $\mathrm{b}$ \\
\hline & \multirow{3}{*}{ Total } & Soja & 15,21 & 0,0269 & a \\
\hline & & Pastura s/pastoreo & & & $a b$ \\
\hline & & Pastura c/pastoreo & & & $\mathrm{b}$ \\
\hline \multirow{9}{*}{ 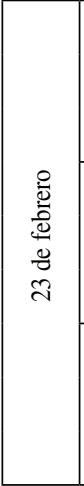 } & \multirow{3}{*}{ Adultos } & Soja & 11,81 & 0,0378 & $\mathrm{a}$ \\
\hline & & Pastizal & & & $\mathrm{ab}$ \\
\hline & & Pastura s/pastoreo & & & $\mathrm{b}$ \\
\hline & \multirow{3}{*}{ Juveniles } & Pastizal & 38,11 & 0,0074 & $\mathrm{a}$ \\
\hline & & Pastura s/pastoreo & & & $\mathrm{b}$ \\
\hline & & Soja & & & $\mathrm{b}$ \\
\hline & \multirow{3}{*}{ Total } & Pastizal & 6,9 & 0,0754 & - \\
\hline & & Pastura s/pastoreo & & & - \\
\hline & & Soja & & & - \\
\hline \multirow{3}{*}{ 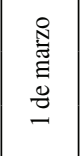 } & \multirow{3}{*}{ Adultos } & Pastura s/pastoreo & 1,05 & 0,4512 & - \\
\hline & & Pastura c/pastoreo & & & - \\
\hline & & Pastizal & & & - \\
\hline
\end{tabular}

\begin{tabular}{|c|c|c|c|c|c|}
\hline Fecha & Variable & Recursos & $\mathbf{F}$ & $\mathbf{p}$ & Tukey \\
\hline \multirow{6}{*}{ 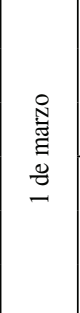 } & \multirow{3}{*}{ Juveniles } & Pastura s/pastoreo & 7,82 & 0,0645 & - \\
\hline & & Pastura c/pastoreo & & & - \\
\hline & & Pastizal & & & - \\
\hline & \multirow{3}{*}{ Total } & Pastura s/pastoreo & 1,96 & 0,2853 & - \\
\hline & & Pastura c/pastoreo & & & - \\
\hline & & Pastizal & & & - \\
\hline \multirow{9}{*}{ 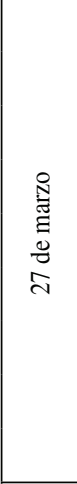 } & \multirow{3}{*}{ Adultos } & Pastura s/pastoreo & 0,91 & 0,4911 & - \\
\hline & & Pastura c/pastoreo & & & - \\
\hline & & Pastizal & & & - \\
\hline & \multirow{3}{*}{ Juveniles } & Pastura s/pastoreo & 1,02 & 0,4593 & - \\
\hline & & Pastura c/pastoreo & & & - \\
\hline & & Pastizal & & & - \\
\hline & \multirow{3}{*}{ Total } & Pastura s/pastoreo & 0,74 & 0,5498 & - \\
\hline & & Pastura c/pastoreo & & & - \\
\hline & & Pastizal & & & - \\
\hline \multirow{9}{*}{$\begin{array}{l}\bar{\Xi} \\
\tilde{0} \\
0 \\
0 \\
0 \\
0\end{array}$} & \multirow{3}{*}{ Adultos } & Pastura s/pastoreo & 33,33 & 0,0089 & $\mathrm{a}$ \\
\hline & & Pastura c/pastoreo & & & $\mathrm{a}$ \\
\hline & & Pastizal & & & $b$ \\
\hline & \multirow{3}{*}{ Juveniles } & Pastura s/pastoreo & 0,11 & 0,8984 & - \\
\hline & & Pastura s/pastoreo & & & - \\
\hline & & Pastizal & & & - \\
\hline & \multirow{3}{*}{ Total } & Pastura s/pastoreo & 6,5 & 0,0812 & - \\
\hline & & Pastura s/pastoreo & & & - \\
\hline & & Pastizal & & & - \\
\hline \multirow{9}{*}{ 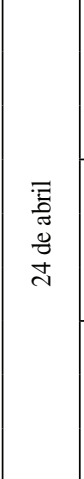 } & \multirow{3}{*}{ Adultos } & Pastura c/pastoreo & 10,50 & 0,0442 & $\mathrm{a}$ \\
\hline & & Pastura s/pastoreo & & & $\mathrm{ab}$ \\
\hline & & Pastizal & & & $\mathrm{b}$ \\
\hline & \multirow{3}{*}{ Juveniles } & Pastura c/pastoreo & 0,81 & 0,5240 & - \\
\hline & & Pastura s/pastoreo & & & - \\
\hline & & Pastizal & & & - \\
\hline & \multirow{3}{*}{ Total } & Pastura c/pastoreo & 2,88 & 0,2001 & - \\
\hline & & Pastura s/pastoreo & & & - \\
\hline & & Pastizal & & & - \\
\hline
\end{tabular}

Referencias: F: Estadístico de Snedecor (ANVA); el valor de $\mathrm{p}<0,05$ implica que la prueba es significativa. Para la prueba de Tukey, letras diferentes en la última columna significa que las medias, ordenadas de mayor a menor, fueron significativamente diferentes $($ alfa $=0,05)$. 


\section{RESULTADOS}

La abundancia de tucuras fue representada por fecha de muestreo en la Figura 3, donde se aprecia que el máximo fue superior en el pastizal, seguida por la pastura sin pastoreo, la soja y por último la pastura con pastoreo. El relevamiento en soja fue más corto y finalizó cuando el cultivo entró en $R_{8}$. Los valores representados por parcela provienen de $=[8$ transectas $* 50$ golpes de red/transecta $=$ 400 golpes de red].

En la Tabla 1 se presentan los resultados de la comparación de abundancia por recurso; el análisis se llevó a cabo cuando se hallaban los datos completos para ambas parcelas. La densidad resultó significativamente diferente en 5 de 8 pruebas para la densidad de adultos, en 3 de 8 para la densidad de juveniles y en 1 de 8 para la densidad total. La prueba de Tukey separó 2 grupos, donde el ordenamiento fue: pastizal $>$ pastura s/pastoreo $>$ pastura c/pastoreo $>$ soja (para juveniles y adultos). La abundancia en la soja encabezó el grupo cuando fue relevada ( 2 en 5) y en el resto de las fechas se repartió entre los demás recursos.

En la Tabla 2 se detalló la ubicación taxonómica de los ejemplares colectados. Por otra parte, su presencia relativa en cada recurso fue representada en la Figura 4, para la cual se consideraron -según su composición florística- soja, pastura y pastizal.

De acuerdo con la Figura 4, en el pastizal más del 95\% de las capturas como adultos y juveniles estuvo representado por una sola especie de Tettigonüdae, (Suborden Ensifera) un saltamontes verde; el resto ( $1,6 \%$ para los juveniles y $6,3 \%$ para los adultos) correspondió a las otras 8 especies. El 76,85\% del total de individuos capturados en el pastizal correspondió a juveniles del mismo saltamontes.

En la pastura, la captura se repartió de modo equitativo entre los juveniles $(55,71 \%)$ y los adultos $(44,29 \%)$. En general, las especies que dominaron las capturas como adultos también lo hicieron como juveniles. Con respecto a las especies, 5 representaron entre el 76 y $80 \%$ de las capturas y las restantes 8 especies acumularon entre el 14 y $20 \%$ del total.
PASTIZAL

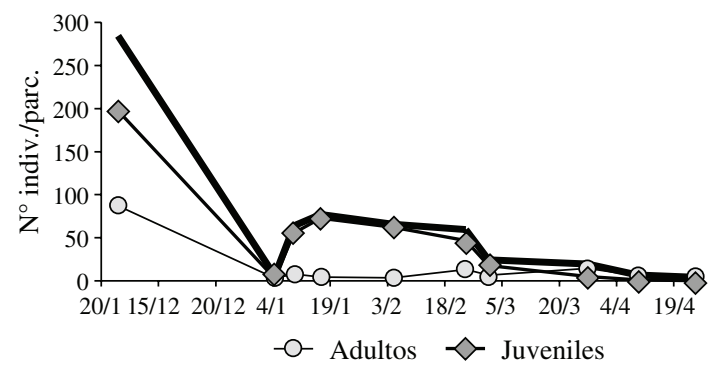

PASTURA S/pastoreo

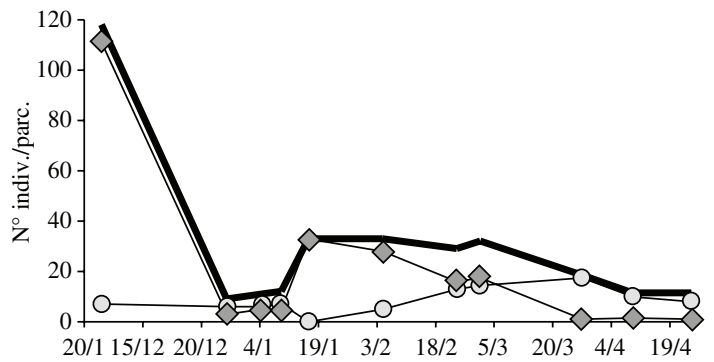

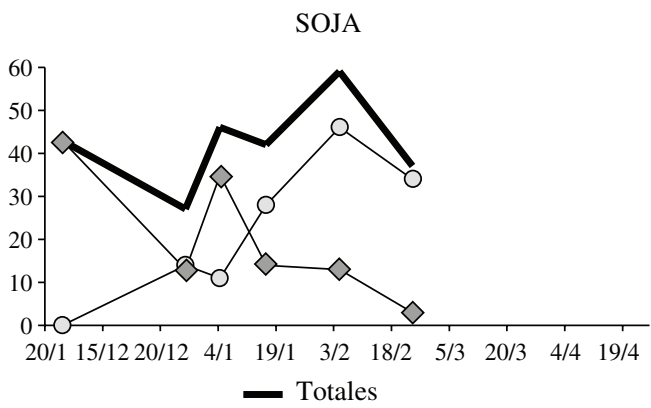

PASTURA C/pastoreo

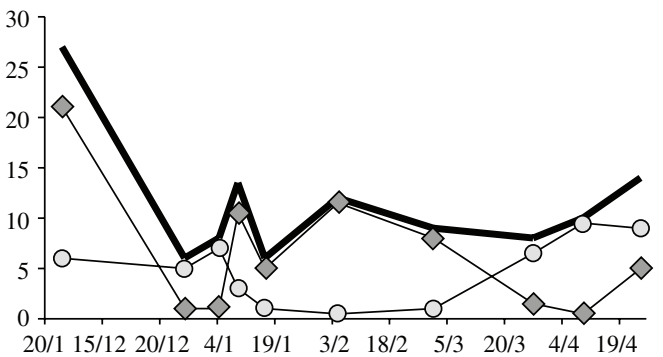

Fecha de Muestreo

Figura 3. Abundancia de tucuras (juveniles y adultos) por recurso. 


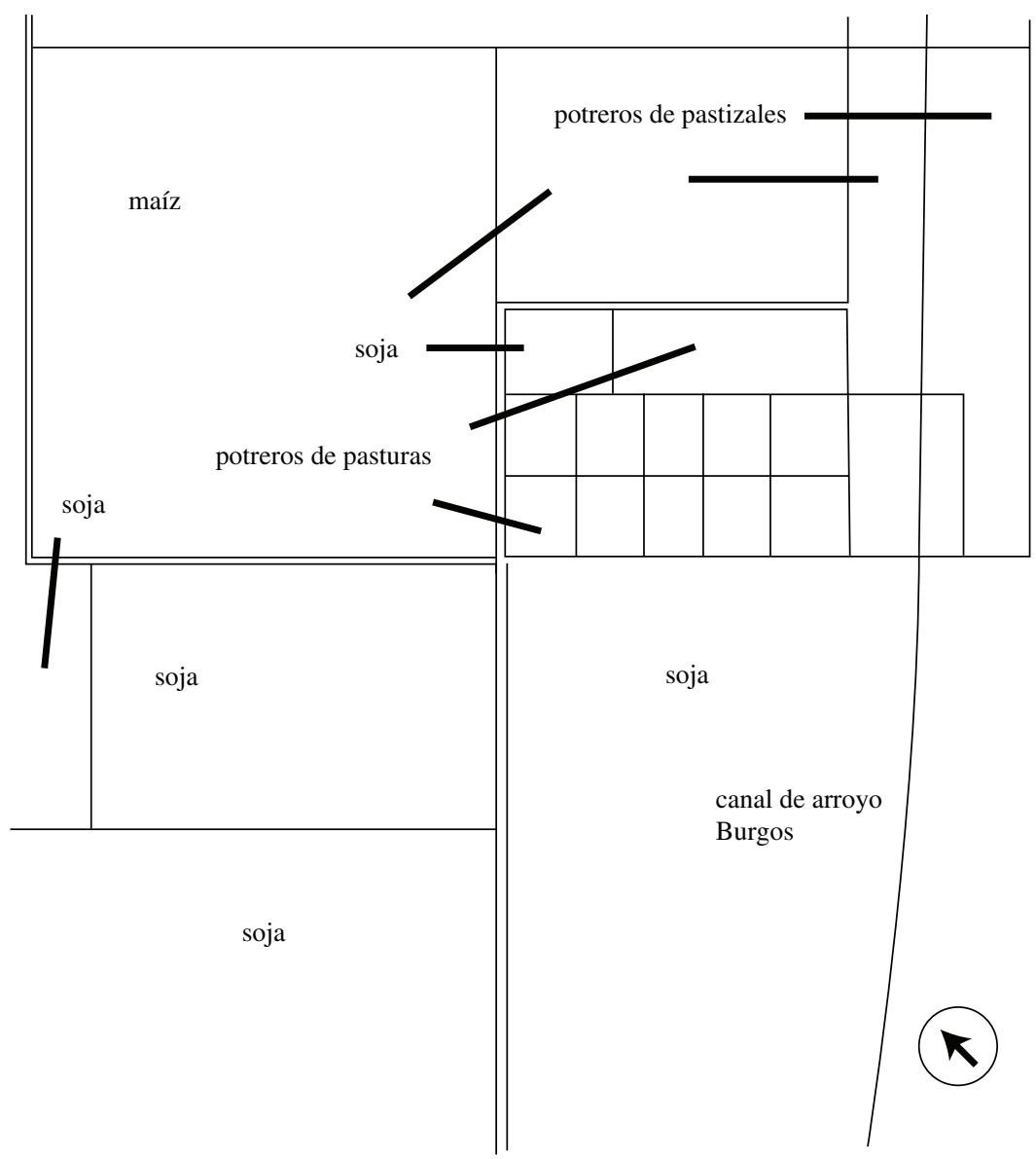

Figura 1. Esquema de la distribución de potreros y recursos en el Establecimiento Agrícola-Ganadero "La Angela".

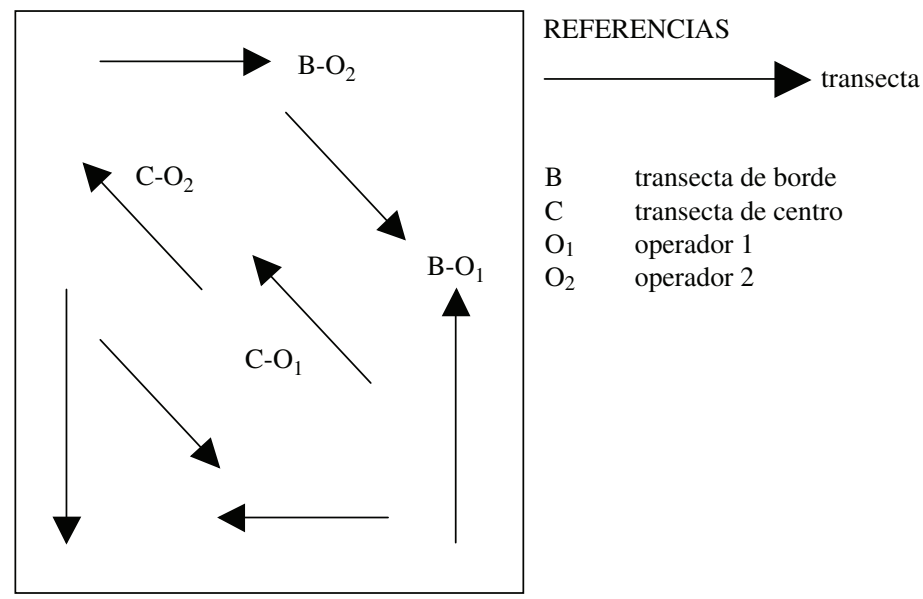

Figura 2. Distribución de las transectas y operadores en las parcelas. 


\section{INTRODUCCIÓN}

La denominación de tucuras incluye varias familias y engloba unas 300 especies, doce de las cuales serían perjudiciales (Liebermann 1972). Son tratadas como un grupo, ya que las prácticas de intervención no difieren entre especies. Sin embargo, si a partir de cambios en el uso de la tierra se modificaran las poblaciones de tucuras o sus relaciones de dominancia entre las especies, dejaría de ser una mera cuestión de nombres, ya que tales relaciones impactan directamente en las prácticas necesarias para su manejo.

Según Ronderos (1996) Dichroplus maculipenne, de aparición tardía, con 1 generación por año (INTA 1972) sería la especie dominante. La emergencia de la segunda generación -para las especies que presentan dos por año- no tendría importancia relativa. Por el contrario, si alguna de aquellas especies fuera dominante, colocaría a la soja en una situación crítica, dado que iniciarían esta segunda generación durante el mes de enero (INTA 1972).

La abundancia de tucuras se relaciona con el tipo de laboreo del suelo, ya que se incrementa a medida que el manejo pasa del sistema convencional a la labranza vertical y de éste a la siembra directa (Ves Losada y Baudino 1998). Esto resulta de la eliminación de un factor de mortalidad sin relación con la densidad, ya que estas especies superan el invierno en estado de huevo bajo tierra. Los asesores locales han dado la alarma acerca del incremento en la densidad de tucuras en los cultivos de soja en siembra directa, donde la escasa remoción del suelo aumentaría la supervivencia invernal de los desoves.

El manejo de tucuras se sustenta en la detección oportuna de los juveniles que emergen más tempranamente en la campaña (INTA 1970). Para relevar sus estados activos a fin de tomar medidas oportunas de control, la red de arrastre obtiene resultados rápidamente, es de empleo sencillo y requiere un entrenamiento mínimo, por lo cual es una técnica más factible de ser apropiada por los posibles destinatarios de su uso (INTA 1970).

La red de arrastre es considerada menos precisa respecto de otros sistemas, debido a la movilidad de estos insectos y su uso requiere de ajustes. Se conoce que se producen diferencias al relevar en el centro o borde de la parcela, por incidencia de un camino o cultivo vecino, o aun como efecto de la diferente manipulación de los operadores (Salto y Beltrame 1999 b; Ves Losada y Baudino 1998; Guido y Carbonell 1965). El objetivo del presente trabajo fue analizar la abundancia de especies de tucuras a través del mosaico de recursos de un establecimiento agrícola-ganadero en Arrecifes.

\section{MATERIALES Y MÉTODOS}

El trabajo se llevó a cabo en el Establecimiento "Santa Angela", en el cuartel $6^{\circ}$ entre paraje Cañada Marta y Brisas Alegres (Arrecifes, Prov. Bs. As.) (Figura 1).

Se consideraron 4 tratamientos o recursos, con 2 parcelas homogéneas $(\mathrm{n}=2)$, relevadas 2 veces por mes, entre noviembre de 2004 y abril de 2005. Se empleó red de lona $(\varnothing 38 \mathrm{~cm}$ x $80 \mathrm{~cm})$. El diseño fue completamente al azar (Montgomery, 1991) para el punto de inicio y dirección de la trayectoria de las transectas, estando la mitad de ellas en el borde de la parcela y las restantes en el centro. En cada parcela se realizaron 8 transectas, de 100 pasos en línea recta y 50 golpes de red en cada una. Dos operadores de similar contextura física, edad y entrenamiento se alternaron en los muestreos (Figura 2).

Detalle de los tratamientos (recursos, Figura 1):

1. Soja (bajo siembra directa): DM 4800

2. Pastizal natural (Ptzl): Juncus, Trifolium repens

3. Pastura bajo pastoreo (Past. C/p): Medicago sativa, T. repens, Lolium, Bromus

4. Pastura sin pastoreo (Past. $\mathrm{S} / \mathrm{p}$ ): $M$. sativa, T. repens, Lolium, Bromus

La abundancia de juveniles y adultos por recurso fue comparada mediante ANVA y Tukey (DBA). Considerando la abundancia por sector relevado y operador (variables de monitoreo) fue comparada mediante ANVA para un modelo en parcelas divididas y prueba de comparaciones múltiples DGC (Di Rienzo et al., 2002) considerando los factores: cultivo (Past. S/p, Past. C/p, Soja y Ptzl.) en la parcela principal y operador (A y B) y posición $(\mathrm{C}$ : centro y B: borde) en subparcela (Infostat, 2004) (Figura 2). 


\title{
ABUNDANCIA DE ESPECIES DE TUCURAS (ORTHOPTERA: ACRIDIDAE) A TRAVÉS DEL MOSAICO DE RECURSOS DE UN ESTABLECIMIENTO EN ARRECIFES (PROV. DE BUENOS AIRES) ${ }^{1}$
}

\author{
ABUNDANCE OF GRASSHOPPERS (ORTHOPTERA: ACRIDIDAE) THROUGH \\ RESOURCES WITHIN A REEF FARM (BUENOS AIRES PROVINCE)
}

\author{
P. Carrizo ${ }^{2}$; A. Pontacuarto; J.I. Cuirolo; M.V. López ${ }^{3}$
}

\begin{abstract}
RESUMEN
Se analizó la abundancia de tucuras a través del mosaico de recursos de un establecimiento agrícola-ganadero. Considerando cuatro recursos: pastura (con y sin pastoreo), pastizal y soja, dos operadores llevaron a cabo muestreos mediante red, entre noviembre y abril ( 8 transectas/parcela, 4 en bordes, 4 en centro). Se comparó la densidad total mediante ANVA (DBA) y Tukey. En un diseño de parcela dividida se consideraron: Posición (parcela mayor) y Operadores (parcela menor) mediante ANVA y DGC. En el pastizal predominaron ( $>90 \%$ ) los Tettigonüdae (saltamontes), sin relevancia $(<5 \%)$ en la soja. Los Acrididae (tucuras verdaderas) predominaron $(>90 \%)$ en la soja y fueron más importantes en la pastura (>60\%) respecto de los Tettigonüdae (30\%). Los más abundantes en la primera generación, en la pastura y pastizal fueron D. punctulatus y un Tettigonüdae (Ensifera). En la segunda, dominaron dos Gomphocerinae (Acrididae). Para la soja, el máximo de enero correspondió a los juveniles y la alta densidad de febrero correspondió a los adultos (R. (Dichrolplus) bergi, un Gomphocerinae y D. punctulatus). En pastizales y pasturas, las mismas especies dominaron las capturas como adultos y juveniles, lo que no sucedió en la soja. El Tettigonüdae con alta abundancia en el pastizal, invadió las pasturas, pero no la soja. Si su migración produce una alta demanda de forraje en las pasturas, podría forzar a los Acridoidea predominantes en pasturas y soja, a migrar hacia ésta. En los bordes se detectó una mayor densidad a partir de un vecino riesgoso como fuente de infestación: un recurso similar en aquellos con alta densidad o las áreas sin remoción (caminos o canales). Al considerar todos los bordes en forma conjunta, se diluye este efecto y tal diferencia entre estratos no es detectada. No se detectaron diferencias entre los operadores.
\end{abstract}

Palabras clave: tucuras, abundancia, red de arrastre, recursos.

\begin{abstract}
We analysed the abundance of grasshoppers through forage resources within a farm. Four types were considered: legumes pasture (with and without grazing), grass pasture and soybean. Two operators performed the sampling with net, between November and April (8 lines/plot: 4 in their edges, 4 inside). They were compared in total abundance by means of ANVA (DBA) and Tukey. In a Split-Plot designed location (higher plot) and Operator (small plot) by means of ANVA and DGC. Tettigonüdae dominated in grasses (>90\%), and had no relevance $(<5 \%)$ in soybean. Acrididae (true grasshoppers) dominated $(>90 \%)$ in soybean and were the most important in legume pasture $(>60 \%)$ while the Tettigonüdae $(30 \%)$ was the second. Those with the highest abundance in first generation in legume pasture and grasses were D. punctulatus and a Tettigonüdae. In the second generation, two Gomphocerinae (Acrididae) were the most important. In soybean, the highest abundance in January was because of juvenile forms and in February was because of adults (R. (Dichroplus) bergi, a Gomphocerinae and D. punctulatus). In grasses and legume pastures, the same species trended to dominate as adults and juveniles; although it did not happen in soybean. That Tettigonüdae very abundant in grasses, were also in high numbers in legume pastures, but almost did not appear in soybean. However, if that species would require high levels of forage in legume pasture, it could force the dominant Acridoidea there, to move to the soybean. In edges of plots were detected high densities only related with certain kind of neighbours: a similar resource with high densities or non-removed areas (roads and water canals). When considering all edges with the same plot, this effect was diluted and there was not difference between them and the centre of the plot. Differences between operators were not detected.
\end{abstract}

Key words: grasshoppers, abundance, net, resources.

\footnotetext{
Tesis de grado, Ingeniero Agrónomo. FAUBA.

Zoología Agrícola.

3 Estadística. Facultad de Agronomía UBA. Av. San Martín 4453. Buenos Aires. C1417DSE. pcarrizo@agro.uba.ar
}

Fecha de Recepción: 02 Octubre 2007

Fecha de Aceptación: 12 Noviembre 2007 
HASSAN, S.A. 1997. Criação da traça do milho Sitotroga cerealella, para produção massal de Trichogramma. In: PARRA, J.R.P.; ZUCCHI, R.A., Trichogramma e o controle biológico. Piracicaba: FEALQ. 324 p.

MONJE, J.C.; ZEBITZ, C.P.W.; OHNESORGE, B. 1999. Host and host age preference of Trichogramma galloi and T. pretiosum (Hym.:Trichogrammatidae) reared on different hosts. Journal Economical of Entomolology. 92: 97-103.

NAVARRO, M.A. 1998. Trichogramma spp. Procucción, Uso y Manejo en Colombia. Guadalajara de Buga: Impretec. 176 p.

NICOLI, E.M.; PRATISSOLI, D.; REIS, E.F.; SANTOS, H.S 2004. Viabilidade e razão sexual de Trichogramma atopovirilia Oatman \& Platner, 1983 (Hymenoptera, Trichogrammatidae) sob influência do hospedeiro Anagasta kuehniella (Zeller, 1879) (Lepidoptera, Pyralidae) em condições de laboratório. Entomologia y Vecterinaria. 11: 521-533.

PARRA, J.R.P. 1997. Técnicas de criação de Anagasta kuehniella, hospedeiro alternativo para produção de Trichogramma. In:
PARRA, J.R.P.; ZUCCHI, R. A. Trichogramma e o controle biológico aplicado. Piracicaba: FEALQ. 324 p.

PARRA, J.R.P. 2002. Criação massal de inimigos naturais. In: PARRA, J.R.P., BOTELHO, P.S.M., CORRÊA-FERREIRA, BENTO, J.M.S. Controle biológico no Brasil: Parasitóides e Predadores. Barueri, Manole. 609 p.

PRATISSOLI, D.; PARRA, J.R.P. 2000. Desenvolvimento e exigências térmicas de Trichogramma pretiosum Riley, criados em duas traças do tomateiro. Pesquisa Agropecuária Brasileira. 35: 1281-1288.

VINSON, S.B. 1994. Physiological interactions between egg parasitoids and their hosts. In: WAJNBERG, E.; HASSAN, S A. (eds.) Biological control with egg parasitoids. Wallingford: CAB International. 286 p.

ZUCCHI, R.A.; MONTEIRO, R.C. 1997. O gênero Trichogramma na América do Sul. In: PARRA, J. R. P.; ZUCCHI, R. A. (eds.), Trichogramma e o Controle Biológico Aplicado, FEALQ. 324 p 
Tabela 1

Valores médios \pm EP de taxa de parasitismo, viabilidade e razão sexual de Trichogramma exiguum, em ovos de Anagasta kuehniella e Sitotroga cerealella. $\left(25 \pm 1^{\circ} \mathrm{C}\right.$, $\mathrm{UR}=70 \pm 10 \%$ e fotofase $=14 \mathrm{~h})$. Alegre, UFES, 2006

\begin{tabular}{|l|c|c|c|}
\hline \multirow{2}{*}{ Hospedeiro } & \multicolumn{3}{|c|}{ Idade do parasitóide } \\
\cline { 2 - 4 } & 1 dia & 2 dias & 3 dias \\
\hline & \multicolumn{3}{|c|}{ Taxa de parasitismo $(\%)$} \\
\hline A. kuehniella & $36,65 \pm 1,41^{\mathrm{a}}$ & $17,36 \pm 0,95^{\mathrm{a}}$ & $19,21 \pm 2,09^{\mathrm{a}}$ \\
\hline S. cerealella & $27,08 \pm 1,12^{\mathrm{b}}$ & $12,70 \pm 2,30^{\mathrm{b}}$ & $9,68 \pm 2,38^{\mathrm{b}}$ \\
\hline & \multicolumn{3}{|c|}{ Viabilidade $(\%)$} \\
\hline A. kuehniella & $90,58 \pm 1,52^{\mathrm{a}}$ & $86,47 \pm 2,93^{\mathrm{a}}$ & $87,46 \pm 1,23^{\mathrm{a}}$ \\
\hline S. cerealella & $93,70 \pm 2,96^{\mathrm{a}}$ & $90,97 \pm 1,97^{\mathrm{a}}$ & $91,21 \pm 2,41^{\mathrm{a}}$ \\
\hline A. kuehniella & $1,00 \pm 0,0^{\mathrm{a}}$ & $1,00 \pm 0,0^{\mathrm{a}}$ & $0,96 \pm 0,02^{\mathrm{a}}$ \\
\hline S. cerealella & $1,00 \pm 0,0^{\mathrm{a}}$ & $1,00 \pm 0,0^{\mathrm{a}}$ & $1,00 \pm 0,00^{\mathrm{a}}$ \\
\hline
\end{tabular}

Pares de médias seguidas pela mesma letra minúscula na coluna não diferem entre si pelo teste de Tukey a $\mathrm{p} \leq 0,05$.

menor aceitação em ovos de $S$. cerealella. Vários são os fatores que podem afetar o parasitismo de Trichogramma, como por exemplo, o tamanho do ovo, espessura do córion e a presença de químicos voláteis. Contudo, no caso de A. kuehniella e $S$. cerealella a qualidade nutricional é o fator que mais influencia na aceitação do parasitóide, sendo os ovos de A. kuehniella mais nutritivos em relação aos ovos de S. cerealella (Pratissoli \& Parra, 2000).

Tanto em ovos de S. cerealella, quanto em ovos de A. kuehniella, a viabilidade do parasitóide foi superior a $86 \%$ (Tabela 1). Esta viabilidade é considerada satisfatória no manual de controle de qualidade de produção de Trichogramma (Navarro, 1998). Resultados encontrados por Alencar et al.

\section{LITERATURA CITADA}

ALENCAR, J.A.; HAJI, F.N.P.; OLIVEIRA, J.V.; MOREIRA, A.N. 2000. Biologia de Trichogramma pretiosum Riley em ovos de Sitotroga cerealella (Olivier). Pesquisa Agropecuária Brasileira. 35: 1669-1674.

GOMES, S.M. 1997. Comparação de três hospedeiros alternativos para criação e produção massal de Trichogramma pretiosum e T. galloi. Piracicaba, ESALQ, 106 p. (Disertação de mestrado).

GONÇALVES, J.R.; HOLTZ, A.M.; PRATISSOLI, D.; GUEDES, R.N.C. 2003. Avaliação da qualidade de
(2000) atestam a adequação de $S$. cerealella para T. pretiosum com valor de $88 \%$ de viabilidade. Nicoli et al., (2004) estudando a viabilidade de $T$. atopovirilia em ovos de A. kuehniella obteve $96 \%$ nestas mesmas condições, confirmando a qualidade do hospedeiro.

A razão sexual dos descendentes de T. exiguum criados em ovos de A. kuehniella foi semelhante a $S$. cerealella (Tabela 1), demonstrando que com a utilização destes hospedeiros pode-se produzir um alto número de fêmeas do parasitóide e atingir o índice aceitável, exigido no controle de qualidade de Trichogramma, com valor igual ou superior a 0,5 (Navarro, 1998). Gonçalves et al. (2003) demonstraram que o valor de razão sexual para $T$. pretiosum não foi afetado, ficando também acima de 0,5. De acordo com Vinson, (1994), o sexo da progênie pode ser influenciado pela qualidade do hospedeiro demonstrado que de acordo com os resultados ambos hospedeiros se mostram adequados para o desenvolvimento desta espécie de parasitóide.

\section{CONCLUSÃO}

Ambos hospedeiros alternativos podem ser utilizados na criação massal de T. exiguum, porém, levando em consideração a importância da taxa de parasitismo, A. kuehniella demonstrou maior aptidão.

\section{AGRADECIMENTOS}

Ao Conselho Nacional de Desenvolvimento Cientifico e Tecnológico (CNPq) e à Coordenação de Aperfeiçoamento de Pessoal de Nível Superior (CAPES) pela concessão de bolsas.
Trichogramma pretiosum (Hymenoptera: Trichogrammatidae) em ovos de Sitotroga cerealella (Lepidoptera: Gelechiidae). Acta Scientiarum. Agronomy. 25: 485-489.

GREENBERG, S.M.; MORRISON, R.K.; NORDLUND, O.A.; KING, E.G. 1998. A review of thescientitic literature and methods for production of factitions hosts for use in mass rearing of Trichograrnma (Hym.: Trichogrammatidae) in the former Soviet Union, the United States, Western Europe and China. Journal Entomology Science. 33: 15-32. 
alternativos mais utilizados em todo mundo para criação massal destes parasitóides.

Entretanto as características físico-químicas particulares de cada hospedeiro podem afetar tanto a aceitação quanto a adaptação da espécie e/ou linhagem do parasitóide, interferindo nas características biológicas e na sua agressividade, comprometendo assim a qualidade e eficiência do mesmo. Desta forma a escolha do hospedeiro alternativo mais adequado é o primeiro passo no processo de produção massal de parasitóides do gênero Trichogramma (Monge et al.,1999).

No passado, muitos insucessos na utilização de parasitóides ocorreram pela falta de conhecimentos básicos durante a criação massal, como as interações entre parasitóide e hospedeiro. Sendo assim, objetivou-se com este trabalho avaliar algumas características de Trichogramma exiguum Pinto \& Platiner, (Hymenoptera: Trichogrammatidae) criado sobre ovos dos hospedeiros alternativos A. kuehniella e $S$. cerealella, visando à produção destes parasitóides para utilização no controle biológico de pragas.

\section{MATERIAL E MÉTODOS}

O experimento foi conduzido no Núcleo de Desenvolvimento Científico e Tecnológico em Manejo Fitossanitário "NUDEMAFI" situado no campus do Centro de Ciências Agrárias da UFES (CCA-UFES), Alegre-ES, em câmara climatizada com temperatura de $25 \pm 1^{\circ} \mathrm{C}$, umidade relativa de $70 \pm 10 \%$ e fotofase de 14 horas.

A linhagem de T. exiguum utilizada foi coletada com armadilhas contendo ovos de A. kuehniella, em plantios comerciais de tomate no município de Piaçú, Espírito Santo, sendo os espécimes obtidos, divididos em dois lotes, um criado em ovos de A. kuehniella e o outro em ovos de $S$. cerealella. Ambos os lotes foram mantidos em laboratório por 10 gerações até o inicio dos experimentos.

A metodologia empregada na criação do hospedeiro alternativo A. kuehniella foi à desenvolvida por Parra et al. (1997), porém foi adaptada para as condições do setor Entomologia do NUDEMAFI, utilizando uma dieta à base de farinha de trigo integral e de milho (97\%) e levedura de cerveja (3\%).

O preparo da dieta para a criação do hospedeiro $S$. cerealella teve como base à metodologia desenvolvida por Hassan (1997), com algumas modificações, utilizando uma dieta à base de grãos de trigo descarificado, com umidade variável entre 11-14\%. As condições climáticas da sala de criação de A. kuehniella e $S$. cerealella foram de $25 \pm 2{ }^{\circ} \mathrm{C}$ e umidade relativa $70 \pm 10 \%$.

A criação e multiplicação do parasitóide T. exiguum baseou-se na metodologia descrita por Parra et al. (1997). Ovos de $S$. cerealella e A. kuehniella colados com goma arábica diluída a $10 \%$ em retângulos de cartolina azul celeste (cartelas) $(4,0 \times 2,0 \mathrm{~cm})$, foram oferecidos aos parasitóides em recipientes de vidro $(8,5 \times 2,4 \mathrm{~cm})$, onde foi permitido o parasitismo por 24 horas. Os ovos de A. kuehniella foram inviabilizados em lâmpada germicida por 50 minutos, devido a esta espécie apresentar habito canibal.

Para cada hospedeiro avaliado foram utilizadas 25 fêmeas recém emergidas individualizadas em tubos de vidro $(4,0 \times 0,7 \mathrm{~cm})$, contendo gotículas de mel de abelha para alimentação e tamponados com filme plástico PVC. Cada fêmea constituiu uma repetição, e recebeu 40 ovos do respectivo hospedeiro, colados com goma arábica diluída a $10 \%$ em um retângulo de cartolina $(3,5 \times 0,5 \mathrm{~cm})$ de cor azul-celeste. Foi permitido o parasitismo por 24 horas, sendo que ao término a cartela era trocada por uma nova. O procedimento foi realizado durante três dias devido a este período responder normalmente por cerca de $70 \%$ do parasitismo total. As cartelas retiradas a cada 24 horas foram acondicionadas em tubos de vidro $(8,5 \times 2,4 \mathrm{~cm})$ e mantidas nas mesmas condições de criação do parasitóide até a emergência dos descendentes.

Foram avaliadas a percentagem de parasitismo, a viabilidade dos ovos e a razão sexual de $T$. exiguum criado nos hospedeiros alternativos A. kuehniella $\mathrm{e}$ $S$. cerealella. O delineamento utilizado foi o inteiramente casualizado, as médias foram comparadas pelo teste de Tukey a 5\%.

\section{RESULTADOS E DISCUSSÃO}

Ambos hospedeiros alternativos foram aceitos por T. exiguum. No entanto, foi observado que a taxa parasitismo foi maior em ovos de A. kuehniella nos três dias de avaliação em que foram oferecidas cartelas contendo ovos do hospedeiro (Tabela 1). Comportamento semelhante a este foi encontrado por Gomes (1997), quando avaliou a agressividade de cinco linhagens $T$. pretiosum, encontrando também 


\title{
CARACTERÍSTICAS BIOLÓGICAS DE TRICHOGRAMMA EXIGUUM EM OVOS DE ANAGASTA KUEHNIELLA E SITOTROGA CEREALELLA
}

\author{
BIOLOGICAL CHARACTERISTICS OF TRICHOGRAMMA EXIGUUM IN THE \\ EGGS OF ANAGASTA KUEHNIELLA END SITOTROGA CEREALELLA
}

\author{
Dirceu Pratissoli ${ }^{1}$; Leandro Pin Dalvi ${ }^{1 *}$; Ricardo Antonio Polanczyk ${ }^{1}$; Gilberto Santos Andrade ${ }^{2}$, \\ Anderson Mathias Holtz ${ }^{1}$; Henrique Otes Nicoline ${ }^{1}$
}

\section{RESUMO}

O objetivo deste trabalho foi obter informações sobre alguns aspectos biológicos de Trichogramma exiguum Pinto \& Platiner, (Hymenoptera: Trichogrammatidae) criado nos hospedeiros alternativos Anagasta kuehniella Zeller (Lepidoptera: Pyralidae) e Sitotroga cerealella Oliver (Lepidoptera: Gelechiidae), visando à produção desses parasitóides para utilização no controle biológico de pragas. A maior taxa de parasitismo de T. exiguum foi encontrada em ovos de A. kuehniella. A viabilidade foi superior em ovos de $S$. cerealella. A razão sexual foi semelhante para ambos os hospedeiros alternativos. Estes resultados demonstram que ambos hospedeiros alternativos podem ser utilizados na criação massal de T. exiguum, porém levando em consideração a importância da taxa de parasitismo, A. kuehniella demonstrou maior aptidão.

Palavras-chave: insecta, controle biológico, criação massal, parasitóides de ovos.

\begin{abstract}
The objective of this work was to evaluate information about biological characteristics of egg of parasitoid Trichogramma exiguum Pinto \& Platiner, (Hymenoptera: Trichogrammatidae) on the alternative hosts Anagasta kuehniella Zeller (Lepidoptera: Pyralidae) and Sitotroga cerealella Oliver (Lepidoptera: Gelechiidae) aiming to use in biological control programs. The higher rate of parasitism of the $\mathrm{T}$. exiguum was verified on eggs of $\mathrm{A}$. kuehniella. The viability of eggs was higher on eggs of $\mathrm{S}$. cerealella. There is not influence in both alternative hosts in the sex ratio. Both alternative hosts can be used in massal rearing of T. exiguum, however due to the importance of the rate of parasitism, A. kuehniella is better adapting.
\end{abstract}

Key words: insecta, biological control, massal rearing, egg parasitoid.

\section{INTRODUÇÃO}

Os parasitóides de ovos do gênero Trichogramma, apresentam ampla distribuição geográfica e grande número de hospedeiros naturais, especialmente os da ordem Lepidoptera, sendo criados massalmente em vários países utilizando-se diversos hospedeiros alternativos (Zucchi \& Monteiro, 1997; Parra, 2002). As mariposas-praga de grãos são preferidas, por serem de fácil criação e multiplicação, baixo custo e por não afetarem o desenvolvimento desse inimigo natural (Navarro, 1998). De acordo com Greenberg et al. (1998), Sitotroga cerealella Olivier (Lepidoptera: Gelechiidae), Anagasta kuehniella Zeller (Lepidoptera: Pyralidae) e Corcyra cephalonica Staiton (Lepidoptera: Pyralidae) são os hospedeiros

* Autor para correspondência (leandro-mpv@cca.ufes.br)

1 Centro de Ciências Agrárias da UFES; Alto Universitário s/nº, C. Postal - 16, CEP: 29500-000 - Alegre - ES; e-mail: dirceu @ npd.ufes.br; leandro-mpv@cca.ufes.br; ricardo@cca.ufes.br; aholtz@insecta.ufv.br; otes.hn@bol.com.br

2 Dept $^{\mathrm{o}}$ Entomologia, Universidade Federal de Viçosa, Viçosa-MG. gilberto.br@ click21.com.br

Fecha de Recepción: 01 Octubre 2007

Fecha de Aceptación: 16 Enero 2008 

con forraje verde hidropónico de cebada en los indicadores productivos y el rendimiento en canal de conejos Nueva Zelanda durante la fase de engorde. II congreso de cunicultura de las Américas. pp. 03-85

NIEVES, D.; CALDERÓN, J. 2001. Inclusión de harina de lombriz (Eisenia foetida) en dietas no convencionales y suplementación con Trichanthera gigantea en conejos de engorde. Investigación agrícola. [Documento en Línea] disponible: http://www.redpavfpolar.info.ve/danac/volumen6/art4/index.html. [Consulta: 18-03-2007].

NIEVES, D.; LÓPEZ, D.; CADENA, D. 2001. Alimentación de conejos de engorde con dietas basadas en materias primas no convencionales y suplementación con Trichanthera gigantea. Revista UNELLEZ, Guanare. (2): 01-14.

SAS. 1998. SAS User's guide: Statistics. SAS Inst., Inc., Car., N.C. 
Los tratamientos arrojaron un efecto significativo $(\mathrm{p}<0,05)$ para la variable conversión alimenticia con el alimento balanceado comercial. Se observan en la tabla 3 los promedios obtenidos, siendo los mejores los que incorporaron en la ración el fruto de mango. Esto refleja el efecto nutricional que este recurso aportó a los conejos en esta fase de producción bajo estas condiciones.

\section{Tabla 3}

Promedios y errores estándar de la conversión alimenticia con alimento balanceado comercial

\begin{tabular}{|c|c|}
\hline Tratamiento & $\begin{array}{c}\text { Conversión Alimento Balanceado } \\
\text { Comercial }(\mathbf{k g} / \mathbf{k g})\end{array}$ \\
\hline $\mathrm{T} 1$ & $4,43 \pm 0,07^{\mathrm{a}}$ \\
\hline $\mathrm{T} 2$ & $3,24 \pm 0,08^{\mathrm{b}}$ \\
\hline $\mathrm{T} 3$ & $2,41 \pm 0,02^{\mathrm{c}}$ \\
\hline $\mathrm{T} 4$ & $2,13 \pm 0,06^{\mathrm{d}}$ \\
\hline
\end{tabular}

abcd: medias con letras diferentes entre columnas difieren estadísticamente a una probabilidad menor a $5 \%$.
Estos valores son superiores a los señalados por Morales et al. (2002) $(3,30 \mathrm{~kg} / \mathrm{kg})$ cuando utilizaron Leucaena leucocephala con niveles de $25 \%$ de inclusión en dietas para conejos de engorde. Sin embargo, los resultados obtenidos proporcionan una aceptable conversión alimenticia debido a la alta aceptación del mango por los conejos. Es necesario destacar que a medida que aumentan los niveles de inclusión del mango criollo, la conversión con alimento balanceado comercial (CAABC) disminuye considerablemente, lo que refleja una reducción importante en los gastos de alimentación de la producción cunícola.

\section{CONCLUSIONES}

La mejor respuesta productiva la obtuvieron los animales que consumieron la dieta correspondiente al tratamiento 1 (120 g ABC). Sin embargo, el comportamiento de los animales al tratamiento $2(80 \mathrm{~g}$ $\mathrm{ABC}+40 \mathrm{~g}$ mango) se considera admisible para estas condiciones. Además existe alta aceptación del fruto del mango criollo por parte de los conejos, lo que indica la factibilidad de utilizarlo en la etapa de engorde.

Tabla 2

Promedios y errores estándar de las variables ganancia diaria de peso, peso final y consumo total

\begin{tabular}{|c|c|c|c|}
\hline Tratamiento & GDP $(\mathbf{g})$ & Peso Final $(\mathbf{g})$ & Consumo Total $(\mathbf{g})$ \\
\hline T1 & $26,69 \pm 1,34^{\mathrm{a}}$ & $2083,75 \pm 7,85$ & $7434,37 \pm 6,80^{\mathrm{a}}$ \\
\hline T2 & $23,46 \pm 1,56^{\mathrm{b}}$ & $1861,50 \pm 11,06^{\mathrm{b}}$ & $7251,88 \pm 28,71^{\mathrm{b}}$ \\
\hline T3 & $22,00 \pm 1,40^{\mathrm{b}}$ & $1736,00 \pm 6,47^{\mathrm{b}}$ & $6677,5 \pm 44,78^{\mathrm{b}}$ \\
\hline T4 & $19,98 \pm 1,17^{\mathrm{c}}$ & $1652,50 \pm 18,43^{\mathrm{c}}$ & $7087,88 \pm 2,55^{\mathrm{c}}$ \\
\hline
\end{tabular}

abc: medias con letras diferentes entre columnas difieren estadísticamente a una probabilidad menor a $5 \%$.

\section{LITERATURA CITADA}

CHEEKE, P.; RAHARJO, Y. 1988. Evaluación de forrajes tropicales y subproductos agrícolas como alimento para conejos. Memorias CIPAV (1): 33-41.

DE BLAS, J. 1989. Alimentación del Conejo. 2da edición. Mundi prensa (5): 43-49, 139.

HURTADO, E.; ROMERO, R. 1999. Efectos no genéticos sobre el comportamiento productivo de conejos (Oryctolagus cuniculus) durante el crecimiento post destete. Revista Fac. Ciencias Veterinarias. UCV, Maracay, Venezuela (1): $139-142$
LUKEFAHR, S.; CHEEKE, P. 1990. Rabbit project planning strategies for developing countries, 1: practical considerations. Livestock. Research for Rural Development (1): 2-9.

LUKEFAHR, S.; CHEEKE, P. 1991. Rabbit project development strategies insubsistence farming system. Editor s. s. Branckaert. World Animal Review a Quarterly Journal on Animal Health, Production and Products FAO (2): 69.

MORALES, M.; JUÁREZ, A.; ÁVILA M.; FUENTES, B.; VELÁSQUEZ, G. 2002. Efectos de la suplementación 
Tabla 1

Composición nutricional del alimento balanceado comercial (ABC) y el mango criollo

\begin{tabular}{|l|c|c|}
\hline \multicolumn{1}{|c|}{$\begin{array}{c}\text { Valor } \\
\text { nutricional }\end{array}$} & $\begin{array}{c}\text { Alimento balanceado } \\
\text { comercial }(\boldsymbol{\%})\end{array}$ & $\begin{array}{c}\text { Mango criollo } \\
\mathbf{( \% )}\end{array}$ \\
\hline Materia seca & 90,50 & 18,2 \\
\hline Proteína cruda & 14,85 & 2,74 \\
\hline Carbohidratos & 49,73 & 90,10 \\
\hline Grasas & 7,93 & 0,54 \\
\hline Fibra cruda & 16,98 & 3,84 \\
\hline
\end{tabular}

Fuente: Laboratorio de nutrición animal Universidad de Oriente, Monagas, Venezuela.

\section{EXPERIMENTO}

Se utilizaron 32 gazapos de 30 días de edad, con un peso de 402,5 $\pm 28,61$ durante 63 días en jaulas de crianza de $0,80 \times 0,60 \times 0,40 \mathrm{~m}$, entre los meses de junio, julio y agosto del año 2005 , en un diseño completamente aleatorizado con cuatro tratamientos y cuatro repeticiones, teniendo como covariable al peso inicial, con dos conejos por unidad experimental. Los tratamientos fueron los siguientes: $\mathrm{T} 1 \mathrm{l} 120 \mathrm{~g}$ alimento balanceado comercial (ABC); T2: $80 \mathrm{~g} \mathrm{ABC}+40 \mathrm{~g}$ mango; $\mathrm{T} 3$ : $60 \mathrm{~g} \mathrm{ABC}+60 \mathrm{~g}$ mango y $\mathrm{T} 4: 40 \mathrm{~g} \mathrm{ABC}+80 \mathrm{~g}$ mango.

Las variables bajo estudio medidas fueron:

- Ganancia diaria de peso promedio (GDP): Se estableció por la diferencia entre el peso final y el peso inicial de la semana dividido entre siete días, durante todo el ensayo.

- Consumo total durante el ensayo (CONSTOTAL): Se refiere al consumo de alimento total al final del ensayo por animal. El cual es la suma de todos los consumos diarios hasta la edad de sacrificio y se obtuvieron por diferencia de pesos entre el alimento ofrecido y el rechazado.

- Peso final (PESOFIN): El peso alcanzado a los 93 días de edad.

- Conversión alimenticia con alimento balanceado comercial (CAABC): Se calculó a través de la fórmula (De Blas 1989):

- $\mathrm{CAABC}=($ consumo de alimento $(\mathrm{kg})) /($ peso final - peso inicial (kg)) expresada en $\mathrm{kg}$ de alimento consumido $\mathrm{x} \mathrm{kg}$ de peso vivo obtenido del destete hasta los 93 días de edad.

\section{ANÁLISIS ESTADÍSTICO}

Los datos se analizaron mediante un análisis de varianza (SAS, 1998) con un modelo de clasificación simple que tuvo a los tratamientos como única causa de variación y como covariable el peso inicial. Se realizó la prueba de medias a través del método de Duncan al 5\%, para las variables que resultaron significativas.

\section{RESULTADOS Y DISCUSIÓN}

El análisis de varianza para la ganancia diaria de peso, peso final y consumo total arrojó diferencias estadísticamente significativas entre tratamientos, al igual el efecto significativo que tuvo el peso inicial como covariable. En la tabla 2 se presentan las medias con respecto a los tratamientos, observándose que la mejor respuesta la obtuvieron los animales alimentados con el tratamiento 1 (120 g ABC). Sin embargo, se encontraron valores aceptables para el tratamiento 2 ( $80 \mathrm{~g} \mathrm{ABC}+40 \mathrm{~g}$ Mango).

Con respecto a la ganancia diaria promedio, estos resultados superan a los niveles reportados por cu Cheeke y Raharjo (1988) cuando utilizaron ramio blanco (Boehmeria nivea, $L$ Gaud) en un $25 \%$ y $75 \%$ de $\mathrm{ABC}$ como alternativa para disminuir los costos de alimentación en los sistemas de producción de conejos (19,241 g/animal/día), y a los reportados por Nieves y Calderón (2001) en dietas no convencionales con Trichanthera gigantea cuando se suministró ad libitum y lombriz roja californiana (Eisenia foetida) (en un 2\% de inclusión) 19,29 g/animal/día. Entretanto, para el peso final los valores obtenidos para el tratamiento $2(1.861,50 \mathrm{~g})$ son aceptables debido a la inclusión del mango criollo y a la reducción de costos que la sustitución representa en la alimentación de conejos.

Los consumos totales estuvieron dentro de lo normal. Se observó un consumo total de alimento balanceado comercial en los tratamientos en donde se incluía el fruto de mango, además del consumo de la fuente energética. Es importante señalar que no se presentaron problemas digestivos en los animales, teniéndose registrado cero mortalidad.

Los valores obtenidos corroboran lo reportado en la literatura sobre la adaptabilidad de esta especie a distintos recursos alternativos que pueden ser viables en la alimentación de conejos de engorde. 


\section{INTRODUCCIÓN}

La producción de conejos debe ser considerada como una realidad alterna que permitirá satisfacer las necesidades actuales y futuras de alimentación de los sectores más pobres de la población, tanto rural como urbana, principalmente en sistemas caseros de producción donde los conejos pueden aportar cantidades razonables de carne con relativamente poca inversión (Hurtado y Romero, 1999).

La cunicultura representa una alternativa para producir proteína animal de excelente calidad y a bajo costo, sustentada en la alta eficiencia reproductiva del conejo. Debido a que una coneja adulta es capaz de producir 25,2 gazapos destetados anualmente, los cuales al ser llevados al sacrificio se traducen en $48,6 \mathrm{~kg}$ de peso vivo (PV) por coneja por año. Sin embargo, para mantener estos índices en países subdesarrollados debe fortalecerse la investigación en relación a la alimentación de esta especie en estas condiciones (Lukefahr y Cheeke, 1991).

La alimentación de conejos a base de alimentos concentrados comerciales en los países tropicales es altamente costosa y poco conveniente debido a la existencia de un potencial natural, representado por la abundancia de biomasa vegetal, que hasta ahora no ha sido aprovechado de la forma más eficiente. La utilización de cultivos tropicales de alta capacidad de adaptación al medio, en la alimentación de conejos constituye un elemento importante en la construcción de sistemas sostenibles de producción cunícola. Por ello, es necesario entonces identificar recursos alternativos alimenticios con el fin de sustituir parcialmente el alimento concentrado comercial en condiciones tropicales (Nieves y Calderón, 2001).

En el medio tropical $-\mathrm{y}$ especialmente en Venezuela- se cuenta con una gran variedad de fuentes alimenticias con un alto valor biológico que no son utilizadas por otras especies. La alta disponibilidad de plantas probadas o potencialmente útiles para conejos, sustenta la posibilidad de incluirlas en dietas balanceadas preparadas en la granja, para aprovechar la capacidad herbívora de la especie (Nieves et al., 2001).

Diferentes investigaciones han tenido como objetivo sustituir parcialmente al alimento balanceado comercial $(\mathrm{ABC})$ en raciones para conejos por alimentos alternativos (en tal sentido surgen los bloques multinutricionales, inclusión de leguminosas forrajeras y frutas, entre otros) (Nieves y Calderón, 2001).
En países africanos los conejos pueden ser llevados a peso de sacrificio sin el uso de cereales en su ración mediante el uso de leguminosas u otras especies con elevado contenido de proteínas y energía asociadas al uso de subproductos del procesamiento de cereales, como el arroz (Lukefahr y Cheeke, 1990).

El objetivo de la presente investigación es evaluar el comportamiento productivo de conejos durante el período de crecimiento-engorde alimentados con frutos de mango (Mangifera indica) en sustitución parcial del alimento balanceado comercial. Luego, sobre la base de las respuestas obtenidas, se realizará una estimación económica que permita comparar la eficiencia del mango.

\section{MATERIALES Y MÉTODOS}

\section{UBICACIÓN Y CARACTERÍSTICAS DE LA UNIDAD DE PRODUCCIÓN}

El presente estudio se realizó en la finca "TAYU”, ubicada en el sector Chaparral, municipio Piar del estado Monagas, Venezuela. Las coordenadas geográficas son: longitud oeste: $63^{\circ}$ $12^{\prime}$ y latitud norte: $09^{\circ} 07^{\prime}$. El paisaje corresponde a una formación de pie de monte, con temperaturas promedios anuales de $23,7^{\circ} \mathrm{C}$ y precipitaciones de $1.005 \mathrm{~mm}$.

El manejo utilizado en la granja con respecto a la producción cunícola es intensivo, ya que se utiliza alimento balanceado comercial y se llevan los registros de producción de los individuos. Posee un número de animales conformado por 70 madres en producción y 12 reproductores machos y 200 conejos (gazapos y de crecimiento-engorde). Se crían conejos mestizos de las razas Nueva Zelanda y California hasta alcanzar pesos que varían entre 2 y $2,5 \mathrm{~kg}$; la explotación está destinada a la producción de carne de conejo.

\section{MANEJO ALIMENTICIO}

La alimentación se basó en dietas compuestas por alimento balanceado comercial y el fruto del mango criollo fresco, con la composición nutricional que se muestra en la tabla 1 . Se utilizó el fruto de mango con un grado de maduración intermedio a los que se realizó un pequeño corte en la concha antes de ser ofrecidos los animales. 


\title{
COMPORTAMIENTO PRODUCTIVO DE CONEJOS DURANTE EL PERÍODO DE CRECIMIENTO-ENGORDE ALIMENTADOS CON FRUTOS DE MANGO (MANGIFERA INDICA) EN SUSTITUCIÓN PARCIAL DEL ALIMENTO BALANCEADO COMERCIAL
}

\author{
PRODUCTIVE BEHAVIOR IN RABBITS DURING THE FATTENING GROWTH \\ PERIOD-FED WITH MANGO AS PARTIAL SUBSTITUTION OF THE \\ COMMERCIAL BALANCED FOOD
}

O. R. Palma ${ }^{1}$; E. A. Hurtado 2

\section{RESUMEN}

Con el fin de evaluar el comportamiento productivo de conejos durante el período de crecimiento-engorde, se realizó un experimento que consistió en la sustitución parcial del alimento balanceado comercial $(\mathrm{ABC})$ por el fruto de mango criollo (Mangifera indica) en una granja comercial del estado Monagas, Venezuela. El experimento tuvo una duración de 63 días, se utilizaron 32 conejos mestizos Nueva Zelanda x California de 30 días de edad alojados en jaulas. Se realizó un diseño completamente aleatorizado con cuatro tratamientos: $\mathrm{T} 1: 120 \mathrm{~g}$ de $\mathrm{ABC} ; \mathrm{T} 2: 80 \mathrm{~g}$ de $\mathrm{ABC}+40 \mathrm{~g}$ de mango criollo; $\mathrm{T} 3: 60 \mathrm{~g}$ de $\mathrm{ABC}+60 \mathrm{~g}$ de mango criollo y T4: $40 \mathrm{~g}$ de $\mathrm{ABC}+80 \mathrm{~g}$ de mango criollo. Las variables dependientes fueron: ganancia diaria de peso promedio (GDP), peso final a los 93 días de edad (PESOFIN), consumo total (CONSTOTAL) y conversión alimenticia con alimento balanceado comercial (CAABC). Se realizó un análisis de varianza por el método de mínimos cuadrados. Los resultados arrojaron diferencias significativas para las variables bajo estudio, siendo los mayores promedios en GDP para T1: 26,69 $\pm 1,34 \mathrm{~g}$; PESOFIN para T1: 2083,75 \pm 26,09 g; CONSTOTAL fue para T1: 7434, $37 \pm 6,80 \mathrm{~g}$. Las mejores CAABC se obtuvieron en los tratamientos que incorporaron el mango criollo. En general los resultados obtenidos permiten inferir la utilización del fruto del mango como recurso alternativo en la alimentación de conejos de engorde.

Palabras clave: Conejos, alimento balanceado comercial, mango, comportamiento productivo.

\section{ABSTRACT}

With the purpose of evaluating the productive behavior of rabbits during the period of fattening growth, I made an experiment that consisted on the partial substitution of the commercial balanced food by the Mango fruit (Mangifera indicates) in a commercial farm of the Monagas state, Venezuela. The experiment lasted 63 days, there were used 32 racially mixed rabbits from New Zealand and California being 30 days of age, lodged in cages. Four treatments were used, with a design completely randomized and four repetitions settled down. T1: 120 commercial balanced food (BFC), T2: 80 BFC g + 40 Mango g, T3: 60 BFC g + 60 Mango g and T4: 40 BFC $g+80$ Mango $g$. The dependent variables were: daily gain of weight average (DGW), final gain of weight $(F G W)$, nutritional conversion with commercial balanced food (NCABFC), final weight at 93 days of age (FP), total consumption (TC). There was made an analysis of variance by the method of square minimums. The results showed significant differences for the variables under study. Being the greater averages in DGW for T1: 26,69 $\pm 1.34 \mathrm{~g}$; FP for T1: 2083,75 $\pm 7.85 \mathrm{~kg}$; TC was for $T 1: 7434,37 \pm 11,23$. The best NCABFC were obtained in the treatments that incorporated the Mango fruit. In general the results obtained allow to infer the use of the fruit as alternative resource in the feeding of fattening rabbits.

Key words: Rabbits, commercial balanced food, Mango, productive behavior.

Ingeniero Producción Animal. Escuela de Zootecnia, Universidad de Oriente, Núcleo Monagas, Venezuela.

2 Profesor Asociado de la Escuela de Zootecnia. Universidad de Oriente. Venezuela. E-mail: ernestohurta@gmail.com. Escuela de Zootecnia, Universidad de Oriente, Núcleo Monagas, Venezuela. 
3. FERNÁNDEZ, RAMONA. 1999. Obtención y Evaluación de un inoculante microbiano a partir de Azospirillum sp. Tesis (en opción al título de Máster en Ciencias Microbiológicas). Universidad de La Habana. Pp. 14-19, 20-26, 26-35, 36-59.

4. FERNÁNDEZ, L.; ORTEGA, E.; GRIMM, B.; HAINEZAL, M.R. 2006. Variación en la concentración de aminoácidos y azúcares en plantas de caña de azúcar inoculadas con Pantoea sp. Taller de biofertilización de los Trópicos". Congreso Científico del INCA (14: 2006, nov. 9-12, La Habana). Memorias. CD-ROM. Instituto Nacional de Ciencias Agrícolas. ISBN 959-7023-27-X

5. FERNÁNDEZ, R.; DÁVILA, A.; DEL TORO, F. 1983. Botánica y Fisiología de la Caña de Azúcar. Editorial. Pueblo y Revolución. Pp. 22, 120-153.

6. FRANCO, HIDALGO, R. (EDS.) 2003. Análisis Estadístico de Datos de Caracterización Morfológica de Recursos Filogenéticos. Boletín Técnico $\mathrm{N}^{\circ} 8$, Instituto Internacional de Recursos Filogenéticos (IPGRI), Cali, Colombia. 22, 27, 39.

7. GARCÍA DEL RISCO, E.; VÁZQUEZ FERNÁNDEZ, A. 2002. Los suelos y fertilización de la caña de azúcar. Instituto Nacional de Investigaciones de la Caña de Azúcar. Ciudad de La Habana. P. 46.

8. GUZMÁN,T.;SULROCA,F.; BOULART,L.;HERNÁNDEZ S. 1986. Agrotecnia de la Caña de azúcar III. Tomo I. Editorial ISAJAE. Ciudad de La Habana. P. 397-399.
9. HERNÁNDEZ, A; PLANA, R.; MARTÍN, G.; SANTANDER, J.L. 2002. Estudio de algunos géneros microbianos asociados a diferentes variedades de trigo (Triticum aestivum L.) en suelo Ferralítico Rojo. Rev. Cultivos Tropicales. Vol. 23, No 1, p. 15-20.

10. ROLDÓS, J.E.; CASA, M.; PÉREZ, J. 1994. Uso de los biofertilizantes en suelos Ferralíticos cultivados con caña de azúcar. Resúmenes. RECAR. La Habana. P. 9.

11. SERFE. 1996. Curso I. Los suelos dedicados al cultivo de la caña de azúcar. Instituto de Investigaciones de la Caña de Azúcar. P1, 31.

12. SAURA, G.; FERNÁNDEZ, R. 2003. Fijador de nitrógeno Azospirillum. En: www.fiago.org.sv. Rev. 5/11/2006.

13. TORRIENTE, DORIS. 2004. Aplicación de biofertilizante a base de Azospirillum soportado en turba en el cultivo de la caña de azúcar. En: Simposio internacional sobre caracterización y manejo de microorganismos rizosféricos y VII Taller de Biofertilización de los Trópicos. Congreso Científico del INCA (14:2004 nov. 9-12, La Habana). Memorias. CD-ROM. Instituto Nacional de Ciencias Agrícolas. ISBN 959-7023-27-X.

14. TRETO, EOLIA; GARCÍA, MARGARITA; BRUNET, R.; HERRERA, J.; KESSEL, J.; GÓMEZ, R.; IGLESIAS, R.; SANTANA, H. 1997. Nutrición y fertilización de la piña, 20 años de investigación en el Instituto Nacional de Ciencias Agrícolas. Cultivos Tropicales. 13(2-3) Pp. 5-59. 


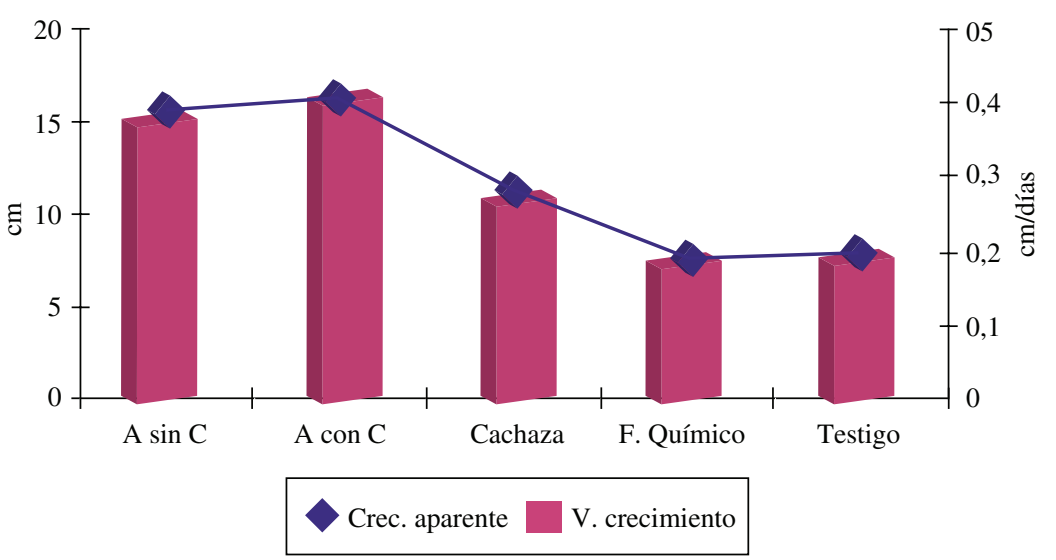

Figura 7. Crecimiento aparente y velocidad crecimiento del tallo para las variantes biológicas.

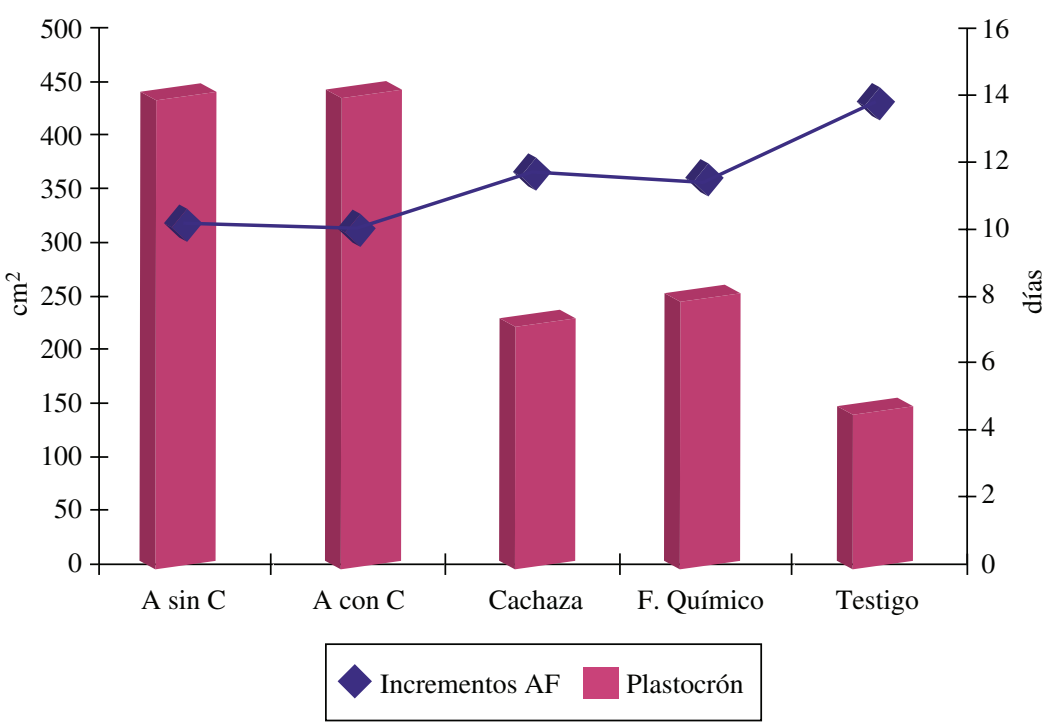

Figura 8. Relación del incremento del área foliar de las plantas con el tiempo de emisión de las hojas (plastocrón).

\section{CONCLUSIONES}

1. Que las variables longitud del tallo, grosor del tallo, ancho de la hoja, longitud de la hoja y área foliar, en ese orden, mostraron su influencia sobre la variabilidad del sistema.

\section{LITERATURA CITADA}

1. ARZOLA, N.; PANEQUE, H.; BATTLE, L.; MOREJÓN, C.; ALFONSO, B.; HERNÁNDEZ, G. 1990. La cachaza como enmienda orgánica y fertilizantes para la caña de azúcar. Folleto divulgativo. INCA. La Habana.
2. Que las variables relacionadas con el tallo aportaron mayor variabilidad explicada que las asociadas a las hojas.

3. Las variantes soportadas en cachaza mostraron mejores resultados que las soportadas en líquidos.

2. CARMENATE, $\mathbf{C}$. La producción de Azospirillum brasilence para el cultivo de la caña de azúcar. Tesis presentada en opción del título de ingeniero Agrónomo. Universidad de Matanzas. Camilo Cienfuegos. Pp. 46-58. 
soportada sólida alcanzó un valor $\left(443,20 \mathrm{~cm}^{2}\right)$ que duplica al área obtenida en el testigo o control y supera a la variante química.

Teniendo en cuenta que el análisis de componentes principales mostró que las variables relacionadas con el tallo juegan un papel muy importante en el sistema estudiado, la figura 7 muestra el crecimiento aparente y la velocidad del mismo para las variantes analizadas.

Se observa que el Azospirillum soportado en cachaza alcanzó los mayores valores. Esto se debe sin lugar a dudas a que la cachaza tiene un contenido de nutrientes que contribuye al desarrollo de la planta y además se puede aseverar que el microorganismo soportado en materiales orgánicos posee mejores condiciones de supervivencia que de forma líquida.

Estudios similares han demostrado las bondades que brinda la cachaza en este cultivo. (11); ha encontrado una estabilidad y viabilidad del Azospirillum en cachaza de $1,2 \times 10^{9}$ UfC hasta $2,7 \times 10^{8}$ durante 60 días, rango éste dentro de los parámetros establecidos para el uso de las bacterias como fertilizante biológico.

El ACP indicó que los estudios de la parte aérea de las plantas ocuparon el segundo lugar en importancia y dentro de ellos el área foliar fue uno de los que menos aportó a la variabilidad en el sistema, después de las variables relacionadas con el tallo. No obstante, las partes aéreas son las responsables de la producción de fotosintatos utilizados en el crecimiento y desarrollo de la planta.

En la figura 8 se muestra que los mayores incrementos en el área foliar alcanzados por las variantes Azospirillum sin y con cachaza, le correspondieron los menores tiempos de emisión de las hojas. El mayor tiempo de emisión de una hoja lo alcanzó el testigo al utilizar 13,8 días, con los menores incrementos de área en el follaje.

Se destaca (3) que este tiempo de emisión de las hojas (plastocrón) durante la fase inicial de la planta es muy breve -de dos a tres días- y en el gran período de crecimiento se puede extender de 6 a 15 días y que puede variar de acuerdo a las condiciones. Destaca a su vez que éste puede ser utilizado para caracterizar aspectos fisiológicos de la planta en determinada condición y ser relacionado con la productividad.

La variante con cachaza sola superó a la utilización de fertilizantes químicos. Esto demuestra que la cachaza posee propiedades químicas física que favorecen a las plantas, cuestión ésta reportada por diferentes autores como (1, 6 y 12).

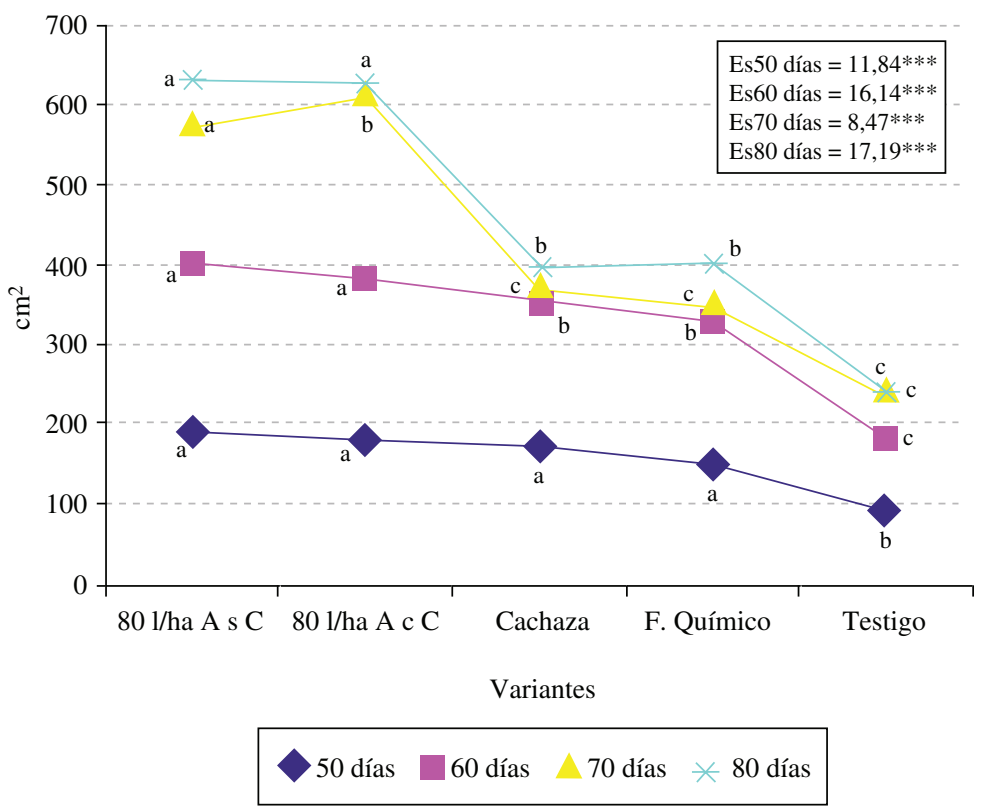

Figura 6. Comportamiento del área foliar para las variantes biológicas. Letras comunes no difieren según Duncan $\mathrm{P}<0,05$. 


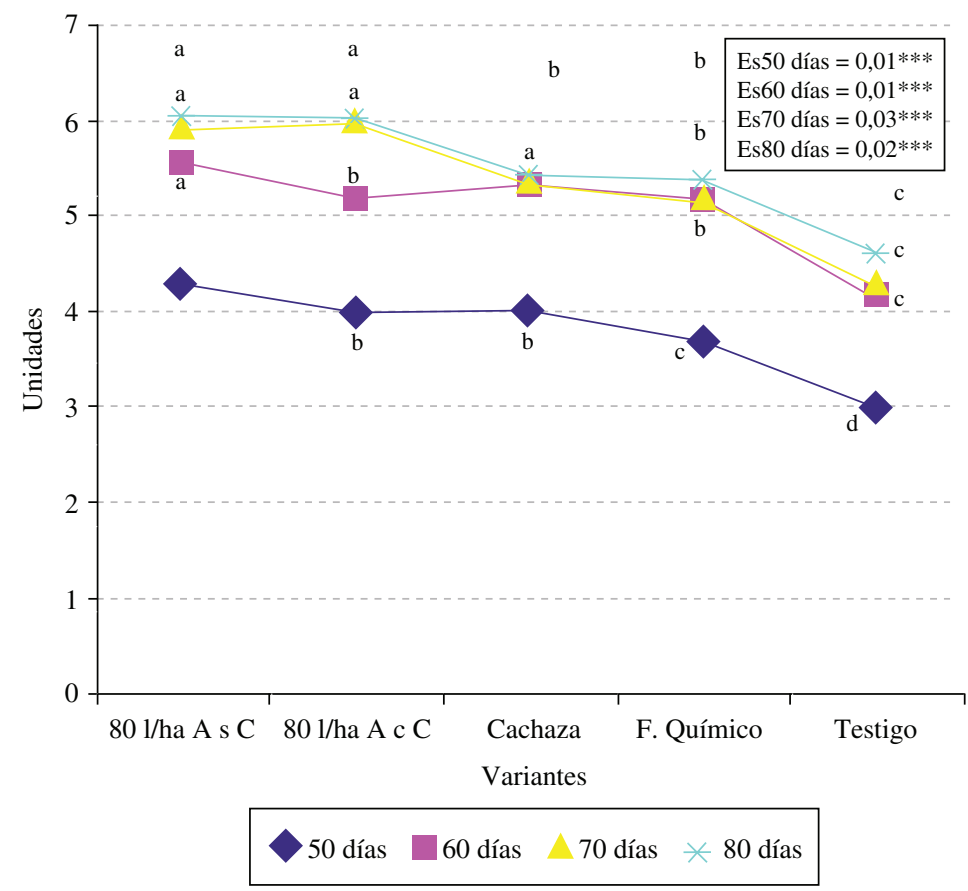

Figura 4. Comportamiento del número de hojas para las diferentes formas soportadas. Letras comunes no difieren. $\mathrm{P}<0.05$.

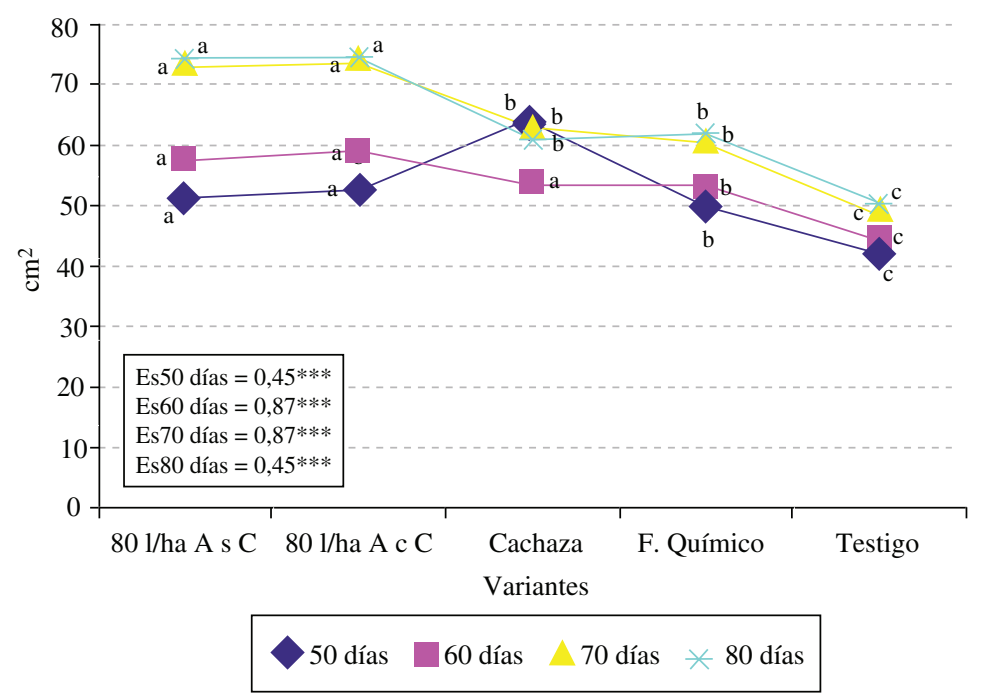

Figura 5. Comportamiento de la longitud de las hojas para las variantes biológicas. Letras comunes no difieren. Según dócimas Duncan para $\mathrm{P}<0.01$.

significativas entre las variantes estudiadas y con el testigo. A medida que se avanzó en edad esta condición sufrió variaciones y las alternativas biológicas se diferenciaron significativamente del resto de las variantes estudiadas.
A los 70 días se encontraron diferencias entre los soportes líquidos y sólidos alcanzando los mayores valores el Azospirillum con cachaza; ya a los 80 días las diferencias entre ellos no fueron significativas, aunque los incrementos en áreas para la variante 


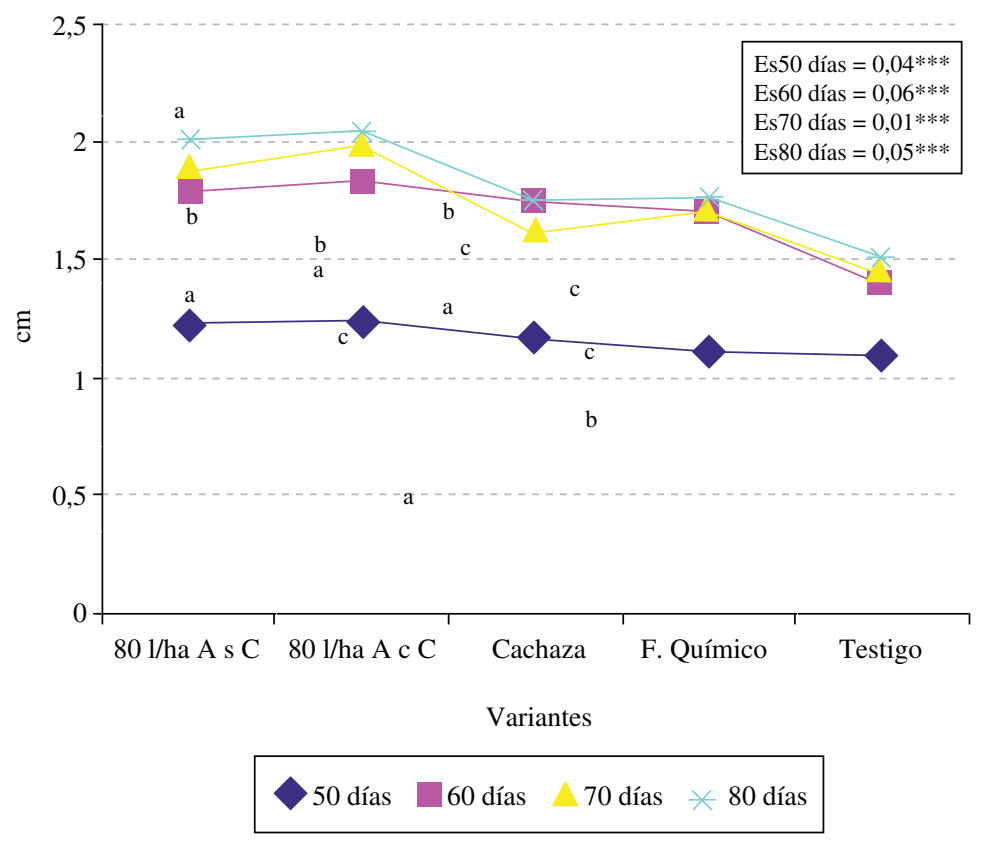

Figura 3. Comportamiento del ancho de las hojas para las diferentes formas de aplicación de Rizobacterias. Letras comunes no difieren. $\mathrm{P}<0.05$.

Destacó además (2) que este subproducto de la industria azucarera posee características como su facilidad de obtención, su bajo peso, posee determinados nutrientes que le permiten al microorganismo mantenerse vivo por más tiempo que en forma líquida, puede aplicarse de forma manual y mecanizada y su aplicación favorece en general a gran variedad de tipos de suelos.

\section{NÚMERO DE HOJAS}

La figura 4 muestra que esta variable a los 50 días mostró diferencias altamente significativas entre las variantes biológicas (líquidas y sólidas), la química y el testigo. En este caso la variante líquida alcanzó mayor valor que la sólida; situación similar se encontró a los 60 días de edad de las plántulas.

A los 70 días sin diferencias significativas entre ellas las aplicaciones sólidas mostraron mejor resultados que las líquidas. Resultado similar se obtuvo a la edad de 80 días de analizada.

No obstante a través de las edades estudiadas se puede observar que la variante Azospirillum con cachaza mostró un mayor incremento en el número de hojas (2 hojas) que la bacteria soportada en líquido (1,75 hojas), lo que muestra un mayor ritmo en el crecimiento en las primeras.

\section{LONGITUD DE LAS HOJAS}

La longitud de las hojas a los 50 días (ver figura 5) no mostró diferencia significativa para las formas soportadas líquidas y sólidas para las edades estudiadas. Se puede destacar que para las aplicaciones químicas y con cachaza sola no se encontraron diferencias. Todas las variantes mostraron diferencias con el testigo o control.

Cuando analizamos los incrementos encontrados en $\mathrm{cm}$ para cada variante los valores más altos se hallaron en el Azospirillum soportado líquido con una diferencia con respecto al químico de $12,05 \mathrm{~cm}$ promedio y para el testigo de $15,51 \mathrm{~cm}$, diferencias éstas importantes para la producción fotosintética en esta etapa.

\section{ÁREA FOLIAR}

La figura 6 muestra que para esta variable a los 50 días no se encontraron diferencias altamente 
sido mayores. Este resultado muestra ventajas que posee la cachaza como suplemento de la nutrición química en muchos casos.

\section{GROSOR TALLO}

En la figura 2 se observa que para la variable grosor del tallo se encontraron diferencias altamente significativas entre las variantes y las edades estudiadas.

A los 50 días se hallaron diferencias entre las aplicaciones biológicas y los soportes utilizados (líquidos y sólidos), mostrando mejor valor las formas líquidas, mientras que para el resto de las edades no se muestran diferencias significativas entre el Azospirillum sin y con cachaza. Éstas a su vez sí se diferencian de las aplicaciones químicas y el testigo.

Estos resultados corroboran las ventajas que ofrece aplicar bacterias a los diferentes cultivos y las mismas pueden sustituir en muchos casos a las aplicaciones químicas con el consiguiente ahorro, por el gasto en que se incurre con los fertilizantes químicos y con el beneficio que las alternativas biológicas proporcionan al medio ambiente.

En el cultivo de la caña de azúcar se han estudiado ampliamente los beneficios que se obtienen con el empleo de la cachaza.

Algunos autores sugieren (7) que en muchos países su empleo es una práctica usual porque mejora las condiciones físicas y microbiológicas del suelo y suministra nutrientes. Destacan que $25 \mathrm{t} / \mathrm{ha}$ de cachaza equivalen a $154 \mathrm{~kg}$ de cloruro de potasio, $554 \mathrm{~kg}$ de superfosfato triple, $815 \mathrm{~kg}$ de urea y 15 t de materia orgánica.

\section{ANCHO DE LA HOJA}

Para esta variable, ver figura 3, a los 50 días no se encontraron diferencias significativas entre las variables estudiadas, ya para los 60 días se observan diferencias entre las variantes biológicas y el testigo. Para los 70 días entre las formas líquidas y sólidas si se hallaron diferencias, alcanzando los mayores valores la variante soportada en cachaza. Esta respuesta está avalada por el hecho reiterado anteriormente que las aplicaciones de Azospirillum promueven el crecimiento vegetal con resultados superiores en muchos casos a los obtenidos con la fertilización química y que las aplicaciones sólidas ofrecen mayor seguridad para el microorganismo.

$\mathrm{Al}$ respecto se estudió (2) en condiciones de laboratorio para la caña de azúcar a la cachaza como sustrato para el desarrollo de diferentes microorganismos como Azospirillum y se comprobó que la misma constituye un medio apropiado para el crecimiento y desarrollo de la bacteria.

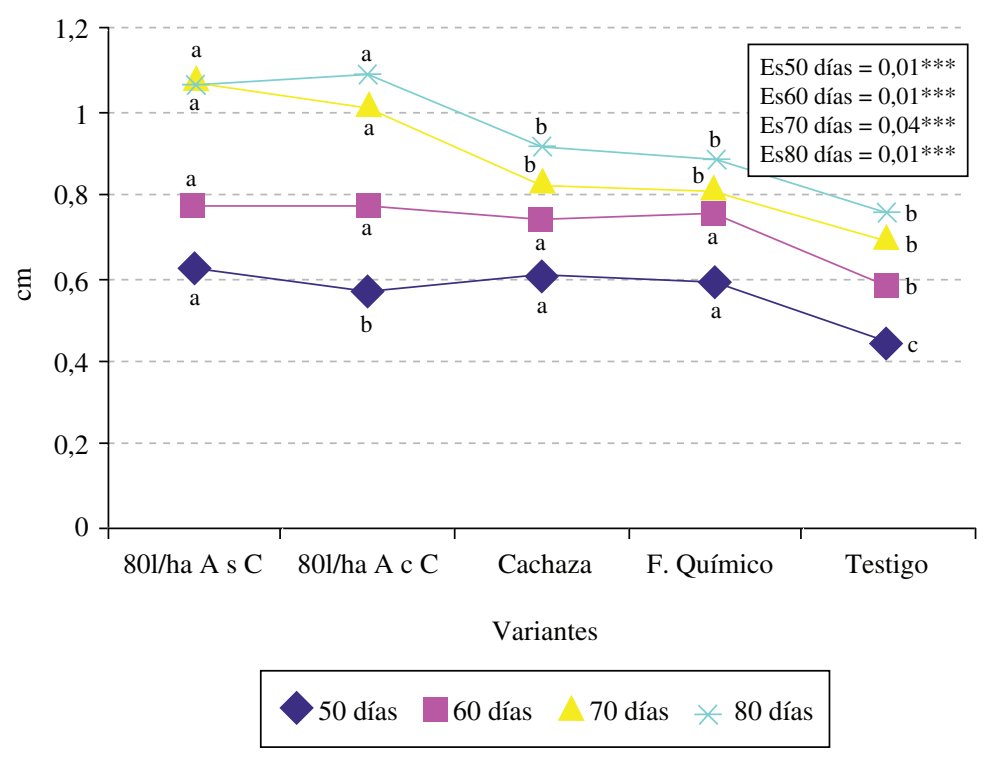

Figura 2. Comportamiento del grosor del tallo para las diferentes variantes y edades de las plántulas. 


\section{LONGITUD TALLO}

La figura 1 muestra que para esta variable se encontraron diferencias significativas para la interacción variantes estudiadas y las edades de la planta analizadas. Se observa que a los 50 días se encontraron diferencias entre las variantes biológicas y las químicas y no así entre las aplicaciones sin y con cachaza, pero los mejores valores le correspondieron a las rizobacterias soportadas en sólidos.

A los 60 días de edad las plantas manifiestan diferencias altamente significativas con respecto a la edad anterior y entre las variantes biológicas y el testigo, los mejores valores le correspondieron a las aplicaciones de Azospirillum sin cachaza. Ya para los 70 días se observa el mayor valor en la inoculación soportada en sólido y al final de estudio, es decir a los 80 días de edad de las plántulas, se muestran diferencias altamente significativas entre la adicción de las rizobacterias sin y con cachaza, es decir, líquida y sólida. Esto es debido a las ventajas que ofrece el aplicar la bacteria soportada, pues el material orgánico le sirve de protección ante las dificultades que pueden encontrarse en el traslado al campo y en su manejo de forma general.

Se sugiere (3) que los formulados líquidos son las formas más simples de emplear los biopreparados. Es como tal que sale de los fermentadores, pero indica que es la menos apropiada, ya que requiere mover grandes volúmenes con peligro de contaminación en el transporte y almacenamiento y lo más importante es que el microorganismo llega al suelo desprovisto de protección y expuesto a los rigores del medio (calor, humedad, microflora, etc.), lo que disminuye la posibilidad de supervivencia.

Muchos autores recomiendan esta forma para casos donde no se pueda tratar la semilla botánica y que sea necesario aplicarlos al suelo directamente (4); refieren que la aplicación líquida de inoculantes micorrízicos es de hecho un reto debido a la baja protección osmótica de los propágulos aplicados en medio acuático y a sistemas de riego.

Nótese que entre las aplicaciones químicas y las de cachaza se han encontrado diferencias significativas y, cuando no ha sido así, los valores correspondientes al subproducto de la industria han

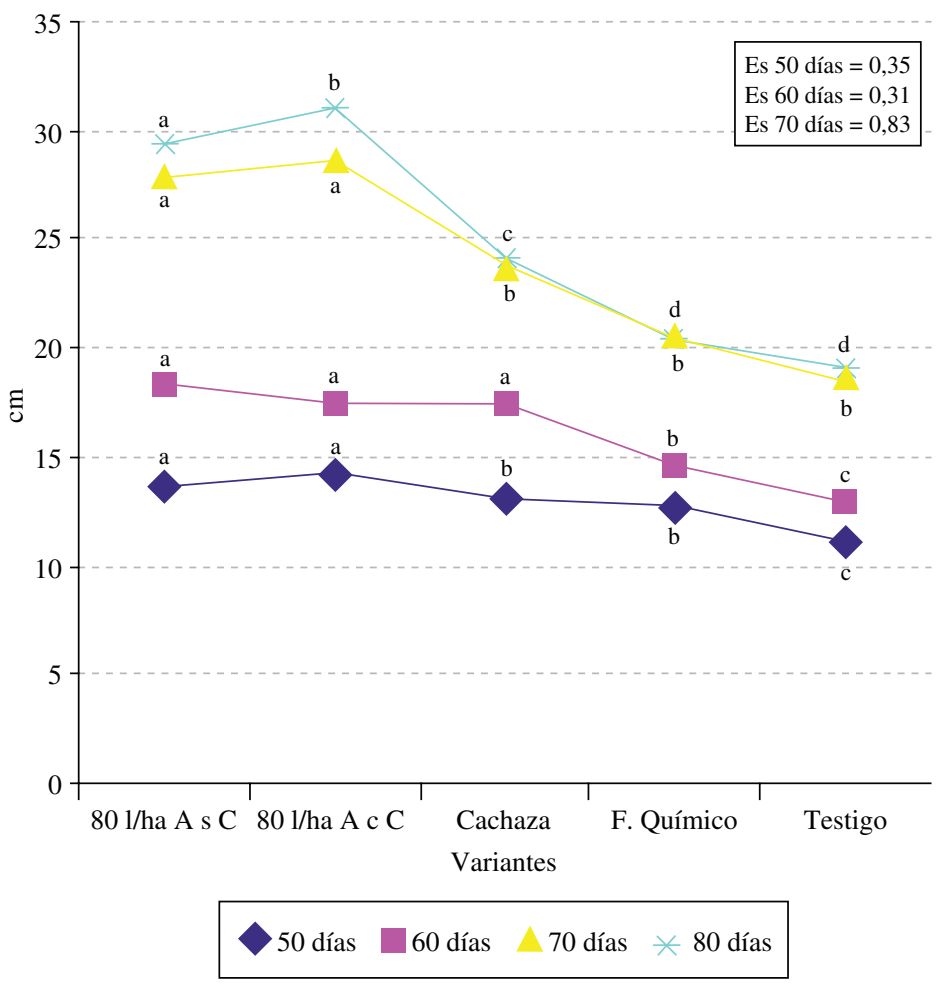

Figura 1. Comportamiento de la longitud del tallo para las variantes biológicas en las diferentes edades evaluadas. 


\section{METODOLOGÍA DE MUESTREO}

Se realizaron muestreos sistemáticos a los 50, 60, 70 y 80 días de edad de las plántulas a las siguientes variables respuestas:

- $\quad$ Longitud de la hoja +1 (según clasificación Kuiper citado por Dillewijn (1975)) en cm.

- Ancho de la hoja +1 en cm.

- Números de hojas activas, en unidades.

- Área foliar (longitud de la hoja*ancho de la hoja*número de hoja * 0,7) en $\mathrm{cm}^{2}$.

- Grosor del tallo en cm.

- Longitud del tallo en cm.

- Número de hojas.

- Crecimiento aparente (longitud inicial y longitud final desde la base del tallo hasta el último dewlap visible).

- Tiempo de emisión de las hojas (plastocrón) tiempo que transcurre durante la emisión de una hoja a otra) en días.

- Velocidad de Crecimiento (incremento en longitud por día) $\mathrm{cm} /$ día.

\section{ANÁLISIS ESTADÍSTICO}

Los resultados fueron sometidos a un análisis $\mathrm{ACP}$ al siguiente grupo de variables: longitud y ancho de la hoja, área foliar, grosor del tallo, número de hijos, longitud del tallo y tratamientos, para decidir cuáles son las variables de mayor importancia y las que aportaron a la variabilidad de los sistemas estudiados.

Se realizó además Análisis de Varianza según clasificación Doble con Interacción para los factores edad y soportes. En los casos de existir diferencia significativa se aplicó la Dócima de Comparación Múltiple de Duncan 1955.

\section{RESULTADOS Y DISCUSIÓN}

Para la selección de los valores propios significativos se partió del criterio Cliff (1987) citado (6), por el cual se adapta bien al objetivo del análisis. La descripción de los resultados se hará en función de los dos primeros componentes que explican el $78,66 \%$ de la varianza según tabla 19. Éstos dan una idea clara de la estructura que subyace en las variables estudiadas.
Tabla 1

Matriz de componentes y valores propios de las variables originales evaluadas en la aplicación de rizobacterias inoculadas en cachaza

\begin{tabular}{|l|c|c|}
\hline \multirow{2}{*}{ Variables } & \multicolumn{2}{c|}{ Componente } \\
\cline { 2 - 3 } & $\mathbf{1}$ & $\mathbf{2}$ \\
\hline Edad & $0,94_{1}$ & $-0,20$ \\
\hline Soportes & $-0,15$ & $-0,96_{1}$ \\
\hline Long. hoja & $0,77_{6}$ & $0,56_{2}$ \\
\hline Ancho hoja & $0,85_{4}$ & 0,35 \\
\hline No de hoja & $0,83_{5}$ & 0,43 \\
\hline Área foliar & $0,68_{7}$ & 0,35 \\
\hline Grosor tallo & $0,88_{3}$ & 0,35 \\
\hline No de hijo & 0,43 & 0,12 \\
\hline Long. tallo & $0,89_{2}$ & 0,32 \\
\hline Porcentaje de varianza & 67,05 & 11,61 \\
\hline Porcentaje de varianza acumulada & 67,05 & 78,66 \\
\hline
\end{tabular}

El primer componente principal contribuyó con más del $67 \%$ de la varianza total explicada, mientras que la distribución de los coeficientes del primer vector y de correlación indican, según tabla 21, que la edad de la planta, largo y grosor del tallo fueron las variables que más contribuyeron en forma positiva al componente, seguidas por ancho, número y largo de las hojas y por último el área foliar.

El segundo componente contribuyó solamente con el 11,6\% de la varianza total explicada y dentro de él la variable soportes fue la que más contribuyó de forma negativa; en segundo lugar, el largo de las hojas aportó sobre el resto de las variables una contribución destacada.

Esto nos indica que las variables asociadas al crecimiento del tallo mostraron los mejores resultados, dado esto por la etapa o fase de desarrollo objeto de estudio, es decir que la planta se encuentra en período de crecimiento, el cual se caracteriza por un encañamiento porque la planta comienza a formar los primeros canutos y comienzan a encañar y es donde la actividad fisiológica de la planta es máxima. Se destaca por parte de (5) que en esta fase ocurren fenómenos tales como la división, diferenciación y elongación celular. 
de ellas se destacan las relacionadas con los niveles de contaminación del producto y por problemáticas asociadas al manejo, almacenamiento y traslado de la bacteria al campo. (10)

Los estudios de las formulaciones recomendadas por los autores anteriores sugieren determinadas instrucciones necesarias a utilizar con estos productos como son: emplear para el almacenamiento y traslado al campo recipientes de acero inoxidable, de cristal o tanques plásticos limpios previamente tratados con vapor durante 15 minutos; debe existir la más exacta sincronización entre el fermentador y la aplicación al campo, para disponer de un producto de óptima calidad, ya que en estas condiciones se garantiza una estabilidad y pureza dentro de los 10 días después de recogida.

Ante estas limitaciones se llevó a cabo un estudio conjunto entre el Instituto de Derivados de la Caña de Azúcar (ICIDCA) y el Instituto de Investigaciones de la Caña de Azúcar (INICA) con el objetivo de formular un producto más estable que garantice una mayor conservación de la bacteria, un manejo más eficiente de la misma y que se adapte a las condiciones prácticas que exige el cultivo de la caña de azúcar.

Se llevaron a cabo estudios de optimización del medio y método de cultivo (3) de la bacteria sobre la formulación simplificada como una alternativa económica y disponible para uso industrial. Obtuvo una variante con la cepa Azospirillum brasilense 8I del INICA un producto con viabilidad $\left(10^{8} \mathrm{Ufc}\right.$ $\mathrm{m}^{-1}$ ) en un período de hasta 60 días.

Por su parte (12) patentizaron una tecnología de un producto a partir de la cepa (8I del INICA) soportada en sólidos (cachaza y turba) con grandes posibilidades de ser utilizada en caña de azúcar.

Para el estudio de estos soportes se utilizó como herramienta estadística el Análisis de Componentes Principales con el objetivo de establecer patrones de comportamiento en los sistemas ecológicos de nutrición de la caña de azúcar.

Partiendo de estos resultados y con la utilización de estos productos soportados en sólidos esta investigación se propone los siguientes objetivos:

1. Utilizar como herramienta estadística al ACP para establecer patrones de comportamiento de los sistemas ecológicos de nutrición de la caña de azúcar.

2. Evaluar de manera comparativa la respuesta fisiológica de la planta a las aplicaciones en soportes líquidos y sólidos (cachaza) de Rizobacterias.

\section{MATERIALES Y MÉTODOS}

\section{DESCRIPCIÓN DEL ÁREA DE ESTUDIO}

Los experimentos fueron montados en el Bloque experimental de la Empresa Cañera Sergio González de la provincia de Matanzas. Ubicado en los límites del Municipio de Perico, limita al norte con la Municipalidad de Martí, al oeste con el Poblado de Deseada, al este con la Empresa Cañera España Republicana y al sur con el Jagüey Grande.

Las variables climatológicas indican que los niveles de precipitaciones en esta área oscilan alrededor de los $1.500 \mathrm{~mm}$, la temperatura media promedio se enmarca entre $23,8{ }^{\circ} \mathrm{C}$ y la humedad relativa de $79 \%$ reportados en los boletines Agrometeorológicos de la Estación Indio Hatuey (1976 a 2005).

\section{MATERIAL UTILIZADO}

Se utilizaron vitroplantas de caña de azúcar en fase de adaptación de la variedad C. 120-78.

El producto utilizado fue obtenido de la cepa de Azospirillum brasilense 8I (INICA) en soporte líquido según metodología reportada por Roldós et al. (1994) y en soporte sólido según tecnología de Saura et al. (2003).

Para las aplicaciones de fertilizantes químicos se utilizaron los siguientes productos según dosis recomendadas por (11): Para nitrógeno la Urea, para fósforo el Superfosfato Triple y para potasio el Cloruro de potasio.

\section{DISEÑO EXPERIMENTAL}

Se diseñó según Bloque al Azar con cinco réplicas, donde los tratamientos consistieron en la combinación de los factores edad $(10,20,30$ y 40 días) y soportes de la Rizobacterias (80 1/ha de Azospirillum líquido, 80 1/ha de Azospirillum en cachaza, cachaza sola, fertilizantes químicos y control).

Se utilizaron 12 plantas por réplica, para un total de 60 para cada tratamiento, las vitroplantas se plantaron en potes de $40 \mathrm{~cm}^{3}$. Se aplicaron las siguientes cantidades del producto: para 80 1/ha líquido del preparado, 7,68 $\mathrm{ml}$ y para 80 1/ha del preparado sólido $2,4 \mathrm{~g}$. 


\title{
EL ANÁLISIS DE COMPONENTES PRINCIPALES EN LA INTERPRETACIÓN DE SISTEMAS AGROECOLÓGICOS PARA EL MANEJO DE RIZOBACTERIAS PROMOTORAS DEL CRECIMIENTO VEGETAL PARA EL CULTIVO DE LA CAÑA DE AZÚCAR
}

\author{
MAIN COMPONENTS ANALYSIS IN THE INTERPRETATION OF \\ AGROECOLOGICAL SYSTEMS FOR MANAGING RHIZOBACTERIA \\ IN THE GROWTH OF SUGARCANE CULTIVARS
}

MSc. Doris Torriente Díaz ${ }^{1}$; Dra Verena Torres Cárdenas ${ }^{2}$

\section{RESUMEN}

El Análisis de Componentes Principales constituye una herramienta estadística que tradicionalmente ha sido poco utilizada por los investigadores de la Rama Agrícola. En esta investigación se muestran las ventajas de su uso sobre otros métodos estadísticos y su utilidad en la interpretación de sistemas alternativos de nutrición de las plantas. Se experimentó sobre suelos Cambisoles en la cepa de retoños de caña de azúcar de más de tres cortes, evaluando el comportamiento de la planta ante diferentes formas de traslado al campo de las Rizobacterias Promotoras del Crecimiento Vegetal (líquido y sólidas). Las formas sólidas son soportadas en cachaza. Se obtuvo como resultados fundamentales que las variables longitud tallo, grosor del tallo, ancho de la hoja, no de hojas, área foliar entre otras, fueron las que más aportaron al sistema evaluado. Además se concluyó que las variables del tallo dentro de los sistemas biológicos como modo de nutrición de las plantas aportan mayor variabilidad a los indicadores productivos.

Palabras clave: Componentes Principales, Rizobacterias.

\section{ABSTRACT}

The Main Component Analysis constitutes a statistical tool that has traditionally been little used by agricultural researchers. This study shows the advantages of its use over other statistical methods and its usefulness in the interpretation of alternative nutrition systems in sugarcane. The experiment was carried out on Cambisol soils in the strain of regrowths of more than three cuttings, evaluating the performance of the plant before different transference forms of the Plant Growth Promoting Rhizobacteria to the field (liquid and solid). The solid forms are based on peat and sugarcane filtered mud. The main results obtained indicated that leaf length, stem width, leaf width, number of leaves, leaf area among others were the variables with the highest contribution to the evaluated system. It was also concluded that the biological systems for the nutrition of sugar cane contribute higher variability to the productive indicators.

Key words: Main components, Rhizobacteria.

\section{INTRODUCCIÓN}

El empleo de Rizobacterias Promotoras del Crecimiento Vegetal en el cultivo de la caña de azúcar soportado en líquido en determinadas con- diciones edafoclimáticas y de manejo agronómico ofrecieron resultados satisfactorios en el $76 \%$ de las experiencias realizadas, pero un $25 \%$ de los experimentos no se obtuvo la respuesta esperada en la planta, dado esto por múltiples razones. Dentro

\footnotetext{
Universidad de Matanzas. Autopista Varadero Matanzas Km 3 1/2. Matanzas. Cuba. doris.torriente@indio.atenas.inf.cu

2 Instituto de Ciencia Animal. vtorres@ica.co.cu
}

Fecha de Recepción: 26 Septiembre 2007

Fecha de Aceptación: 04 Enero 2008 


\section{LITERATURA CITADA}

ANDRADE L.A. 1998. Classificação ecológica do território brasileiro situado a leste do meridiano de $44^{\circ}$ oeste e ao norte do paralelo de $16^{\circ}$ sul: uma abordagem climática. 1998. 147 p. Dissertação (Doutorado em Ciências Florestais). Universidade Federal de Viçosa, Viçosa.

EMBRAPA. 1999. Centro Nacional de Pesquisa de Solos (Rio de Janeiro, RJ). Sistema Brasileiro de classificação de solos. Brasília: Embrapa-SPI; Rio de Janeiro: Embrapa-CNPS, 1412 p.

FUNDAÇÃO SOS MATA ATLÂNTICA E INSTITUTO NACIONAL DE PESQUISAS ESPACIAIS (INPE). 2002. Atlas dos Remanescentes Florestais da Mata Atlântica: período 1995-2000. Relatório Final.

LEOPOLDO, P.R.; SOUZA, A.P.; TUACEK FILHO, S. 1981. Interceptação da água da chuva e cultura de cana-de-açucar. Brasil Açucareiro, 98(6): 9-16.

MIRANDA, E.E.; COUTINHO, A.C. (COORD.). 2007. Brasil Visto do Espaço. Campinas: Embrapa Monitoramento por Satélite, 2004. Disponível em: <http://www.cdbrasil.cnpm. embrapa.br>. Acesso em: 25 abr.

MOREIRA, I.P.S. 1997. Classificação ecológica do território brasileiro situado entre 16 e $24^{\circ}$ de latitude Sul e $39^{\circ} 51$ de longitude Oeste. 1997. 156 p. Dissertação (Doutorado em Ciências Florestais). Universidade Federal de Viçosa, Viçosa.
NAKAMURA, J.; NOVO, E. 2005. Mapeamento da mancha urbana utilizando imagens de média resolução: sensores CCD/CBERS2 e TM/Landsat5 - estudo de caso da cidade de Rio Branco-Acre. In: Simpósio Brasileiro de Sensoriamento Remoto, 12, 2005. Goiânia. Anais... Goiânia: INPE, p. 3843-3850.

NETO, S.N.O. DE. 2000. Classificação ecológica do território brasileiro localizado entre 16 e $24^{\circ}$ latitude sul e 48 e $60^{\circ}$ longitude oeste: uma abordagem climática. 2000.109 p. Dissertação (Doutorado em Ciências Florestais). Universidade Federal de Viçosa, Viçosa.

PEREIRA, A.R.; ANGELOCCI, L.R.; SENTELHAS, P.C. 2002. Agrometeorologia. Porto Alegre: Editora Agropecuária, $190 \mathrm{p}$.

PEZZOPANE, J.E.M.; SANTOS, E.; ELEUTÉRIO, M.M.; A.; REIS, E. F.; SANTOS, A. R. 2004. Espacialização da temperatura do ar no Espírito Santo. Revista Brasileira de Agrometeorologia, v. 12, n. 1, p. 151-158.

THORNTHWAITE, C.W., MATTER, J.R. 1955. The water balance. New Jersey: Publications in Climatology, 8, Centerton, New Jersey, $150 \mathrm{p}$.

THORNTHWAITE, C.W. 1948. Na approach toward a rational classification of climate. Geographical Review. 38: 55-94. 
A Figura 3 indica a situação atual das florestas nativas na região da bacia, evidenciadas em cada sítio delimitado.

A área total de fragmentos florestais da bacia foi de cerca de 116867 ha, correspondendo a 19,7 $\%$ da área da bacia. Deve-se salientar que este resultado deve ser avaliado sabendo que a imagem CBERS-CCD é de média resolução (Nakamura e Novo, 2005), portanto, o nível de detalhamento é reduzido.

Nota-se que a cobertura florestal existente no sítio 1 é melhor conservada que os demais, 24,2 $\%$ de sua área é composta de floresta (83147 ha). Este sítio localiza-se na região serrana onde são encontradas, como já verificado, as maiores altitudes, além da topografia acidentada, tornado essas Áreas de Preservação Permanente (APP's). O sítio 2 e 3 possuem 15,3\% e 11\% de áreas de matas conservadas correspondendo a 23072,9 ha e 10647 ha respectivamente.

A floresta presente à bacia apresenta-se bastante fragmentada com 1957 fragmentos (Tabela 2). Esta intensa fragmentação é decorrente principalmente de atividades agrícolas presentes na bacia como, por exemplo, pastagens e cafeicultura iniciados historicamente com retirada de matas nativas.

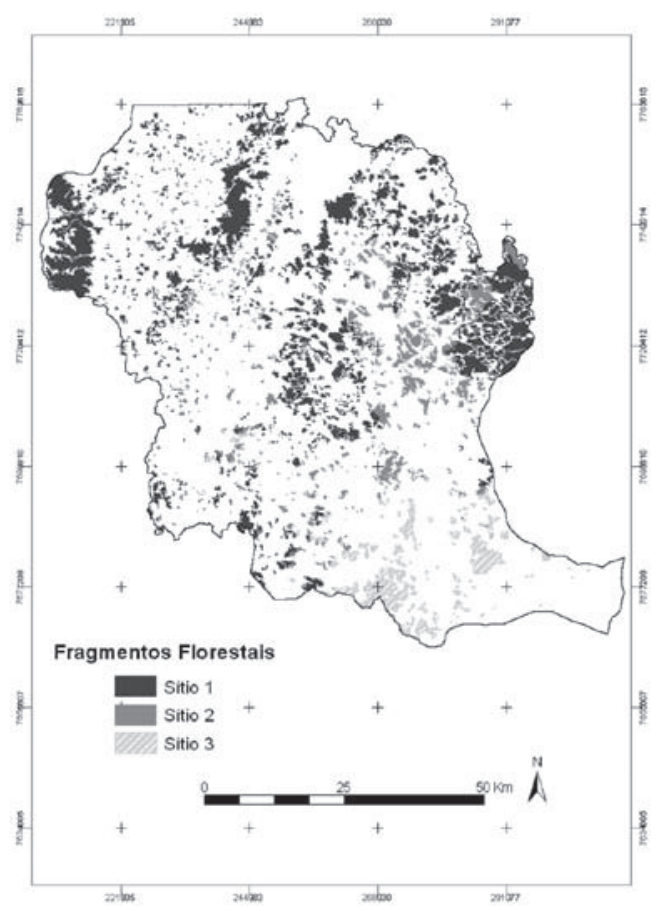

Figura 3. Fragmentação na Bacia do Rio Itapemirim.
Verifica-se que a maior parte dos fragmentos florestais da bacia se encontra na classe de área de 1 a 20 ha. Este resultado indica que cerca de metade deles possuem áreas reduzidas, estando sugeitos a maiores interferências de atividades antropogênicas, o que pode causar desequilíbrios a estes ambientes e consequente extinção destes fragmentos de mata nativa.

Com o conhecimento da situação atual das florestas naturais verificados região da bacia, viu-se necessárias implantações de reflorestamentos como alternativas ecológicas e econômicas. A delimitação dos sítios ambientais pode contribuir para posteriores estudos e aplicações como o planejamento ambiental orientando o plantio de essências florestais e ainda realização de zoneamentos de espécies florestais na bacia do Rio Itapemirim.

Tabela 2

Dados divididos em classe correspondente a área e percentuais da fragmentação florestal, encontrados através de uma imagem CBERS -2 na Bacia do Rio Itapemirim, Sul do Espírito Santo

\begin{tabular}{|c|c|c|}
\hline \multirow{2}{*}{$\begin{array}{c}\text { Classes de } \\
\text { Área (ha) }\end{array}$} & \multicolumn{2}{|c|}{ Fragmentos } \\
\cline { 2 - 3 } & $\mathbf{N}^{\mathbf{0}}$ de Ocorrência & $\%$ \\
\hline$<1$ & 69 & 3,57 \\
\hline $1-20$ & 934 & 47,72 \\
\hline $20-40$ & 353 & 18,03 \\
\hline $40-60$ & 191 & 9,75 \\
\hline $60-80$ & 90 & 4,59 \\
\hline $80-100$ & 68 & 3,47 \\
\hline$>100$ & 252 & 12,87 \\
\hline Total & 1957 & 100 \\
\hline
\end{tabular}

\section{CONCLUSÕES}

Os resultados obtidos permitem concluir que a utilização de variáveis climáticas, juntamente com componentes do balanço hídrico, classes de solos e atributos do relevo, contribuem satisfatoriamente na delimitação de sítios florestais.

O diagnóstico da condição atual da cobertura florestal na Bacia do Rio Itapemirim foi importante para o estudo mais detalhado em relação à cobertura florestal presente em cada sítio delimitado. 


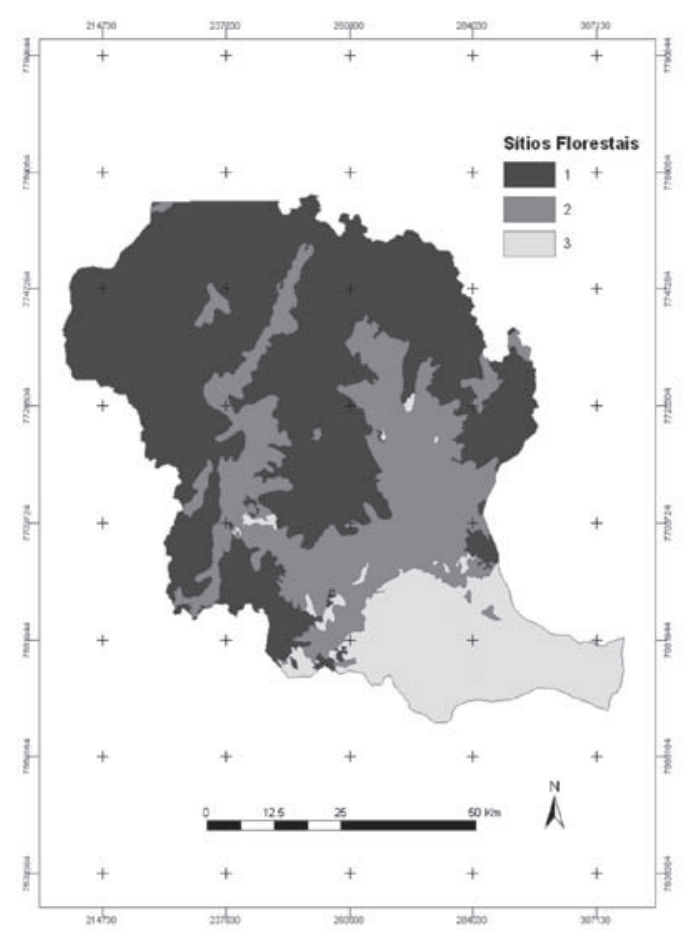

Figura 2. Sítios florestais delimitados na Bacia Hidrográfica do Rio Itapemirim.

região da Bacia, se encontrar o Parque nacional do Caparaó, onde se localiza o Pico da Bandeira com elevação de $2874 \mathrm{~m}$. Verifica-se que, neste mesmo sítio, são encontrados os menores valores médios de temperatura $\left(19,16^{\circ} \mathrm{C}\right)$. O relevo é um fator intrínseco topoclimático, que condiciona o terreno a diferentes exposições à radiação solar direta, logo a configuração do terreno também influi na sua temperatura (Pereira et al. 2002). Confirmando esta correlação, no sítio 3, que abriga o litoral, ou seja, nível de altitudes próximas a zero, a temperatura média foi a maior do que os demais $\left(23,82^{\circ} \mathrm{C}\right)$.
A temperatura do ar exerce influência sobre vários aspectos da produtividade vegetal, estando relacionada com o crescimento e desenvolvimento das plantas, devido ao seu efeito na velocidade das reações químicas e dos processos internos de transporte (Pereira et al. 2002). Antes de se realizar o plantio deve-se, portanto verificar as exigências das espécies em relação a este parâmetro combinados a outros fatores. Pode-se recomendar, para locais com menores temperaturas como, por exemplo, no sítio 1, as espécies: Araucária angustifólia, Pinus elliottii; em locais com temperaturas mais altas, espécies como Cariniana legalis, Dalbergia nigra, Cedrella fissilis dentre outras, além do gênero Eucalipto, amplamente utilizado em projetos de reflorestamento.

A quantidade e a distribuição de chuvas que ocorrem anualmente em uma região podem determinar o tipo de vegetação natural existente já que a água atua como fator indispensável no desenvolvimento da vegetação. O sítio ambiental 1 é a região que apresenta os maiores valores de precipitação anual, com média de $1414 \mathrm{~mm}$, o que pode indicar uma alta taxa de produção de biomassa. Segundo Leopoldo et al., (1981), a cobertura do terreno está intimamente ligada à área foliar, tendo menor influência à quantidade de chuva, assim, essa produção de biomassa fica também condicionado ao grau de interceptação de água pela arquitetura do dossel da floresta.

Nos sítios 2 e 3 foram encontrados valores médios da relação de evapotranspiração 0,92 e 0,87 respectivamente. Para estes, o suprimento hídrico apresenta-se mais restrito já que valores acima de 0,95 desta relação referem-se a condições de deficiencia hídrica, podendo limitar o crescimento e reprodução à cultura florestal a ser implantada, Verifica-se que no sítio 3, a condição média de déficit é mais acentuada (112 mm). Assim, devese ao realizar o plantio de povoamentos florestais, dispor de suporte de irrigação para um melhor desenvolvimento da espécie.

Tabela 1

Média dos parâmetros de climatológicos e de relevo nos sítios da BRI.

\begin{tabular}{|c|c|c|c|c|c|c|}
\hline Sítios & Precipitação $(\mathrm{mm})$ & Altitude $(\mathrm{m})$ & Deficit $(\mathrm{mm})$ & $\mathrm{Er} / \mathrm{Ep}$ & Excedente $(\mathrm{mm})$ & Temperatura $\left({ }^{\circ} \mathrm{C}\right)$ \\
\hline 1 & 1414,00 & 1926,54 & 34,00 & 0,95 & 426,00 & 19,16 \\
\hline 2 & 1385,00 & 701,07 & 47,00 & 0,92 & 336,00 & 22,48 \\
\hline 3 & 1224,00 & 180,66 & 112,00 & 0,87 & 161,00 & 23,82 \\
\hline
\end{tabular}


real (ER) e potencial (EP) calculou-se a razão ER/ EP. Adotou-se capacidade de armazenamento de água no solo de $100 \mathrm{~mm}$.

Na espacialização dos dados climáticos (Figura 1-b), foi utilizado o software IDRISI versão 32. O método utilizado na interpolação foi o da Krigagem linear, propiciando melhores resultados e ser de mais fácil interpretação (Andrade, 1998).

Com os valores individuais de cada pixel do mapa, obtidos dos parâmetros avaliados e suas coordenadas geográficas correspondentes, os dados foram exportados para posterior análise.

Foi efetuada a análise estatística dos dados usando-se o software MATLAB 6.0. Realizou-se o agrupamento não-hierárquico, com o método convergente de agrupamento. Os resultados das análises foram reportados ao software de geo-processamento e assim delimitados os sítios ambientais homogêneos na Bacia Hidrográfica do Rio Itapemirim.

Para realizar o diagnóstico da condição atual dos fragmentos de Mata Atlântica presentes na região da bacia, utilizou-se as imagens do satélite CBERS-2 ("China-Brazil Earth Resources"), produto do sensor CCD, com resolução espacial de 20 m, obtidas através do endereço eletrônico: http:// www.dgi.inpe.br/CDSR na data 03/04/2005. Este sensor possui cinco bandas espectrais, três na faixa do visível uma no infravermelho próximo e outra na pancromática.

Foram adquiridas quatro cenas que compõem toda a áera da bacia. As imagens foram processadas nas coordendadas UTM (Universal Transversa de Mercator), zona 24, datum SAD 69. Realizou-se a correção geométrica e posteriormente o mosaico das quatro imagens com as suas respectivas bandas.

A identificação das áreas de florestas na imagem pôde ser melhor realizada através da composição nas bandas espectrais do azul, verde e infravermelho próximo.

Dispostos dos dados de cobertura florestal nativa na região da bacia, foi verificada a área total de fragmentos pertencentes a cada sítio delimitado para posterior análise.

\section{RESULTADOS E DISCUSSÃO}

Os sítios florestais delimitados na região da bacia do rio Itapemirim - BRI são expostos na Figura 2 apresentando três classes. O sítio 1 se encontra ao norte da bacia e determinadas regiões centrais, é o maior sítio delimitado com área de cerca de 343759 ha, correspondendo a $58.1 \%$ da área total da bacia. O sítio 2 possui área de 151185 ha $(25.5$ $\%$ da área total), situado ao centro da bacia. O sítio 3 , menor deles, localiza-se ao sul da bacia ocupando uma área de 97230 ha (16.4\% da área total).

Os parâmetros para a formação de sítios florestais se encontram na Tabela 1 com valores médios de cada um deles em cada sítio delimitado.

O sítio 1 apresenta altitudes médias expressivamente superior às demais, deve-se ao fato de, nesta

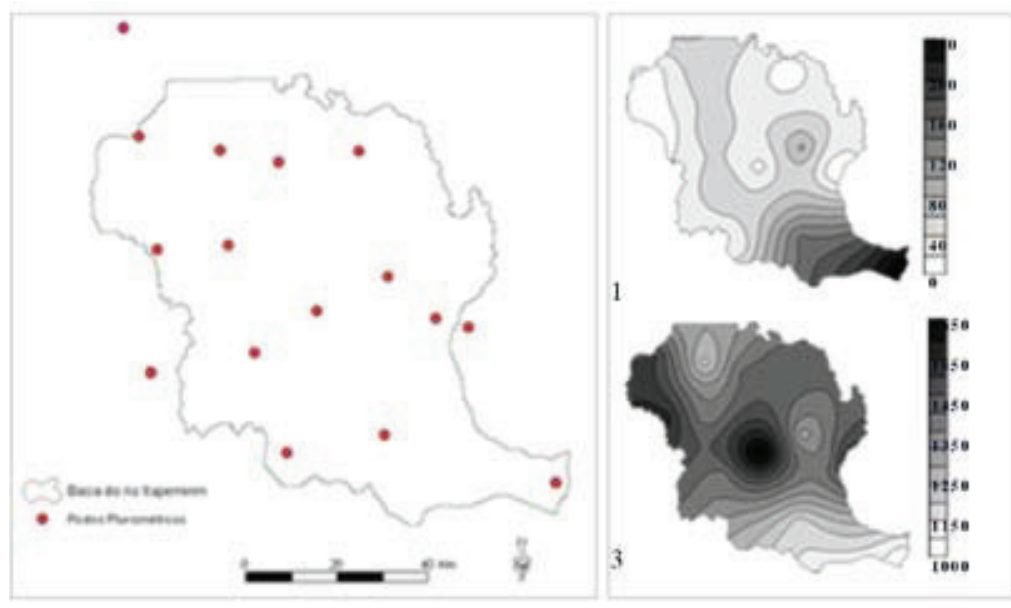

a)

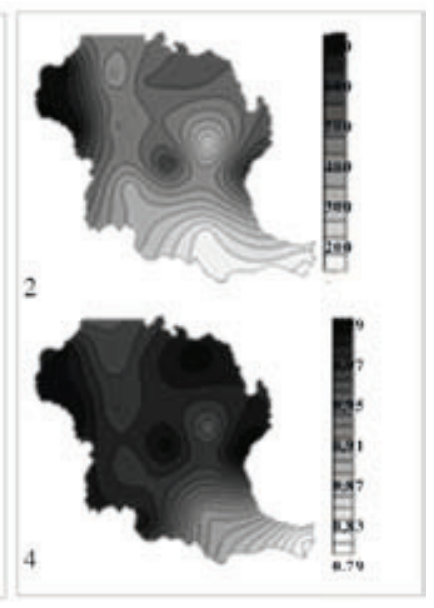

b)

Figura 1. Postos pluviométricos (a); Mapas interpolados: 1- Excedente Hídrico; 2- Déficit Hídrico; 3- Precipitação e 4- ER/EP (b). 
é influenciada pelas condições térmicas e pela distribuição espaço temporal das precipitações. A temperatura influencia os processos fisiológicos da planta, como fotossíntese, respiração, transpiração e divisão celular; enquanto a água é fundamental a todos os processos fisiológicos e bioquímicos (Pereira et al., 2002).

Segundo a Fundação SOS Mata Atlântica e INPE (2002), restam atualmente apenas $8 \%$ da área originalmente coberta pela Mata Atlântica. Esta se encontra extremamente fragmentada, o que torna este ecossistema frágil, despertando preocupações e evidenciando a necessidade de estudos visando subsidiar ações para manter a sustentabilidade dos fragmentos. Para que tornem possíveis as ações que promovam a recuperação e até mesmo a interligação dos fragmentos florestais, através dos corredores ecológicos, é necessária a realização do diagnóstico da atual situação.

Devido às características ambientais e sócioeconômicas a Bacia do Rio Itapemirim (BRI) apresenta um grande potencial para o desenvolvimento de empreendimentos florestais com objetivos econômicos e ambientais. No entanto, a inexistência de uma caracterização ambiental em escala adequada para a bacia e a ausência de trabalhos científicos que indiquem as áreas mais adequadas para o plantio de espécies arbóreas podem comprometer o sucesso dos projetos florestais na região.

O objetivo deste trabalho é delimitar áreas internamente homogêneas e heterogêneas entre si, denominadas sítios florestais, levando-se em consideração fatores edáficos, de relevo e climáticos, realizando posteriormente o diagnóstico da condição atual da cobertura florestal na BRI em relação aos sítios estabelecidos.

\section{MATERIAL E MÉTODOS}

A área de estudo compreende a bacia hidrográfica do Rio Itapemirim, localizada na região Sul do Estado do Espírito Santo, com aproximadamente 592176 ha. A bacia situa-se entre os meridianos $40^{\circ} 48^{\prime}$ 'e $41^{\circ} 52$ ' de longitude Oeste e entre os paralelos $20^{\circ} 10^{\prime}$ e $21^{\circ} 15^{\prime}$ de latitude Sul, abrangendo 17 municípios.

Para a delimitação dos sítios florestais foram utilizados parâmetros edáficos; a altitude como fator topográfico; dados climáticos representados pela temperatura, precipitação, déficit e excedente hídrico e relação de evapotranspiração real e potencial.

As classes de solos da bacia foram obtidas por meio da digitalização da carta do Estado do Espírito Santo, produzida pela Empresa Brasileira de Pesquisa Agropecuária (EMBRAPA, 1999) realizada na escala 1:400.000.

O modelo digital de elevação do terreno utilizado foi originado dos dados de altitude disponibilizados pelo projeto SRTM (Shuttle Radar Topography Mission), obtidos de Miranda e Coutinho (2004). Tais dados apresentam resolução espacial de $90 \mathrm{~m}$ e escalas de digitalização de 1: 250.000.

As temperaturas do ar foram estimadas por meio do modelo matemático desenvolvido por Pezzopane et al. (2004) para o estado do Espírito Santo, no qual a latitude e a altitude são as variáveis independentes e a temperatura do ar a variável dependente, como demonstrado a seguir:

$$
\mathrm{Y}_{\mathrm{i}}=\beta_{0}+\beta_{1} \text { Alt }+\beta_{2} \text { Lat }
$$

em que:

$\mathrm{Y}_{\mathrm{i}}=$ Temperatura do $\operatorname{ar}\left({ }^{\circ} \mathrm{C}\right)$;

Alt $=$ Altitude $(\mathrm{m})$;

Lat $=$ Latitude, em graus e décimos;

$\beta_{0}, \beta_{1}$ e $\beta_{2}=$ coeficientes da equação de regressão ajustados para cada mês do ano.

Na caracterização da disponibilidade hídrica na BRI foram utilizadas séries históricas de chuvas (30 anos) coletadas em postos pluviométricos da Agência Nacional de Águas (ANA). Utilizou-se dados de precipitação média anual, obtidos em 16 postos pluviométricos (Figura 1-a), 13 na bacia e três na vizinhança no período de 1976 a 1997. A inclusão de postos pluviométricos fora do limite da bacia teve como objetivo eliminar o efeito de borda no processo de interpolação, sendo também utilizado por Moreira (1997) e Andrade (1998).

A evapotranspiração potencial foi calculada pelo modelo proposto por Thornthwaite (1948), que é baseado na temperatura média do ar e radiação solar no topo da atmosfera.

A disponibilidade hídrica foi determinada a partir de resultados dos balanços hídricos climatológicos médios (Thornthwaite e Matther, 1955) com dados de déficit e excedente hídricos, calculados em função dos dados de chuva e evapotranspiração mensais. A partir dos valores de evapotranspiração 


\title{
DELIMITAÇÃO DE SÍTIOS FLORESTAIS E ANÁLISE DOS FRAGMENTOS PERTENCENTES NA BACIA DO RIO ITAPEMIRIM
}

\author{
FORESTRY SITES DELIMITATION AND ANALYSIS OF FOREST \\ FRAGMENTS AT ITAPEMIRIM RIVER WATERSHED
}

Yhasmin Gabriel Paiva ${ }^{1}$; Kennedy Ribeiro da Silva ${ }^{1}$; José Eduardo Macedo Pezzopane ${ }^{2}$; André Quintão de Almeida ${ }^{3}$; Roberto Avelino Cecílio ${ }^{4}$

\section{RESUMO}

\begin{abstract}
Devido às características ambientais e sócio-econômicas, a Bacia do Rio Itapemirim (BRI) apresenta grande potencial para o desenvolvimento de empreendimentos florestais com objetivos econômicos e ambientais. Este trabalho consiste em delimitar sítios florestais na BRI, a partir de parâmetros climáticos, edáficos e topográficos e verificar a condição atual da cobertura florestal na BRI. Para delimitação dos sítios florestais foram utilizados dados SRTM de elevação, mapa das classes de solos da bacia e a caracterização da disponibilidade hídrica a partir das Equações de Thorntwaite \& Matter (1955). Os fragmentos florestais foram digitalizados através da classificação visual das imagens do satélite CBERS-CCD. Verificou-se que os parâmetros utilizados apresentaram bons resultados para a delimitação dos sítios florestais na BRI. O diagnóstico da condição atual da cobertura florestal na Bacia do Rio Itapemirim foi importante para o estudo mais detalhado em relação à cobertura florestal presente em cada sítio delimitado.
\end{abstract}

Palavras-chave: Floresta Atlântica, dados SRTM, CBERS-CCD

\begin{abstract}
Itapemirim River Watershed (BRI) brings a great potential to the development of forestry undertakings due to its environmental, social and economics characteristics. This paper shows the delimitation of forestry sites at BRI accounting for climactic, soil and topographical data. A study of the Atlantic Forest fragments conditions at BRI was also done. Forestry sites were delimitated using SRTM elevation data, Thorntwaite \& Matter water balance and soil classes maps. Atlantic Forest fragments were individualized by visual classification of CBERS-CCD satellite images. Results showed that the use of climatic, soil and topographical data are very helpful in forestry sites delimitation.
\end{abstract}

Key words: Atlantic Forest, SRTM date, CBERS-CCD

\section{INTRODUÇÃO}

A delimitação de áreas homogêneas constitui uma eficiente ferramenta no planejamento do uso de recursos naturais e na otimização de investimentos. Esta prática permite avaliar a capacidade produtiva de uma determinada área, correlacionando com a espécie ou espécies que nela se deseja produzir.
Desta forma, grande parte das decisões tomadas no manejo florestal tem base mapeamentos de Habitats Florestais (Andrade, 1998).

Considerados como de maior influência na distribuição e no desenvolvimento da vegetação, os fatores climáticos são os principais componentes em estudos de classificação e zoneamento (Neto, 2000). A disponibilidade hídrica dos solos

\footnotetext{
Engenheiro Florestal, Universidade Federal do Espírito Santo CCA-UFES, CEP 29500-000 Alegre-ES. yhasminp@ hotmail.com Engenheiro Florestal, DS, Professor Adjunto, Universidade Federal do Espírito Santo, CCA-UFES, CEP 29500-000 Alegre-ES.

Engenheiro Florestal, Mestre em Engenharia Ambiental, Universidade Federal do Espírito Santo. CT-UFES, CEP: 29060-900 Vitória-ES, CT-UFES.

4 Engenheiro Agrícola, DS, Professor Adjunto, Universidade Federal do Espírito Santo, CCA-UFES, CEP 29500-000 Alegre-ES.
} 

de plantas frutíferas de clima temperado. 2.ed. Pelotas: UFPel, $178 \mathrm{p}$.

FERNANDES, A.A.; MARTINEZ, H.E.P.; SILVA, DERLY, J.H.; BARBOSA, J.G. 2004. Produção de mudas de tomateiro por meio de estacas enraizadas em hidroponia. Pesquisa Agropecuária Brasileira, Brasília, v. 39, n. $\approx 4$, p. 343-348.

FOSTER, G.S. 1993. Selection and breeding for extreme genotypes. In: AHUJA, M.R.; LIBBY, W.J. (Ed.). Clonal forestry - I: genetics and biotechnology. Berlin: Springer, p. 50-67.

GÛL, A.; TUZEL, Y.; YOLTAS, T. 1994. Possibilities of using side shoots as propagation material in greenhouse tomato production. Acta Horticulturae, n. 366, p. 271-278.

HARTMANN, H.T.; KESTER, D.E. 1990. Propagación de plantas: principios y practicas. 4.ed. México: Continental, $760 \mathrm{p}$.

LAMAIRE, F. 1995. Physical, chemical and biological properties of growing medium. Acta Horticulturae, v. 396, p. 273-284.

LUZ, J.M.Q.; PAULA, E.C.; GUIMARÃES, T.G. 2000. Produção de mudas de alface, tomateiro e couve-flor em diferentes substratos comerciais. Horticultura Brasileira, v. 18 , suplemento, p. 579-581.

MINAMI, K. 1995. Fisiologia da produção de mudas. São Paulo: T.A. Queiroz, 129 p.

PAIVA, H.N.; GOMES, J.M. 1995. Propagação vegetativa de espécies florestais. Viçosa: UFV, 40 p.

PRAGANA, R.B. 1998. Potencial do resíduo da extração da fibra de coco como substrato na produção agrícola. Recife: UFRPE, 84 p. (Tese mestrado).

RIZZO, A.N.; BRAZ, L.T. 2002. Enraizamento de brotos laterais de tomate tipo cereja em diferentes substratos. Campinas: IAC, p. 106 (Documentos).

SILVEIRA, E.B.; RODRIGUES, V.J.L.B.; GOMES, A.M.A.; MARIANO, R.L.R; MESQUITA, J.C.P. 2002. Pó de coco como substrato para produção de mudas de tomateiro. Horticultura Brasileira, Brasília, v. 20, n. 2, p. 211-216.

SMIDERLE, O.J.; SALIBE, A.B.; HAYASHI, A.H.; MINAMI,

K. 2001. Produção de mudas de alface, pepino e pimentão em substratos combinando areia, solo e plantmax. Horticultura Brasileira, Brasília, v. 19, n. 3, p. 253-257. 
No substrato Plantmax ${ }^{\circledR} 10 \%$ da MST foi alocada no sistema radicular, aproximadamente $42,9 \%$ superior a proporção de massa seca acumulada no sistema radicular de mudas crescidas nos substratos $\mathrm{S}+\mathrm{A}+\mathrm{E}$ e areia. Estacas com $5 \mathrm{~cm}$ de altura apresentaram em média maior proporção de massa seca alocada no sistema radicular $(53,8 \%)$.

A altura de estaca não influenciou estatisticamente os parâmetros CSR e DR. Para o substrato $\mathrm{S}+\mathrm{A}+\mathrm{E}$ com valores médios de 5,39 $\mathrm{m}$ e $0,042 \mathrm{~mm}$, respectivamente (Tabela 3). Estacas com $5 \mathrm{~cm}$ apresentaram menor CSR quando submetidas ao Plantmax ${ }^{\circledR}$. No geral, maior CSR foi observado nas estacas de $11 \mathrm{~cm}$ enraizadas no substrato Plantmax ${ }^{\circledR}$ $(12,66 \mathrm{~m})$. Estacas enraizadas na areia apresentaram maior DR. Registra-se que o fato da areia apresentar mudas com raízes mais grossas, presumivelmente, menor condutividade hidráulica radial reduziria a absorção de água por unidade de comprimento de raiz. Cumpre ressaltar que baixa condutividade hidráulica radial, normalmente é uma característica indesejável sob suprimento hídrico abundante, pode reduzir potenciais perdas de água da raiz para o solo, ao longo de ciclos de desidratação, esse fato confirmaria a baixa capacidade da areia de manter a umidade o que causava a murcha das mudas no período de maior evapotranspiração. Ademais, a maior relação PA/SR culminaria em baixa habilidade de controlar perda de água.

Estacas de $5 \mathrm{~cm}$ apresentaram menor relação PA/SR independente do tipo de substrato (Tabela 3). Assim, apresentaram melhor equilíbrio entre superfície transpirante associada a uma maior quantidade relativa de raízes para suprir as perdas transpiratórias, possuindo uma capacidade maior de absorção de água por volume de solo. Menor PA/SR deve concorrer para menores taxa de uso da água e melhor capacidade de tolerar condições adversas. Mudas confeccionadas no substrato Plantmax ${ }^{\circledR}$ com estacas de 5, 8 e $11 \mathrm{~cm}$, nas mesmas condições, aqui descritas, foram levadas para plantio em campo, o melhor equilíbrio morfológico poderia explicar a

\section{REFERÊNCIAS BIBLIOGRAFICAS}

CARMELLO, Q.A.C. 1995. Nutrição e adubação de mudas hortícolas. In: MINAMI, K. Produção de mudas de alta qualidade em horticultura. São Paulo: T.A. Queiroz, p. 33-37.

CARNEIRO, J.G.A. 1995. Produção e controle de qualidade de mudas vegetais. Curitiba: UFPR/FUPEF, 451 p.
Tabela 3

Valores médios dos parâmetros: comprimento do sistema radicular (CSR), diâmetro médio das raízes (DR), massa seca do sistema radicular (MSSR) e relação entre massa seca da parte aérea e do sistema radicular (PA/SR) de mudas do tomateiro provenientes de diferentes substratos e altura de estacas

\begin{tabular}{|c|c|c|c|c|}
\hline \multirow{2}{*}{ Parâmetros } & \multirow{2}{*}{ Estaca } & \multicolumn{3}{|c|}{ Substrato } \\
\hline & & $S+A+E$ & Plantmax ${ }^{\circledR}$ & Areia \\
\hline \multirow{3}{*}{ CSR (m) } & 5 & $6,04^{\mathrm{aB}}$ & $8,91^{\text {bA }}$ & $2,15^{\mathrm{bC}}$ \\
\hline & 8 & $5,61^{\mathrm{aB}}$ & $10,30^{\mathrm{bA}}$ & $4,46^{\mathrm{aB}}$ \\
\hline & 11 & $4,54^{\mathrm{aB}}$ & $12,66^{\mathrm{aA}}$ & $5,54^{\mathrm{aB}}$ \\
\hline \multirow{3}{*}{$\mathrm{DR}(\mathrm{mm})$} & 5 & $0,037^{\mathrm{aB}}$ & $0,035^{\mathrm{bB}}$ & $0,067^{\mathrm{aA}}$ \\
\hline & 8 & $0,053^{\mathrm{aB}}$ & $0,042^{\mathrm{bB}}$ & $0,058^{\mathrm{bA}}$ \\
\hline & 11 & $0,035^{\mathrm{aC}}$ & $0,056^{\mathrm{aB}}$ & $0,063^{\mathrm{bA}}$ \\
\hline \multirow{3}{*}{$\operatorname{MSSR}(\mathrm{g})$} & 5 & $0,049^{\mathrm{aA}}$ & $0,065^{\mathrm{bA}}$ & $0,011^{\mathrm{aB}}$ \\
\hline & 8 & $0,048^{\mathrm{aB}}$ & $0,090^{\mathrm{aA}}$ & $0,017^{\mathrm{aC}}$ \\
\hline & 11 & $0,039^{\mathrm{aB}}$ & $0,100^{\mathrm{aA}}$ & $0,018^{\mathrm{cB}}$ \\
\hline \multirow{3}{*}{ PA/SR $\left(\mathrm{g} \mathrm{g}^{-1}\right)$} & 5 & $10,41^{\mathrm{bA}}$ & $7,38^{\mathrm{bB}}$ & $9,09^{\mathrm{bB}}$ \\
\hline & 8 & $10,63^{\mathrm{bB}}$ & $10,53^{\mathrm{aB}}$ & $23,53^{\mathrm{aA}}$ \\
\hline & 11 & $18,21^{\mathrm{aB}}$ & $10,50^{\mathrm{aC}}$ & $23,33^{\mathrm{aA}}$ \\
\hline
\end{tabular}

Diferenças estatísticas entre médias obtidas entre tamanho de estaca são indicadas por diferentes letras minúsculas. Diferentes letras maiúsculas representam diferenças estatísticas entre médias nos diferentes substratos (Tukey, $\mathrm{p} \leq 0,05$ ).

razão das mudas produzidas com estacas de $5 \mathrm{~cm}$ apresentarem menor taxa de replante.

\section{CONCLUSÃO}

A propagação vegetativa do tomateiro é viável, contudo maiores estudos sobre substratos alternativos, condições de enraizamento e padrão do material vegetal utilizado devem ser realizados.
CHENG, S.S.; CHU, E.Y. 2004. Técnica de Enraizamento de Ponteira para Propagação e Cultivo do Tomateiro. Comunicado técnico. ISSN 1517-2244 Dezembro, Belém, PA.

FACHINELLO, J.C.; HOFFMANN, A.; NACHTIGAL, J.C.; KERSTEN, E.; FORTES, G.R.L. 1995. Propagação 
Tabela 2

Valores médios dos parâmetros: enraizamento (ENR), taxa de crescimento absoluto (TCA), massa seca da parte aérea (MSPA), massa seca total (MST), razão de massa seca da parte aérea (RMSPA) e razão de massa seca do sistema radicular (RMSSR) de mudas do tomateiro em diferentes substratos e altura de estacas

\begin{tabular}{|c|c|c|c|c|c|}
\hline \multicolumn{2}{|c|}{ Parâmetros } & \multicolumn{2}{|c|}{ Substrato } & \multicolumn{2}{|c|}{ Estaca } \\
\hline \multirow{3}{*}{\multicolumn{2}{|c|}{$\operatorname{ENR}(\%)$}} & $\mathrm{S}+\mathrm{A}+\mathrm{E}$ & $96,9^{\mathrm{a}}$ & 5 & $94,3^{\mathrm{a}}$ \\
\hline & & Plantmax ${ }^{\circledR}$ & $94,7^{\mathrm{a}}$ & 8 & $92,3^{\mathrm{a}}$ \\
\hline & & Areia & $83,9^{\mathrm{b}}$ & 11 & $89,1^{\mathrm{a}}$ \\
\hline \multirow{6}{*}{ TCA } & \multirow{3}{*}{$\left(\mathrm{mg} \mathrm{dia}{ }^{-1}\right)$} & $S+A+E$ & $20,50^{\mathrm{b}}$ & 5 & $13,13^{\mathrm{c}}$ \\
\hline & & Plantmax ${ }^{\circledR}$ & $32,57^{\mathrm{a}}$ & 8 & $22,57^{b}$ \\
\hline & & Areia & $8,01^{\mathrm{c}}$ & 11 & $25,38^{\mathrm{a}}$ \\
\hline & \multirow{3}{*}{$\left(\mathrm{mm} \mathrm{dia}{ }^{-1}\right)$} & $S+A+E$ & $4,07^{\mathrm{a}}$ & 5 & $3,14^{\mathrm{a}}$ \\
\hline & & Plantmax® & $4,02^{\mathrm{a}}$ & 8 & $3,03^{\mathrm{a}}$ \\
\hline & & Areia & $1,13^{\mathrm{b}}$ & 11 & $3,05^{\mathrm{a}}$ \\
\hline \multirow{3}{*}{\multicolumn{2}{|c|}{ MSPA (g) }} & $\mathrm{S}+\mathrm{A}+\mathrm{E}$ & $0,58^{\mathrm{b}}$ & 5 & $0,36^{\mathrm{c}}$ \\
\hline & & Plantmax® & $0,83^{\mathrm{a}}$ & 8 & $0,62^{\mathrm{b}}$ \\
\hline & & Areia & $0,31^{\mathrm{c}}$ & 11 & $0,73^{\mathrm{a}}$ \\
\hline \multirow{3}{*}{\multicolumn{2}{|c|}{ MST (g) }} & $S+A+E$ & $0,62^{\mathrm{b}}$ & 5 & $0,41^{\mathrm{b}}$ \\
\hline & & Plantmax $®$ & $0,91^{\mathrm{a}}$ & 8 & $0,67^{\mathrm{a}}$ \\
\hline & & Areia & $0,32^{\mathrm{c}}$ & 11 & $0,78^{a}$ \\
\hline \multirow{3}{*}{\multicolumn{2}{|c|}{ RMSPA }} & $S+A+E$ & $0,92^{\mathrm{a}}$ & 5 & $0,90^{\mathrm{a}}$ \\
\hline & & Plantmax $®$ & $0,90^{\mathrm{a}}$ & 8 & $0,93^{\mathrm{a}}$ \\
\hline & & Areia & $0,94^{\mathrm{a}}$ & 11 & $0,94^{\mathrm{a}}$ \\
\hline \multirow{3}{*}{\multicolumn{2}{|c|}{ RMSSR }} & $S+A+E$ & $0,08^{b}$ & 5 & $0,10^{\mathrm{a}}$ \\
\hline & & Plantmax $®$ & $0,10^{\mathrm{a}}$ & 8 & $0,07^{b}$ \\
\hline & & Areia & $0,06^{\mathrm{b}}$ & 11 & $0,06^{b}$ \\
\hline
\end{tabular}

Médias obtidas entre diferentes substratos e tamanho de estacas seguidas por diferente letra diferem estatisticamente entre si pelo teste de Tukey $(\mathrm{p} \leq 0,05)$.

desenvolvimento do sistema radicular e estabilidade da planta, para assim, proporcionar o suprimento de água e nutrientes necessários ao seu crescimento. Portanto, os maiores valores de TCA apresentados pelo Plantmax ${ }^{\circledR}$ pode ser reflexo de sua composição, por possuir uma maior proporção de matéria orgânica, portanto, mais rico em nutrientes, esse substrato pode propiciar condições mais favoráveis para a planta absorver água e produzir massa seca. Este comportamento pode ser confirmado, avaliando a MSPA e MST. Esses resultados estão de acordo com os resultados alcançados por Rizzo \& Braz (2002), os quais constataram que o uso de substrato comercial Plantmax ${ }^{\circledR}$ proporcionou um bom desenvolvimento das mudas de tomateiro formadas a partir de brotos laterais. As raízes também obtiveram um bom desenvolvimento em seu comprimento e consequientemente, maior massa seca quando utilizou-se substrato comercial. Resultados concordantes foram obtidos por Smiderle et al. (2001), confirmando que o substrato Plantmax ${ }^{\circledR}$ propiciou maior massa de matéria seca das plântulas e das raízes de alface, aos 21 e 40 dias após a semeadura. Contudo, Pragana (1998) em testes de bioensaio com diversas hortaliças verificou que de modo geral, a adição de pó de coco melhorou o desempenho daquele substrato.

A altura inicial de estaca não afetou a TCCA, porém, o acúmulo de massa seca diária, verificada pela TCAM, foi decrescendo com a redução da altura das estacas, apresentando as estacas de $11 \mathrm{~cm}$ valores 12,5 e 93,3\% superior a estacas de 8 e $5 \mathrm{~cm}$, respectivamente (Tabela 2). Comportamento semelhante foi observado para a MSPA (Tabela 2). Após o plantio, as estacas passam por um período de ausência de raízes e folhas, assim, o crescimento é governado pelas reservas metabólicas. Estacas com maiores alturas possuem conteúdo maior de carboidratos que poderá ser utilizados na manutenção de maior taxa de crescimento inicial das mudas, formando primeiramente raízes e novas folhas para iniciar o processo fotossintético, aumentando a fonte de carboidratos que poderá ser utilizada para a respiração de manutenção e de desenvolvimento das mudas. Fachinello et al. (1995) verificaram que a formação de raízes em estacas de videira possui correlação significativa com teor de amido, sendo a porcentagem de enraizamento de $63 \%$ nas estacas mais ricas $35 \%$ nas intermediárias e $7 \%$ naquelas com menor concentração.

A MST foi estatisticamente igual entre as estacas de 8 e $11 \mathrm{~cm}$, apresentando valores médios de $0,72 \mathrm{~g} \mathrm{e} 75,6 \%$ superior a areia $(0,41 \mathrm{~g})$ (Tabela 2$)$. A igualdade entre aquelas estacas é explicada pelo maior acúmulo de massa seca no sistema radicular nas estacas de $8 \mathrm{~cm}$. A RMSPA não apresentou diferenças significativas entre os tratamentos (Tabela 2). No geral, $92 \%$ da MST estava alocada na parte aérea. A RMSSR apresentou respostas significativas entre os diferentes substratos e altura de estacas (Tabela 2). 
Tabela 1

Resumo do teste $\mathbf{F}$ com seus respectivos valores de probabilidade (p) e coeficiente de variação (CV) da análise de variância para as variáveis: ENR - enraizamento (\%), CSR-comprimento do sistema radicular (m), DR- diâmetro médio das raízes ( $\mathrm{mm})$, TCAM - taxa de crescimento absoluto referente ao acúmulo de massa seca (mg dia-1), MSPA - massa seca da parte aérea (g), MSSR - massa seca do sistema radicular (g), PA/SR relação entre massa seca da parte aérea e do sistema radicular $\left(\mathrm{g} \mathrm{g}^{-1}\right)$, MST - massa seca total (g), TCAA taxa de crescimento absoluto referente ao acréscimo em altura $\left(\mathrm{mm} \mathrm{dia}{ }^{-1}\right)$, SRAD - superfície radicular $\left(\mathrm{cm}^{2}\right)$, RMSPA - razão de massa seca da parte aérea ( $\left.\mathrm{g} \mathrm{g}^{-1}\right)$, RMSSR - razão de massa seca do sistema radicular $\left(\mathrm{g} \mathrm{g}^{-1}\right)$, RCSR - razão do comprimento do sistema radicular $\left(\mathrm{m} \mathrm{g}^{-1}\right)$ e CER - comprimento específico de raiz (m kg $\left.\mathrm{g}^{-1}\right)$ de mudas do tomateiro provenientes de diferentes substratos e altura de estacas

\begin{tabular}{|l|c|c|c|c|}
\hline \multirow{2}{*}{ Parâmetros } & \multicolumn{4}{|c|}{ Fonte de Variação } \\
\cline { 2 - 5 } & Substrato & Estaca & Substrato x Estaca & CV $(\%)$ \\
\hline ENR & $26,21(\mathrm{p}<0,001)$ & $1,98(\mathrm{p}=0167)$ & $2,11(\mathrm{p}=0,122)$ & 25,14 \\
\hline CSR & $148,15(\mathrm{p}<0,001)$ & $10,96(\mathrm{p}<0,001)$ & $9,27(\mathrm{p}<0,001)$ & 12,79 \\
\hline DR & $380,56(\mathrm{p}<0,001)$ & $14,39(\mathrm{p}<0,001)$ & $7,77(\mathrm{p}<0,001)$ & 11,25 \\
\hline TCAM & $102,24(\mathrm{p}<0,001)$ & $34,89(\mathrm{p}<0,001)$ & $2,83(\mathrm{p}=0,055)$ & 21,54 \\
\hline MSPA & $102,28(\mathrm{p}<0,001)$ & $49,40(\mathrm{p}<0,001)$ & $2,82(\mathrm{p}=0,056)$ & 16,79 \\
\hline MSSR & $93,44(\mathrm{p}<0,001)$ & $2,11(\mathrm{p}=0,149)$ & $4,76(\mathrm{p}=0,008)$ & 22,68 \\
\hline PA/SR & $19,03(\mathrm{p}<0,001)$ & $62,47(\mathrm{p}<0,001)$ & $10,64(\mathrm{p}<0,001)$ & 17,53 \\
\hline MST & $56,15(\mathrm{p}<0,001)$ & $18,86(\mathrm{p}<0,001)$ & $1,61(\mathrm{p}=0,216)$ & 24,14 \\
\hline TCAA & $44,75(\mathrm{p}<0,001)$ & $0,06(\mathrm{p}>0,999)$ & $20,12(\mathrm{p}=0,120)$ & 24,62 \\
\hline RMSPA & $2,61(\mathrm{p}=0,101)$ & $2,39(\mathrm{p}=0,120)$ & $0,24(\mathrm{p}>0,999)$ & $2,24(\mathrm{p}=0,105)$ \\
\hline RMSSR & $2,59(\mathrm{p}=0,103)$ & $21,55(\mathrm{p}<0,001)$ & 7,14 \\
\hline
\end{tabular}

As estacas apresentaram, em média, $92 \%$ de enraizamento. Estudando ENR nos diferentes substratos, valores semelhantes ( $96 \%)$ foram encontrados para os substratos Plantmax ${ }^{\circledR}$ e $\mathrm{S}+\mathrm{A}+\mathrm{E}$, superior em aproximadamente $12 \%$ a areia $(83,9 \%)$ (Tabela 2$)$. Por ter menor capacidade de retenção de água e reduzida porosidade, a areia não foi um substrato adequado para o enraizamento de estacas para a espécie em estudo. Shmitz et al. (1999) avaliando as características físicas dos diversos substratos comentam que materiais como solo e areia possuem excessiva densidade e reduzida porosidade, sendo deficiente em aeração. Assim, a adição de material orgânico (esterco bovino) ao solo contribuiu para melhoria de suas características físicas melhorando as condições para formação de raízes. Os substratos que apresentaram maior enraizamento exibiram valores semelhantes ao encontrado por Fernandes et al. (2004), que relataram aproximadamente $98 \%$ de enraizamento de estacas de tomateiro cultivar Carmem, em espuma fenólica e Gûl et al. (1994) que estudaram o enraizamento de estacas de tomate tratadas com hormônio e enraizadas em perlita. Contudo, as estacas de tomateiro, o nível interno de hormônio e substâncias relacionadas ao enraizamento foi suficiente para permitir a propagação vegetativa dessa cultura sem aplicação de reguladores de crescimento. As estacas que não apresentaram formação de primórdios radiculares apodreceram sem formar raízes. Esse comportamento foi descrito por Hartman \& Kester (1990) que associaram esse fenômeno com altas concentrações de nitrogênio e baixas concentrações de carboidratos nas estacas de tomate.

A taxa de crescimento absoluto (TCA) referente ao acúmulo de massa seca (TCAM) foi maior no substrato Plantmax ${ }^{\circledR}$, superior em 58,9\% ao $\mathrm{S}+\mathrm{A}+\mathrm{E}$ e 306,6\% a areia (Tabela 2). Quando avaliamos a TCAA não se verifica diferenças significativas entre os substratos Plantmax ${ }^{\circledR}$ e $\mathrm{S}+\mathrm{A}+\mathrm{E}$ apresentando em média $4,05 \mathrm{~mm} / \mathrm{dia}$, superior em $258,4 \%$ ao substrato areia. $\mathrm{O}$ substrato horticula deve garantir o 
deixando somente as folhas apicais. Posteriormente as estacas foram padronizadas em três alturas: 5 , 8 e $11 \mathrm{~cm}$. A padronização foi feita através de um corte em bisel na porção basal de cada estaca.

Após o preparo das estacas, foi realizado no centro de cada recipiente um orifício de $2,5 \mathrm{~cm}$ de profundidade, para o plantio das estacas. O sistema de irrigação utilizado foi o de micro-aspersão, sendo o turno de rega variando de 30 a 120 minutos de acordo com a evapotranspiração. A umidade dos substratos de cultivo foi mantida de modo que não houvesse acúmulo de água na superfície do recipiente.

Os tratamentos foram distribuídos no esquema fatorial $3 \times 3$ (substratos $x$ estacas), em delineamento inteiramente casualizado, com três repetições e 30 mudas por parcela, totalizando 810 mudas. Aos 18 dias após o plantio das estacas foi analisada a porcentagem de enraizamento (ENR), determinada através da proporção de estacas viáveis. Para a avaliação da produção de mudas foram analisadas, aos 24 dias após o plantio, seguintes características agronômicas: comprimento total (CSR) e diâmetro médio do sistema radicular (DR), após serem lavadas e destacadas da parte aérea, as raízes foram dispostas em lâminas de vidro e em seguida digitalizadas. O comprimento e diâmetro do sistema radicular foi estimado através do programa QuantRoot do Departamento de Solos da Universidade Federal de Viçosa, que realiza medição direta das raízes nas imagens digitalizadas em escala real, em que o programa cria linhas de igual comprimento ao das raízes; massa seca da parte aérea (MSPA), do sistema radicular (MSSR) e total (MST=MSPA+MSSR), o material vegetal foi seco em estufa com circulação forçada de ar à temperatura de $70^{\circ} \mathrm{C}$, até peso constante; relação entre massa seca da parte aérea e do sistema radicular (PA/SR=MSPA/MSSR); razão de massa seca da parte aérea (RMSPA=MSPA/MST); razão de massa seca do sistema radicular (RMSSR=MSSR/MST); ( $\mathrm{SRAD}=\pi \times \mathrm{DR} \times \mathrm{CSR})$; razão do comprimento do sistema radicular $(\mathrm{RCSR}=\mathrm{CSR} / \mathrm{MST})$; comprimento específico de raiz (CER=CSR/MSSR); taxa de crescimento absoluto referente ao acúmulo de massa seca [TCAM=(MST-MSE)/24] em que MSE=massa seca das estacas, estimada através da secagem de 5 estacas de cada altura; superfície radicular; taxa de crescimento absoluto referente ao incremento na altura das mudas [TCAA $=(\mathrm{AF}-$ $\mathrm{AE}) / 24]$, em que $\mathrm{AF}=$ altura da parte aérea final e $\mathrm{AE}=$ altura inicial das estacas.
Os dados obtidos foram submetidos à análise de variância e, os fatores significativos analisados pelo teste de Tukey em nível de significância de $5 \%$ de probabilidade.

\section{RESULTADOS E DISCUSSÃO}

Considerou-se o valor de probabilidade igual a $5 \%(\mathrm{p}=0,05)$ como o liminar para concluir a significância da análise estatística. Assim, foram detectados efeitos significativos para a interação entre os tipos de substratos e alturas de estacas nas seguintes características: comprimento do sistema radicular (CSR), diâmetro médio das raízes (DR), relação entre a massa seca da parte aérea e massa seca do sistema radicular (PA/SR), massa seca total (MST) e massa seca do sistema radicular (MSSR) (Tabela 1). Com exceção dos parâmetros razão da massa seca da parte aérea (RMSPA) $(\mathrm{p}=0,101)$ e razão de massa seca do sistema radicular (RMSSR) ( $p=0,103)$, foi verificado diferença significativa entre os substratos para as demais características avaliadas (Tabela 1). A altura das estacas não influenciou significativamente os parâmetros: porcentagem de enraizamento (ENR), MSSR, taxa de crescimento absoluto referente ao acréscimo em altura (TCAA) e RMSPA (Tabela 1). Para todos os parâmetros avaliados, o coeficiente de variação (CV) apresentou valores consideravelmente baixos, aproximadamente $20 \%$, o que credencia os dados apresentados neste trabalho (Tabela 1).

A visualização dos primórdios radiculares ocorreu em média aos 6 dias após o plantio das estacas, sendo 4 dias para o substrato Plantmax ${ }^{\circledR}, 6$ dias para $\mathrm{S}+\mathrm{A}+\mathrm{E}$ e 8 dias para areia, independente da altura das estacas. Fernandes et al. (2004) avaliando o enraizamento de estaca de tomateiro da cultivar Carmem, em espuma fenólica $(5,0 \times 5,0 \times 3,8 \mathrm{~cm})$, visualizaram o aparecimento das raízes na parte externa dos blocos aos 10 dias após a transferência para enraizamento. Em solução nutritiva aerada relataram o aparecimento de pequenas raízes e calos na parte basal das estacas, ocorreu aos 4 dias após a transferência para o enraizamento (Fernandes et al., 2004). Com base nestes dados, admite-se que a condição para o enraizamento afeta o padrão de expressão do potencial organogênico das estacas. Sendo as condições de umidade e aeração fundamentais para que o material vegetal possa expressar eficientemente este potencial. 
do sucesso de uma cultura residem no plantio de mudas de boa qualidade. O processo de produção é altamente dependente da utilização de insumos (Silveira et al., 2002). Neste contexto, o uso de sementes melhoradas, um dos insumos mais importante para o sucesso do empreendimento, porém com alto preço, podendo chegar a cem dólares por mil sementes, no caso do híbrido longa-vida (Fernandes et al., 2004), eleva o custo de produção. Ainda neste contexto, o substrato, tem se destacado em importância devido a sua ampla utilização.

O substrato hortícola pode ser conceituado como o meio onde se desenvolve as raízes das plantas produzidas em sementeiras e/ou viveiros de mudas olerícolas, ornamentais, frutíferas ou silvícolas (Carneiro, 1995). Esse deve garantir por meio de sua fase sólida a manutenção mecânica do sistema radicular e estabilidade da planta; da fase líquida o suprimento de água e nutrientes e; da fase gasosa, o suprimento de oxigênio e o transporte de dióxido de carbono entre as raízes e o ar externo (Lamaire, 1995). Deve ainda estar isento de elementos minerais ou qualquer outra substância em concentração fitotóxica, assim como de fitopatógenos, pragas e plantas indesejáveis (Carneiro, 1995; Minami, 1995). Desta forma, a escolha do substrato é uma das decisões mais importantes para produtores de mudas, principalmente quando se sabe que as condições ideais de cultivo dependem das exigências da espécie cultivada (Silveira et al., 2002). Alguns substratos comerciais atendem os requisitos para a produção de mudas, porém possuem custo elevado. Uma medida adequada consiste em utilizar substratos produzidos com materiais que possam ser obtidos facilmente na região. Assim, tem-se preocupado em introduzir novas tecnologias de produção que supram à necessidade e ao mesmo tempo sejam acessíveis as condições econômicas dos produtores.

Como alternativa para diminuir o custo de produção, com a aquisição de sementes, uma técnica promissora é o uso de propagação assexuada. Este processo consiste na reprodução de indivíduos a partir de partes vegetativas das plantas, caracterizando-se principalmente por manter inalterada a constituição genética do clone durante sucessivas gerações. A propagação vegetativa é comum em muitas espécies comercialmente importantes, sendo a tecnologia de enraizamento de estacas o procedimento mais econômico na propagação em grande escala (Foster, 1993). O tipo de estaca é decisivo para muitas espé- cies, contudo, de forma geral, as estacas de varias espécies de plantas enraízam com facilidade em grande diversidade de meios, porém, em plantas que apresentam dificuldade de enraizamento, o meio pode influir muito, não só na porcentagem de enraizamento, como, também, na qualidade do sistema radicular que se forma (Paiva \& Gomes, 1995). De acordo com Cheng \& Chu (2004), o método de propagação vegetativa do tomateiro via enraizamento do ápice mostrou ser alternativa importante para o cultivo comercial diminuindo o custo de produção, no entanto, segundo Fernandes (2004), o método mais utilizado e difundido para produção de mudas de tomate é por meio de sementes, sendo o enraizamento de estacas pouco comum. Por isso, objetvou-se avaliar a viabilidade da produção de mudas de tomateiro por estaquia em diferentes substratos.

\section{MATERIAIS E MÉTODOS}

Este experimento foi conduzido em casa de vegetação, no Centro de Ciências Agrárias da Universidade Federal do Espírito Santo, localizado no Município de Alegre/ES, latitude $20^{\circ} 45^{\prime}$ Sul, longitude $41^{\circ} 28^{\prime}$ Oeste e altitude de $247 \mathrm{~m}$. Foi avaliada a produção de mudas por estaquia do tomateiro hibrido 'Alambra', em diferentes substratos.

Para a produção de mudas do tomateiro comparou-se os substratos: mistura de solo + areia lavada + esterco bovino (1:1:1, v/v/v), Plantmax ${ }^{\circledR}$ (mistura de matéria orgânica de origem vegetal e vermiculita expandida) e areia lavada. Com exceção do Plantmax ${ }^{\circledR}$, todos os materiais utilizados na confecção dos substratos foram passados em peneira com malha de $2 \mathrm{~mm}$. Os substratos foram acondicionados em recipientes plásticos $(8 \mathrm{~cm}$ de altura e $7 \mathrm{~cm}$ de diâmetro), com capacidade para $200 \mathrm{~mL}$, na parte inferior foi feito aberturas para permitir livre drenagem. Após o enchimento dos recipientes e acondicionamento em casa de vegetação, procedeu-se a irrigação até a capacidade de campo.

As brotações foram retiradas de diferentes posições de plantas matrizes (geração $\mathrm{F}_{1}$, produzidas por semente), com bom aspecto fitossanitário e nutricional, acondicionadas em caixa de isopor, de modo a evitar perda de água. Na preparação das estacas, primeiramente, após pré-seleção do material vegetal, foram retiradas todas as folhas do ramo, 


\title{
PRODUÇÃO DE MUDAS DE TOMATEIRO POR ESTAQUIA: EFEITO DO SUBSTRATO E COMPRIMENTO DE ESTACAS
}

\author{
TOMATO SEEDLING PRODUCTION BY CUTTINGS \\ ROOTED IN DIFFERENT SUBSTRATES
}

\author{
Heder Braun ${ }^{1}$; Paulo Cezar Cavatte ${ }^{2}$; José Augusto Teixeira do Amaral ${ }^{3}$; \\ José Francisco Teixeira do Amaral ${ }^{3}$; Edvaldo Fialho dos Reis ${ }^{5}$
}

\section{RESUMO}

Objetivou-se avaliar a viabilidade da produção de mudas de tomateiro por estaquia em diferentes substratos. O experimento foi conduzido em casa-de-vegetação no Centro de Ciências Agrárias da UFES, em Alegre-ES. Para a produção de mudas do tomateiro comparouse os substratos: mistura de solo + areia lavada + esterco bovino, Plantmax ${ }^{\circledR}$ e areia lavada. Os substratos foram acondicionados em recipientes plásticos ( $8 \mathrm{~cm}$ de altura e $7 \mathrm{~cm}$ de diâmetro), com capacidade para $200 \mathrm{~mL}$. Brotações foram retiradas de diferentes posições de plantas matrizes. Assim, as estacas foram padronizadas em três alturas: 5,8 e $11 \mathrm{~cm}$. O experimento foi instalado em esquema fatorial 3 x 3 (substratos x estacas) com três repetições e 30 mudas por parcela, totalizando 810 mudas. Foram detectados efeitos significativos para a interação entre os tipos de substratos e alturas de estacas nas seguintes características: comprimento do sistema radicular, diâmetro médio das raízes, relação entre a massa seca da parte aérea e massa seca do sistema radicular, massa seca total e massa seca do sistema radicular. Estacas de $5 \mathrm{~cm}$ apresentaram menor relação PA/SR independente do tipo de substrato e maior proporção de massa seca alocada no sistema radicular (53,8\%). A propagação vegetativa do tomateiro é viável, contudo maiores estudos sobre substratos alternativos, condições de enraizamento e padrão do material vegetal utilizado devem ser realizados.

Palavras-chave: Clones, Lycopersicon esculentum, propagação vegetativa.

\section{ABSTRACT}

The use of cuttings to implement tomato crops has fundamental importance for farmers, mainly due to high cost of seeds. This study aimed at evaluating the viability of the tomato seedling production by cuttings rooted in different substrates. The experiment was carried out in greenhouse at the Centro de Ciências Agrárias- UFES, Alegre- ES. The experiment was arranged in a complete randomized design using a $3 \times 3$ factorial scheme (substrate and cutting height) with three replicates. The following seedling characteristics were evaluated: rooting percentage, increase in height of aerial part, total length of root system, mean diameter of root system, dry matter of aerial part, and dry matter of root system. The total length of root system was not affected by the height of cuttings obtained from seedlings, whereas the commercial substrate for the establishment of seedlings provided plants with longer root system. The vegetative propagation of tomato plants via lateral shoots showed to be an alternative for the commercial cropping, becoming viable particularly for small farmers, mainly due the high cost of seeds.

Key words: Clones, Lycopersicon esculentum, vegetative propagation.

\section{INTRODUÇÃO}

Com a modernização da agricultura e a segmentação do mercado, surgiu a especulação na atividade de produção de mudas (Luz et al., 2000). Esta atividade tem sido apontada como uma das etapas mais importantes do sistema produtivo dela depende o desempenho final das plantas no campo de produção, tanto do ponto de vista nutricional, quanto do tempo necessário e, consequentemente, do número de ciclos produtivos possíveis por ano (Carmello, 1995). Segundo Minami (1995), 60\%

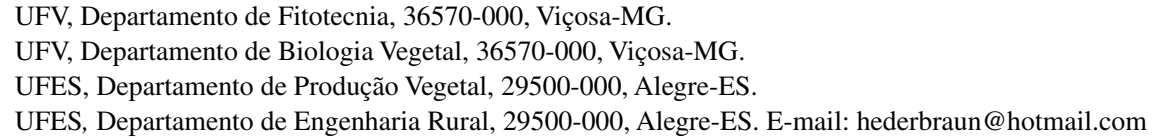



procedentes de fuentes agrarias. Ello debe contemplar ciertamente planes de acción y verificar las implicaciones que existen sobre la fertilización nitrogenada, considerándoles tanto criterios agronómicos, económicos como también medioambientales que permitan tanto la sustentabilidad como la protección de los recursos a largo plazo.

\section{LITERATURA CITADA}

ALLEY, M.; VALLAUWE, B. 2009. The role of Fertilizers in Integrated Plant Nutrient Management. International Fertilizer Industry Association. Tropical Soil Biology and Fertility Institute of the International Centre for Tropical Agriculture. Disponible en http://www.fertilizer.org

CADAHÍA, C. 2005. Fertirrigación de cultivos hortícolas, frutales y ornamentales, $3^{\mathrm{a}}$ ed. 681 p.

FRESCO, L. 2003. Enfoques. Perspectivas de la Agricultura mundial. Los fertilizantes y el futuro. Disponible en: http://www. fao.org/ag/revista/0306sp1.htm

GALLARDO, J. 2007. Conclusiones del IV Congreso Iberoamericano de Física y Química Ambiental. Ecosistemas, 16 (2): 137 140. Disponible en: http://www.revistaecosistemas.net/articulo.asp?Id=478

ORTEGA, R.; MOLINA, M. 2003. Tecnologías para mejorar la eficiencia de uso del nitrógeno en Chile. Agronomía y Forestal UC. 21 (8-11).

ROY, R.; FINCK, A.; BLAIR, G.; TANDON, H. 2006. Plant nutrition for food security, a guide for integrated nutrient management FAO Fertilizer Plant Nutrition Bulletin 16, FAO. Rome.

TASSARA, C.; ORTEGA, R. 2003. Eurepgap y la regulación chilena en el uso de fertilizantes y plaguicidas. Agronomía y Forestal UC. 19 (20-25). 